\title{
CALCULATIONAL CRITICALITY ANALYSES OF 10- AND 20-MW UF 6 FREEZER/SUBLIMER VESSELS
}

\author{
W. C. Jordan
}

Computing and Telecommunications Division

at Oak Ridge National Laboratory

P.O. Box 2008

Oak Ridge, Tennessee 37831-6370

Date Published - February 1993

NOTICE This document contains information of a preliminary nature.
It is subject to revision or correction and therefore does not represent a final report.

MARTIN MARIETTA ENERGY SYSTEMS, INC. managing the

Oak Ridge National Laboratory Oak Ridge Y-12 Plant Oak Ridge K-25 Plant Paducah Gaseous Diffusion Plant under Contract No. DE-AC05-84OR21400

for the

U.S. DEPARTMENT OF ENERGY

\section{MASTER}




\section{CONTENTS}

Page

LIST OF FIGURES $\ldots \ldots \ldots \ldots \ldots \ldots \ldots \ldots \ldots \ldots \ldots \ldots \ldots \ldots$ iv

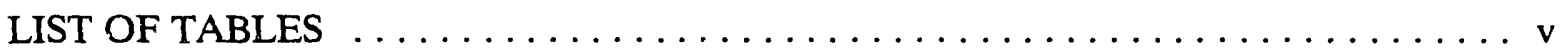

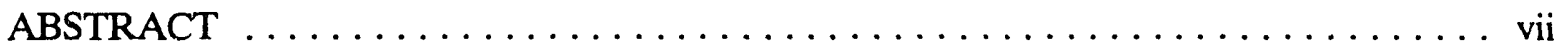

1. INTRODUCTION $\ldots \ldots \ldots \ldots \ldots \ldots \ldots \ldots \ldots \ldots \ldots \ldots \ldots \ldots \ldots \ldots \ldots \ldots$

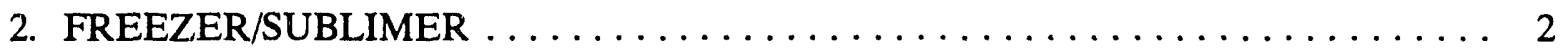

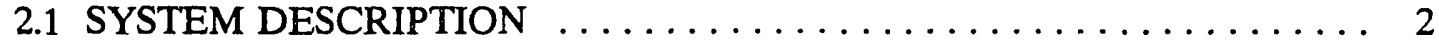

$2.2 \mathrm{~F} / \mathrm{S}$ VESSEL DESCRIPTION $\ldots \ldots \ldots \ldots \ldots \ldots \ldots \ldots \ldots \ldots \ldots$

3. CRITICALITY SAFETY CONSIDERATIONS $\ldots \ldots \ldots \ldots \ldots \ldots \ldots \ldots$

4. FREEZER/SUBLIMER PHYSICS MODEL $\ldots \ldots \ldots \ldots \ldots \ldots \ldots \ldots \ldots \ldots 11$

4.1 CALCULATIONAL METHOD $\ldots \ldots \ldots \ldots \ldots \ldots \ldots \ldots \ldots \ldots \ldots$

4.2 FINNED TUBE ASSEMBLY MODEL $\ldots \ldots \ldots \ldots \ldots \ldots \ldots \ldots$

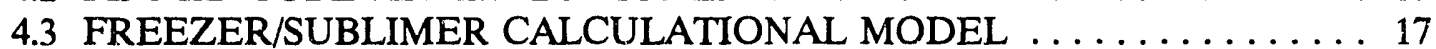

4.3.1 Freezer/sublimer geometry model $\ldots \ldots \ldots \ldots \ldots \ldots \ldots \ldots \ldots \ldots$

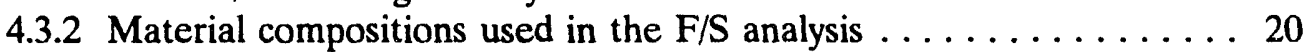

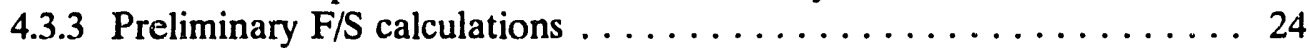

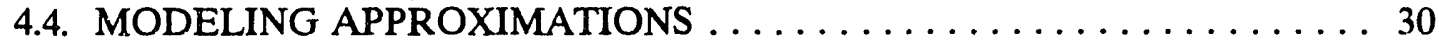

5. CALCULATIONAL RESULTS OF THE F/S ANALYSIS $\ldots \ldots \ldots \ldots \ldots \ldots \ldots 32$

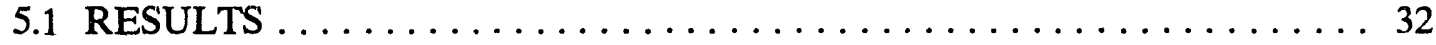

5.2 CONCLUSIONS $\ldots \ldots \ldots \ldots \ldots \ldots \ldots \ldots \ldots \ldots \ldots \ldots \ldots \ldots \ldots \ldots \ldots \ldots \ldots$

6. CODE VALIDATION $\ldots \ldots \ldots \ldots \ldots \ldots \ldots \ldots \ldots \ldots \ldots \ldots \ldots \ldots \ldots \ldots \ldots \ldots \ldots$

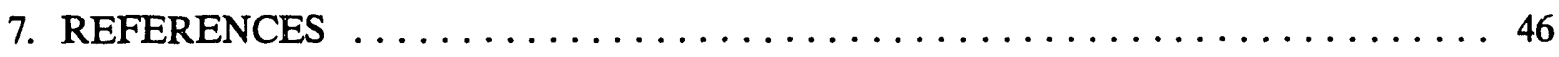

APPENDIX A. $\mathrm{UF}_{6}-\mathrm{HF}$ DENSITIES $\ldots \ldots \ldots \ldots \ldots \ldots \ldots \ldots \ldots \ldots \ldots$

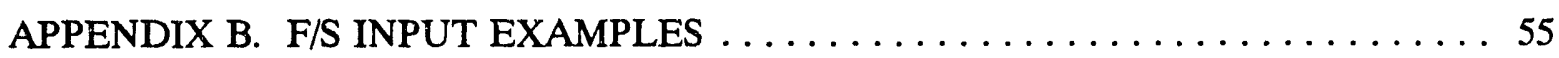




\section{LIST OF FIGURES}

Page

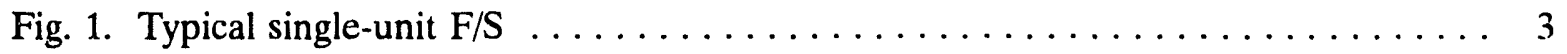

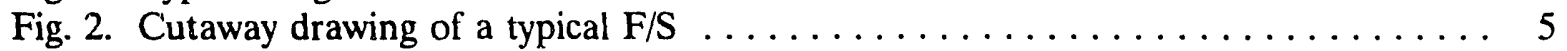

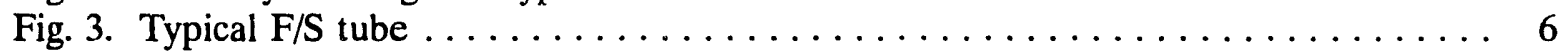

Fig. 4. LATTICECELL and INFHOMMEDIUM approximations

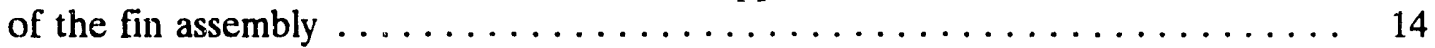

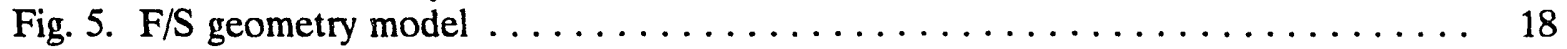

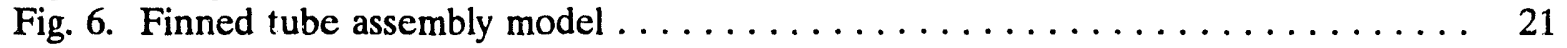

Fig. 7. Preliminary calculations - 20-MW nominally loaded $\mathrm{F} / \mathrm{S} \ldots \ldots \ldots \ldots \ldots \ldots .27$

Fig. 8. Preliminary calculations -20 -MW fully loaded $F / S \ldots \ldots \ldots \ldots \ldots \ldots \ldots 28$

Fig. 9. $k_{\text {eff }}$ vs $\mathrm{H} / \mathrm{U}$ for a $10-\mathrm{MW}$ fully loaded $\mathrm{F} / \mathrm{S}$ with water

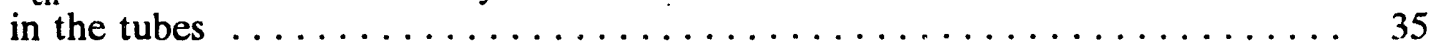

Fig. 10. $\mathrm{k}_{\text {eff }}$ vs enrichment for a $10-\mathrm{MW}$ fully loaded $\mathrm{F} / \mathrm{S}$ with

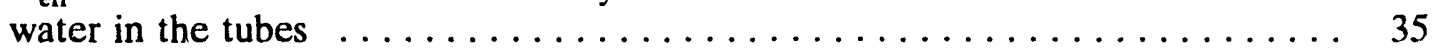

Fig. 11. $\mathrm{k}_{\text {eff }}$ vs enrichment for a 10-MW F/S fully loaded and

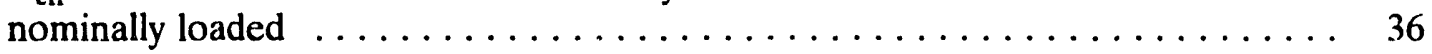

Fig. 12. $\mathrm{k}_{\text {eff }}$ vs $\mathrm{H} / \mathrm{U}$ for a 20 -MW fully loaded $\mathrm{F} / \mathrm{S}$ with water

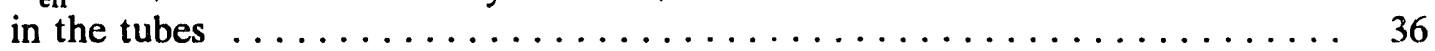

Fig. 13. $\mathrm{k}_{\text {eff }}$ vs enrichment for a $20-\mathrm{MW}$ fully loaded $\mathrm{F} / \mathrm{S}$ with water in the tubes $\ldots \ldots \ldots \ldots \ldots \ldots \ldots \ldots \ldots \ldots \ldots \ldots \ldots \ldots$

Fig. 14. $\mathrm{k}_{\text {eff }}$ vs enrichment for a $20-\mathrm{MW}$ F/S fully loaded and

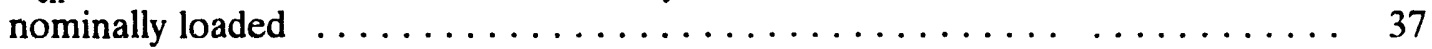

Fig. $15 . \mathrm{k}_{\text {eff }}$ vs $\mathrm{H} / \mathrm{U}$ for a $10-\mathrm{MW}$ F/S $-3.0 \%$ enrichment $\ldots \ldots \ldots \ldots \ldots \ldots \ldots$

Fig. 16. $\mathrm{k}_{\text {eff }}$ vs $\mathrm{H} / \mathrm{U}$ for a $10-\mathrm{MW}$ F/S $-3.2 \%$ enrichment $\ldots \ldots \ldots \ldots \ldots \ldots \ldots \ldots$

Fig. 17. $\mathrm{k}_{\mathrm{eff}}$ vs $\mathrm{H} / \mathrm{U}$ for a $10-\mathrm{MW} \mathrm{F} / \mathrm{S}-3.3 \%$ enrichment $\ldots \ldots \ldots \ldots \ldots \ldots \ldots \ldots . \ldots \ldots$

Fig. 18. $\mathrm{k}_{\text {eff }}$ vs $\mathrm{H} / \mathrm{U}$ for a $10-\mathrm{MW} \mathrm{F} / \mathrm{S}-3.4 \%$ enrichment $\ldots \ldots \ldots \ldots \ldots \ldots \ldots \ldots$

Fig. 19. $\mathrm{k}_{\text {eff }}$ vs $\mathrm{H} / \mathrm{U}$ for a $10-\mathrm{MW} \mathrm{F} / \mathrm{S}-3.5 \%$ enrichment $\ldots \ldots \ldots \ldots \ldots \ldots \ldots$

Fig. $20 . \mathrm{k}_{\text {eff }}$ vs $\mathrm{H} / \mathrm{U}$ for a $10-\mathrm{MW} \mathrm{F} / \mathrm{S}-4.0 \%$ enrichment $\ldots \ldots \ldots \ldots \ldots \ldots \ldots$

Fig. $21 . \mathrm{H} / \mathrm{U}$ vs enrichment to yield a $\mathrm{k}_{\mathrm{eff}}=0.90$ (for a $10-\mathrm{MW} \mathrm{F} / \mathrm{S}$ ) $\ldots \ldots \ldots \ldots \ldots 41$

Fig. 22. $k_{\text {eff }}$ vs AEG for low-enriched validation experiments $\ldots \ldots \ldots \ldots \ldots \ldots \ldots 44$ 


\section{LIST OF TABLES}

Page

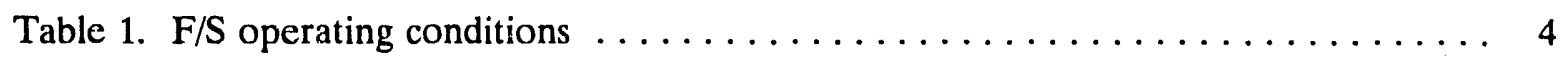

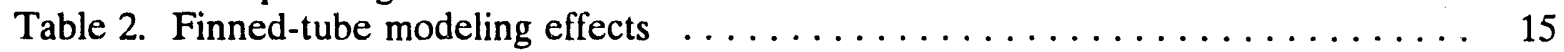

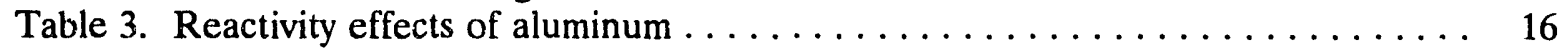

Table 4. 10-MW F/S geometry model $\ldots \ldots \ldots \ldots \ldots \ldots \ldots \ldots \ldots \ldots \ldots \ldots \ldots$

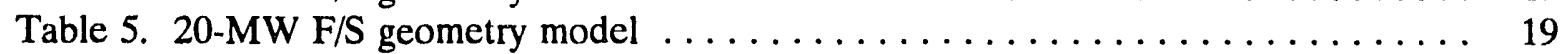

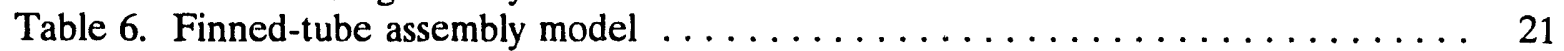

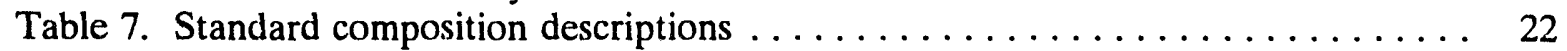

Table 8. Mixture compositions used in the calculations $\ldots \ldots \ldots \ldots \ldots \ldots \ldots \ldots$

Table 9. Calculated $k_{\text {eff }}$ for $20-\mathrm{MW}$ F/S nominal loading, 5 wt $\%{ }^{235} \mathrm{U}$ enrichment $\ldots \ldots 25$

Table 10. Calculated $k_{\text {eff }}$ for $20-\mathrm{MW}$ F/S fully loaded, 5 wt $\%{ }^{235} \mathrm{U}$ enrichment . . . . 26

Table 11. Calculated $k_{\text {eff }}$ for 20 -MW F/S nominal loading, 5 wt $\%{ }^{235} \mathrm{U}$

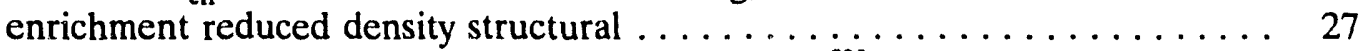

Table 12. Calculated $k_{\text {eff }}$ for $20-\mathrm{MW}$ F/S fully loaded, $5 \mathrm{wt} \%{ }^{235} \mathrm{U}$ enrichment reduced density structural $\ldots \ldots \ldots \ldots \ldots \ldots \ldots \ldots \ldots \ldots \ldots \ldots$

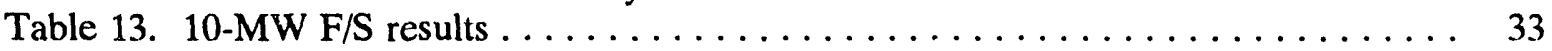

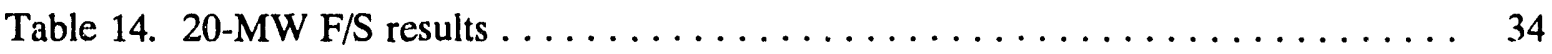

Table A.1. $\mathrm{UF}_{6}-\mathrm{HF}$ Density $-5.0 \%$ Enrichment $\ldots \ldots \ldots \ldots \ldots \ldots \ldots \ldots \ldots \ldots$

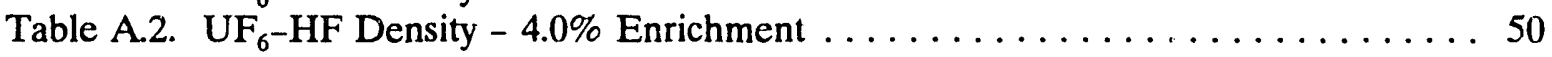

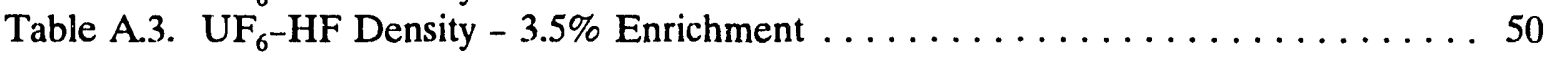

Table A.4. $\mathrm{UF}_{6}-\mathrm{HF}$ Density $-3.4 \%$ Enrichment $\ldots \ldots \ldots \ldots \ldots \ldots \ldots \ldots \ldots \ldots \ldots \ldots \ldots \ldots \ldots \ldots \ldots$

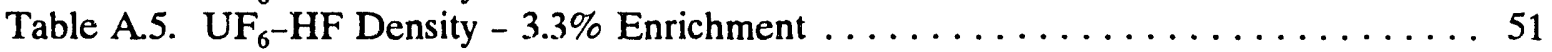

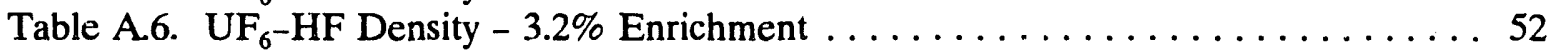

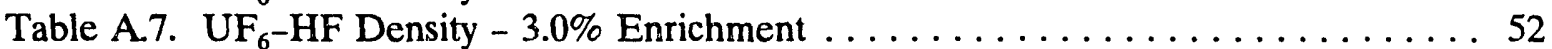

Table A.8. $\mathrm{UF}_{6}-\mathrm{HF}$ Density $-2.0 \%$ Enrichment $\ldots \ldots \ldots \ldots \ldots \ldots \ldots \ldots \ldots \ldots \ldots$ 


\begin{abstract}
Calculational criticality analyses have been performed for 10 - and 20-MW UF freezer/sublimer vessels. The freezer/sublimers have been analyzed over a range of conditions that encompass normal operation and abnormal conditions. The effects of HF moderation of the $\mathrm{UF}_{6}$ in each vessel have been considered for uranium enriched between 2 and $5 \mathrm{wt} \%{ }^{235} \mathrm{U}$. The results indicate that the nuclearly safe enrichments originally established for the operation of a 10-MW freezer/sublimer, based on a hydrogen-to-uranium moderation ratio of 0.33 , are acceptable. If strict moderation control can be demonstrated for hydrogen-io-uranium moderation ratios that are less than 0.33 , then the enrichment limits for the $10-\mathrm{MW}$ freezer/sublimer may be increased slightly. The calculations performed also allow safe enrichment limits to be established for a 20 -MW freezer/sublimer under moderation control.
\end{abstract}




\section{INTRODUCTION}

The purpose of this report is to present calculational criticality analyses of 10 - and $20-\mathrm{MW}$ freezer/sublimer (F/S) vessels. A $10-\mathrm{MW} \mathrm{F} / \mathrm{S}$ has been previously analyzed by Taylor. ${ }^{1.2}$ This report has three goals: (1) to reconfirm the results of the previous analysis using current computer codes and neutron cross-section libraries; (2) to provide analyses that can be used to establish safe operating limits for the $20-\mathrm{MW}$ F/S; and (3) to provide a discussion of the assumptions used in this analysis, why they were made, and how they affect the calculated results.

The original Taylor reports were written primarily for use by the criticality safety group and criticality engineers directly responsible for the review and approval of the operation of the F/S vessels at Oak Ridge Gaseous Diffusion Plant (ORGDP). The analyses were comprehensive, and considerable detail was given of intermediate results used to reach conclusions on the nuclearly safe ${ }^{235} U$ enrichment for an $F / S$. Over a period of several years the documents were referenced in a number of safety analysis reports. Some attempts have been made to redefine the acceptable operation of the F/S based on intermediate results presented in Taylor's reports. It is hoped that the discussion presented here will clarify the criticality control parameters for the F/S and identify assumptions that should be made when certain parameters are not controlled.

This report presents a calculational criticality analysis of a F/S vessel; it does not represent a complete criticality safety evaluation and does not constitute nuclear criticality safety approval for operation. The calculated reactivity or multiplication factor of an $\mathrm{F} / \mathrm{S}$ for specific conditions of loading, including $\mathrm{UF}_{6}$ mass, ${ }^{235} \mathrm{U}$ enrichment, and moderation level, are given. No attempt is made to specify the safe enrichment or conditions of operation (and related control parameters) for the system. The values of the control parameters will need to be established elsewhere, and the criticality engineers responsible for the approval of operations of the F/S system will need to determine acceptable conditions of operation.

Section 2 of this report gives a brief review of the F/S system. The modes of operation of the F/S are discussed, and " general description of the F/S vessel is presented.

Section 3 gives a discussion of general concepts of criticality safety and the F/S. A comparison is made between the F/S equipment and operations of the cascade and product withdrawal.

Section 4 gives the details of the codes and cross sections used in this calculational analysis. Detailed geometric models are presented for both 10- and 20-MW F/S vessels.

Section 5 gives calculational results. Discussions of code validation and applicability to the $\mathrm{F} / \mathrm{S}$ are given in Sect. 6. 


\section{FREEZER/SUBLIMER}

\subsection{SYSTEM DESCRIPTION}

The F/S system is designed to allow rapid control of in-process $\mathrm{UF}_{6}$ inventory in a diffusion plant. A $10-\mathrm{MW} \mathrm{F/S}$ is capable of removing (treezing, desubliming) or replacing (subliming) about $4000 \mathrm{~kg}$ of $\mathrm{UF}_{6}$ in $1 \mathrm{~h}$. The $20-\mathrm{MW}$ unit has twice the capacity of a 10-MW unit and is capable of freezing or subliming about $8000 \mathrm{~kg}$ of $\mathrm{UF}_{6}$ in $1 \mathrm{~h}$.

The F/S system consists of an F/S vessel, a condenser/reboiler (C/R), and interconnecting piping pumps and instrumentation. A schematic of an F/S system is shown in Fig. 1. Both the $\mathrm{F} / \mathrm{S}$ vessel and the $\mathrm{C} / \mathrm{R}$ are large-geometry heat exchangers. The $\mathrm{F} / \mathrm{S}$ vessel is a single-pass, finned-tube heat exchanger. The $C / R$ is a U-tube heat exchanger. Heat is removed or supplied to the primary side of the $\mathrm{C} / \mathrm{R}$ by the recirculating cooling water $(\mathrm{RCW})$ system. The refrigerant $\mathrm{R}-114$ (dichlorotetrafluoroethane) is used on the secondary side to move heat between the $C / R$ and the $F / S$ vessel. The $R-114$ loop is required to provide dual wall isolation between the $\mathrm{UF}_{6}$ in the $F / S$ vessel and water in the $C / R$. The $R-114$ is chemically inert to $U_{6}$ and is not considered a moderating material. On the other hand, water reacts vigorously with $\mathrm{UF}_{6}$ and is a good moderator. Water entry into the $\mathrm{F} / \mathrm{S}$ vessel would have significant impact on cascade operation and the criticality safety of the vessel.

The F/S system has five modes of operation: freeze, cold standby, sublime, hot standby, and modified hot standby. A brief description of these modes extracted from the Gaseous Diffusion Plant Safety Analysis Report (GDP SAR) ${ }^{3}$ is given below for reference purposes.

The freeze mode allows $\mathrm{UF}_{6}$ from the "B" line to enter the $\mathrm{F} / \mathrm{S}$ at a controlled rate and to be stored in a solid phase. The $\mathrm{UF}_{6}$ is frozen on the outside of the finned tubes in the F/S by passing cold R-114 through the tubes. The fins on the tubes project horizontally from the vertical tubes, such that the fins serve as trays to hold the solid $\mathrm{UF}_{6}$. Any noncondensible gases entering the $\mathrm{F} / \mathrm{S}$ are returned to the cascade cell " $\mathrm{A}$ " bypass through a vent line. During the freeze mode, R-114 is cooled by flowing supply-side (cold) RCW through the C/R. The cool $\mathrm{R}-114$ enters the F/S vessel from the bottom. As the heat of desublimation is absorbed, the $\mathrm{R}-114$ boils. The $\mathrm{R}-114$ vapors flow to the elevated $\mathrm{C} / \mathrm{R}$ where they are condensed, and the heat is passed to the RCW system. The condensed R-114 then flows back to the F/S. The mass of $\mathrm{UF}_{6}$ entering the vessel is monitored by weight-load cells.

Cold standby mode maintains $\mathrm{UF}_{6}$ in the frozen state and is the standby condition when the $\mathrm{F} / \mathrm{S}$ is not in the freeze or sublime mode. In cold standby, the $\mathrm{F} / \mathrm{S}$ is isolated from the cascade by closing valves to the $A$ and $B$ lines and the vent. The R-114 in the system is maintained in the condensed state by flowing supply-side RCW through the $\mathrm{C} / \mathrm{R}$. The $\mathrm{R}-114$ flows by gravity to the $F / S$, where it removes the normal cell heat and vaporizes back to the $C / R$ in an essentially steady-state operation.

In the sublime mode, $\mathrm{UF}_{6}$ is returned to the cascade from the $\mathrm{F} / \mathrm{S}$ vessel at a controlled rate. The heat of sublimation is supplied by pumping return-side (hot) $R C W$ through the C/R causing the R-114 to vaporize. As the R-114 vapor passes through the F/S, it condenses, passing heat into the $\mathrm{UF}_{6}$. The condensed $\mathrm{R}-114$ liquid is pumped back to the $\mathrm{C} / \mathrm{R}$. The $\mathrm{UF}_{6}$ process gas is returned to the cascade through the $A$ line. The rate of return to the cascade is monitored using the F/S load cells.

The hot-standby mode consists of heating the R-114 in the C/R using return-side RCW with the R-114 pump off and the $\mathrm{UF}_{6}$ lines and vent closed. Hot standby is used if there is a low RCW temperature, low R-114 temperature, or low R-114/RCW differential pressure. 


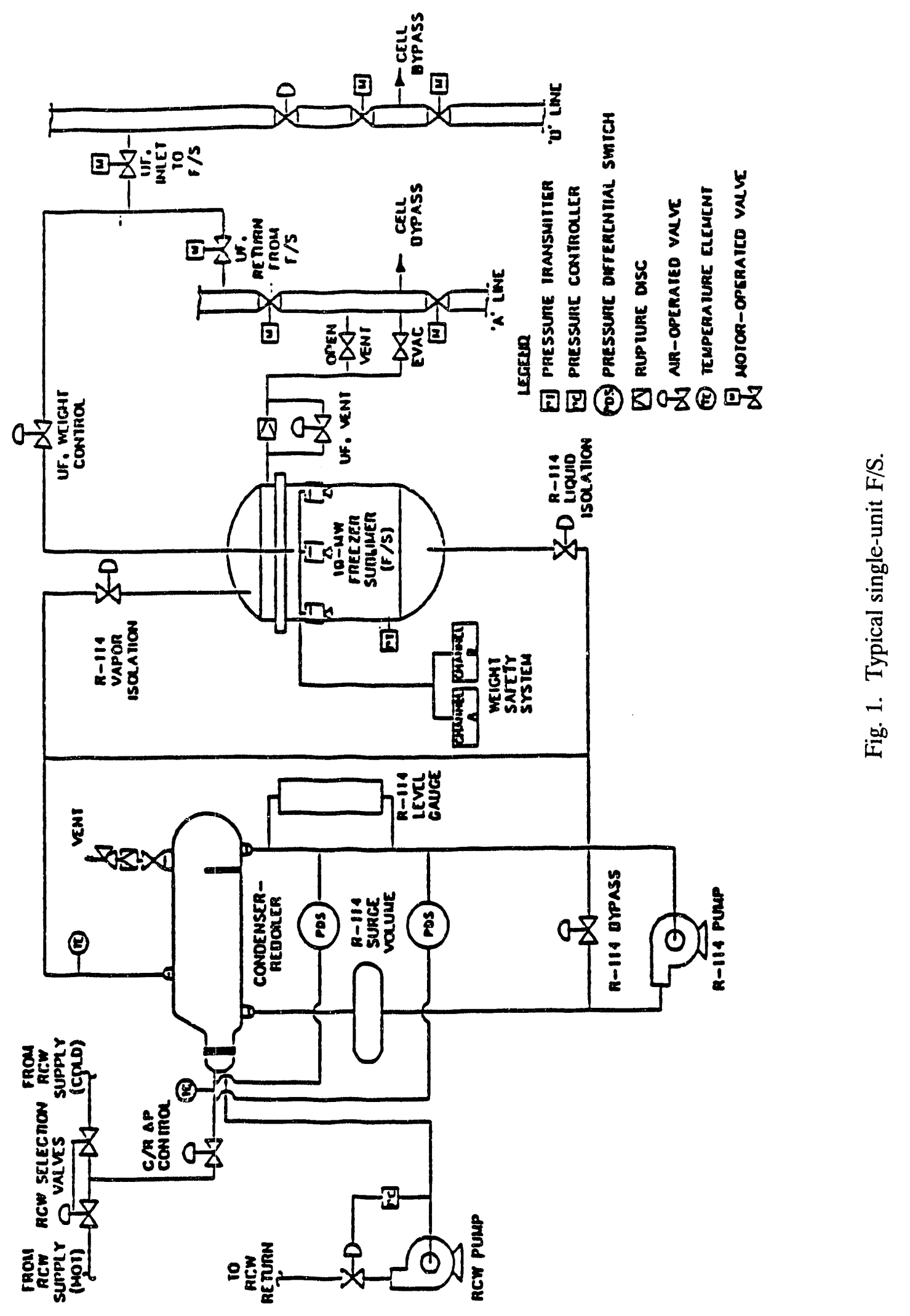


The modified hot-standby mode occurs only when there are indications of excess $\mathrm{UF}_{6}$ in the $\mathrm{F} / \mathrm{S}$ vessel. It is the same as the hot-standby mode, except that the $\mathrm{UF}_{6}$ return line and vent are open.

Table 1 gives the range of normal operating conditions for the F/S system.

Table 1. F/S operating conditions

\begin{tabular}{lcrrr}
\hline \multicolumn{1}{c}{ Mode } & $\begin{array}{l}\mathrm{RCW} \\
\text { temp. } \\
\left({ }^{\circ} \mathrm{F}\right)\end{array}$ & $\begin{array}{c}\text { RCW } \\
\text { press. } \\
(\mathrm{psig})\end{array}$ & $\begin{array}{l}\text { R-114 } \\
\text { temp. } \\
\left({ }^{\circ} \mathrm{F}\right)\end{array}$ & $\begin{array}{c}\text { R-114 } \\
\text { press. } \\
(\mathrm{psig})\end{array}$ \\
\hline Freeze & $80-95$ & $25-45$ & $80-107$ & $17-36$ \\
Sublime & $120-160$ & $0-10$ & $112-160$ & $40-94$ \\
Cold standby & $80-95$ & $25-45$ & $80-100$ & $17-31$ \\
Hot standby & $120-160$ & $0-10$ & $112-160$ & $40-94$ \\
Modified hot standby & $120-160$ & $0-10$ & $112-160$ & $40-94$ \\
\hline
\end{tabular}

\subsection{F/S VESSEL DESCRIPTION}

An F/S is a finned-tube heat exchanger. The $10-\mathrm{MW} \mathrm{F} / \mathrm{S}$ vessel is $4 \mathrm{ft}$ in diameter with an overall height of approximately $9.5 \mathrm{ft}$. The tube bundle consists of 204 cupronickel finned tubes mounted vertically between two fixed tube sheets. The tubes consist of a 1-in. outside diameter (OD) cupronickel base to which 2.25-in.-OD aluminum fins have been bonded. The tubes are $7 \mathrm{ft}$ in length, with a finned length of $6.5 \mathrm{ft}$. Process gas is admitted to the center of the tube bundle through a 6-in. pipe connection that penetrates the top tube sheet, allowing the $\mathrm{UF}_{6}$ to flow radially outward. The R-114 is admitted to the vessel through either a 4-in.-diam pipe connection located in the bottom dished head or a 6-in. off-center pipe nozzle at the top of the vessel. A 2-in. vent line located just below the top iube sheet is provided to remove noncondensibles. A double-ply expansion joint is installed in the shell to compensate for differential thermal expansion. The vessel is supported on three dual bridge load cells, which are used to measure and control $\mathrm{UF}_{6}$ inventory within the $\mathrm{F} / \mathrm{S}$.

The $20-\mathrm{MW}$ F/S vessel is $4.75 \mathrm{ft}$ in diameter, with an overall height of $13 \mathrm{ft}$. Its tube bundle consists of 288 tubes of the same outside diameter (OD) and construction as used in the $10-\mathrm{MW}$ unit. The tubes are $10 \mathrm{ft}$ in length with a finned exposure of $9.42 \mathrm{ft}$. The $\mathrm{UF}_{6}$ and $\mathrm{R}-114$ connections are dimensionally the same as for the smaller vessel.

Figure 2 shows a cutaway drawing of a typical F/S vessel. Figure 3 shows a schematic of a typical finned-tube section. 
ORNL.DWG 93M-5367

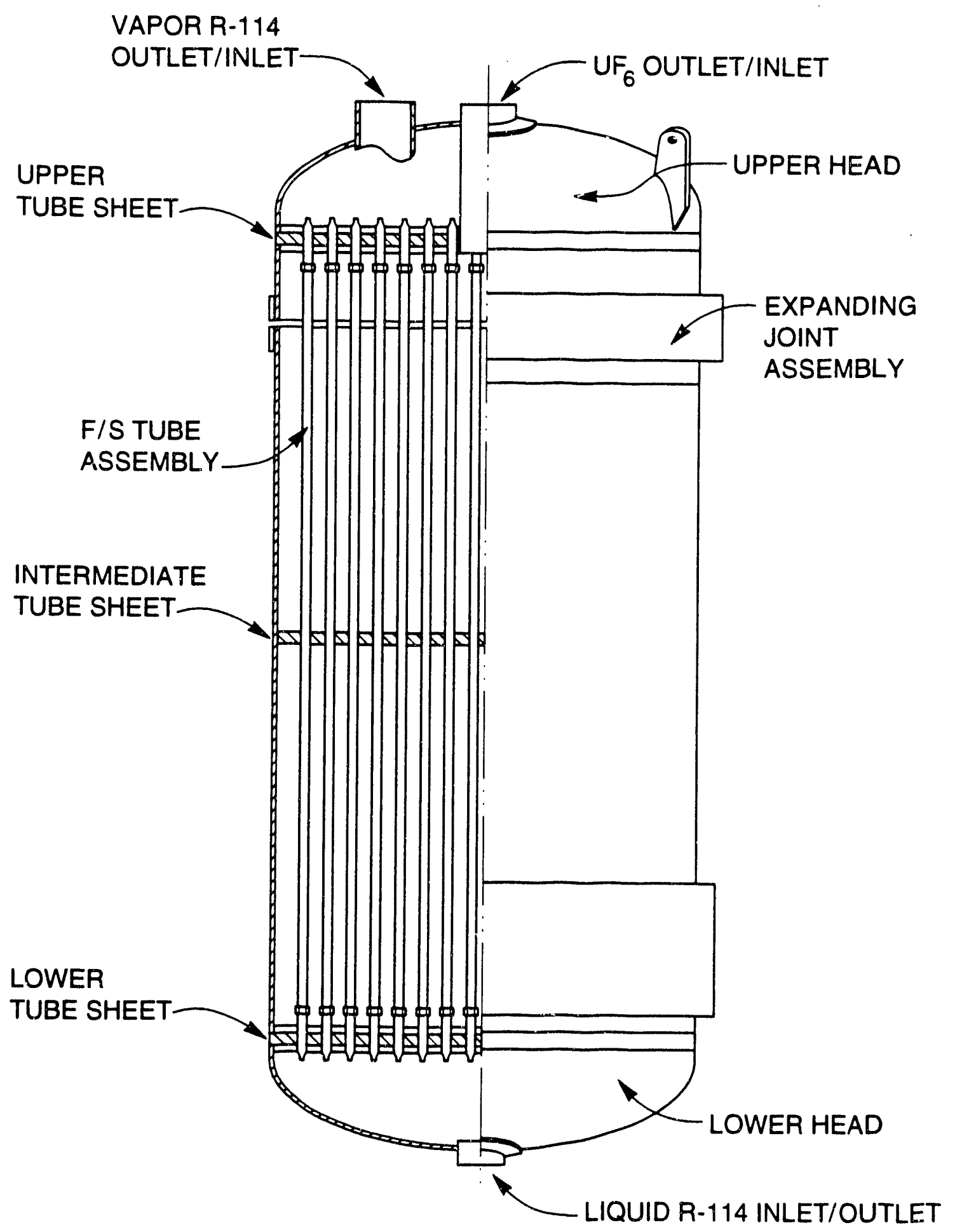

Fig. 2. Cutaway drawing of a typical F/S. 
总

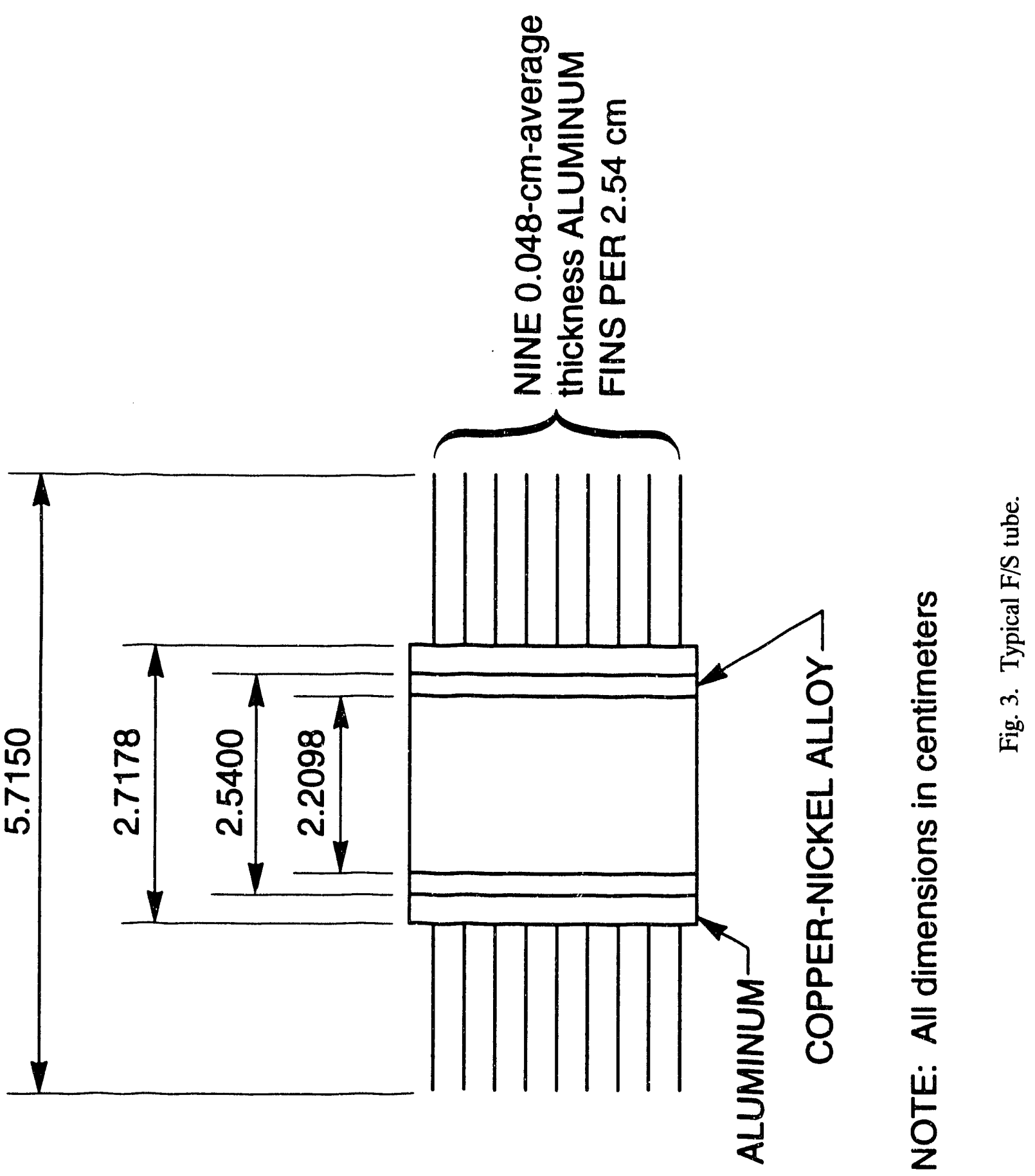




\section{CRITICALITY SAFETY CONSIDERATIONS}

The F/S vessel and the operation of the F/S system in the cascade are unique in that the $\mathrm{F} / \mathrm{S}$ vessel is large geometry and is designed to contain large quantities of solid-phase $\mathrm{UF}_{6}$. The purpose of this section is to give a brief overview of criticality safety nomenclature and its application to the F/S. A comparison is made between the F/S system, the cascade, and $\mathrm{UF}_{6}$ withdrawal equipment and operations.

Where practicable, the nuclear safety of equipment or operations that involve fissile material are based on single-parameter limits, such as safe mass or geometry for a specific enrichment. For purposes of this discussion, nuclearly safe geometry may be defined as that geometry which, for a given enrichment and fissile material, is subcritical at optimum moderation and full water reflection. Similarly, nuclearly safe mass may be defined as the mass of fissile material which, for a given enrichment, is subcritical at optimum moderation in spherical geometry and is fully water reflected. The only other controls required for these individually safe units controlled to a single parameter limit are those related to neutronic interaction and placement relative to other individually safe units.

Design fundamentals for the gaseous diffusion plant state that with the exception of cascade equipment that handles uranium in the gaseous state, all uranium-containing equipment should meet the requirements of a geometrically safe system wherever feasible. ${ }^{4,5}$ Where it is impractical to design a system of safe geometry, equipment of unsafe geometry should generally be designed to operate on positive control of the ${ }^{235} \mathrm{U}$ mass or concentration.

The double-contingency principle is used to evaluate the criticality safety of equipment and operations involving fissile material. ${ }^{6}$ Double contingency requires that two unlikely, independent, and concurrent changes in conditions essential to the nuclear safety of the operation must occur before criticality is possible. Criticality controls are the physical and/or administrative limitations imposed on one or more processes or nuclear variables of a given system such that criticality is not possible as long as these limitations are maintained. An important concept in a diffusion plant is that certain "controlled" nuclear variables are process limited, and the true nature of the controls are the administrative controls of the existing process system and operations.

The $\mathrm{F} / \mathrm{S}$ is considered unsafe geometry. For uranium enriched to greater than $1 \%$, the $\mathrm{F} / \mathrm{S}$ vessel is large enough in diameter to sustain criticality if sufficiently moderated. The term "sufficiently moderated" is important in the criticality safety of the F/S. The F/S is designed to contain large quantities of $\mathrm{UF}_{6}$ and, therefore, a mass of ${ }^{235} \mathrm{U}$, which represents multiple safe masses for enrichments above $1 \%$. In order for an $F / S$ to be demonstrated to be adequately subcritical for enrichments greater than $1 \%$, the moderation level of the uranium in the vessel must be controlled to a sufficiently small value.

Low-enriched uranium has a useful property related to neutron moderation in that uranium enriched to less than $5 \mathrm{wt} \%{ }^{235} \mathrm{U}$ cannot be made critical in the absence of a moderator, where hydrogen is the most common moderator considered. The subcriticality of low-enriched uranium may be achieved by controlling the moderation. For the purpose of this report, moderation control is defined as the strict limitation of the level of moderator present such that the effective neutron multiplication factor of the $F / S$ is less than a subcritical acceptance value under all credible conditions. Moderation control has been widely recognized as a primary criticality safety control in the area of transport and storage of low-enriched UF $_{6}$ (ref. 7).

In the strictest sense, moderation control implies (1) the ability to measure the moderation level and (2) the means to prevent a specified level from being exceeded. In 
application, no device is available that measures moderation levels. Instead, controls are put in place to prevent or limit the addition of a moderator to a system.

Moderation by water or other hydrogenous compounds (e.g., oil) is prevented by using barriers such as the wall of the container or eliminating their use in a system. Another hydrogenous moderating compound that is present in a diffusion cascade and which must be considered in $\mathrm{UF}_{6}$ processing is $\mathrm{HF}$. $\mathrm{UF}_{6}$ is stable in $\mathrm{HF}$. The primary source of $\mathrm{HF}$ as an impurity in a diffusion plant is the result of wet-air inleakage into the cascade. Moisture in the air reacts with $\mathrm{UF}_{6}$ to form $\mathrm{UO}_{2} \mathrm{~F}_{2}$ and $\mathrm{HF}$. The $\mathrm{UO}_{2} \mathrm{~F}_{2}$ deposits as a solid at or near the site of the reaction; HF gas mixes with the $\mathrm{UF}_{6}$ and passes through the cascade. $\mathrm{HF}$ gas, as an impurity in the $\mathrm{UF}_{6}$, ir always present at some level in an operating cascade. Historically, because the level of HF in the $\mathrm{UF}_{6}$ gas stream is not known or monitored, and because all the events that could lead to HF in the process gas stream were not known or not specifically identified, it was assumed in criticality safety evaluations that there was an unlimited supply of $\mathrm{HF}$ in the process gas as a binary $\mathrm{UF}_{6}-\mathrm{HF}$ mixture. HF moderation is of great concern in an operating $F / S$.

HF moderation control may be accomplished by controlling the pressure and temperat ure simultaneously to prevent condensation of liquid HF or surface sorption of HF. Several anci ary concepts and criteria are related to moderation control. One of these is that the diffusion plant equipment is sufficiently small such that criticality is not possible for gaseous $\mathrm{UF}_{6}$ independent of the moderation level of HF in the gas mixture. This equipment includes compressors, converters, coolers, and surge drums. The density of the $\mathrm{UF}_{6}$ (i.e., $\mathrm{UF}_{6}$ in the gas phase as opposed to a liquid or a solid phase) is a primary criticality control for cascade equipment. The moderation level of HF in the gas phase is unknown and assumed to be at a worst-case condition for criticality safety analysis.

A principal difference between the F/S criticality safety and the safety of the operating cascade is the density of the $\mathrm{UF}_{6}$ under normal operating conditions. A primary control for the cascade is that the uranium is in the gas phase and not frozen out or deposited in the equipment. Before criticality is possible in operating diffusion equipment, an abnormal condition must occur, resulting in a deposit of solid uranium. In the $\mathrm{F} / \mathrm{S}$, the presence of solid $\mathrm{UF}_{6}$ is a normal mode of operation.

A possibility does exist in diffusion equipment that $\mathrm{UF}_{6}$ will not remain in the gas phase but "freeze out" irito the solid phase. This situation can and has occurred at cold spots in the cascade. The diffusion plant equipment is not safe geometry for solid-phase UF 6 . Freezeouts are considered an abnormal condition of operation which is protected against by maintaining temperatures and pressures for normal cascade operation. Administrative controls and procedures, along with a deposit monitoring program, are used to help minimize the possibility of a freezeout and/or to detect the freezeout and allow corrective action to minimize the mass of uranium involved and the length of time that the condition exists. However, freezeouts have occurred in the past at a frequency such that it is marginal that they should be considered unlikely events.

The safety of the cascade miust be demonstrated when the condition of $\mathrm{UF}_{6}$ freezeout occurs. Historically, ti:is has been addressed by evaluating freezeout locations and assuming an upper bound on the moderation level in the freezecut. Gas coolers in the cascade are one location where $\mathrm{UF}_{6}$ freezeout is considered more likely to occur. The safety of gas coolers containing $\mathrm{UF}_{6}$ has been evaluated based on an assumed hydrogen-to-uranium $(\mathrm{H} / \mathrm{U})=0.33$ 
(ref. 5)." Cascade operating conditions and the physical characteristics of $\mathrm{UF}_{6}$ and HF are used to justify the moderation control presumption in the event of a freezeout. Two conditions must occur before criticality is possible: (1) a deposit of uranium must occur or exist, and (2) a moderator must be introduced or be present such that an $\mathrm{H} / \mathrm{U}=0.33$ is exceeded. These considerations have led to criticality safety acceptance of cascade operation.

$\mathrm{UF}_{6}$ withdrawal by compression liquefaction is another operation that has criticality safety concerns and controls which are similar to those related to $\mathrm{F} / \mathrm{S}$ operation. Gas-phase $\mathrm{UF}_{6}$ is compressed and condensed to a liquid and drained into unsafe geometry product cylinders. The safety of the withdrawal operation is based on a combination of safe geometry and moderation control. The pressure/temperature of the liquid $\mathrm{UF}_{6}$ is monitored and controlled to demonstrate that $\mathrm{HF}$ is not present in quantities that could result in criticality. Moderation control is demonstrated in safe geometry equipment before the $\mathrm{UF}_{6}$ is allowed to drain into unsafe geometry. At the Portsmouth and Oak Ridge diffusion plants, moderation control is/was demonstrated in safe geometry accumulators before being drained into unsafe geometry cylinders. Because the accumulator at the Paducah plant is unsafe geometry, moderation control must be demonstrated at the condenser prior to draining into the accumulator.

Moderation from other sources such as oil from compressors or pumps has been addressed by limiting the size of the pumps and the oil volume available, or by isolating the pumps from the $\mathrm{UF}_{6}$ by traps or automatic valves which prevent backflow of oil into the $\mathrm{UF}_{6}$ system. Moderation from external sources, such as fire sprinklers, requires that the $\mathrm{UF}_{6}$ containment boundary be breached. Because the withdrawal system operates above atmospheric pressure, any breach in the $\mathrm{UF}_{6}$ boundary, at least initially, results in a $\mathrm{UF}_{6}$ release, not an introduction of a moderator into equipment containing solid or liquid $\mathrm{UF}_{6}$. The nuclear safety of the withdrawal system is based on demonstration of moderation control before $\mathrm{UF}_{6}$ is drained into unsafe geometry and on equipment design and operating characteristics making it improbable that water or oil will enter the system.

$\mathrm{UF}_{6}$ withdrawal and $\mathrm{F} / \mathrm{S}$ operations are similar in that both operations take gas-phase $\mathrm{UF}_{6}$ to a more compact solid or liquid state. Both operations rely on moderation control as the primary (only) control after some point in the process. The operations are different in several respects. The $\mathrm{F} / \mathrm{S}$ takes gas-phase $\mathrm{UF}_{6}$ and freezes it directly into unsafe geometry. The $\mathrm{F} / \mathrm{S}$ operates below atmospheric pressure, and there are different controls required to prevent introduction of water or oil. The F/S handles $\mathrm{UF}_{6}$ in the solid phase as opposed to a liquid. These and other differences result in a different set of controls and ronsiderations for operation of the $\mathrm{F} / \mathrm{S}$ than those used for cascade operation and $\mathrm{UF}_{6}$ withdrawal. Some of these controls are discussed below.

\footnotetext{
*There have been several values of $\mathrm{H} / \mathrm{U}$ moderation level used as an assumed upper bound over the years at the various diffusion plants. The value of $\mathrm{H} / \mathrm{U}=0.33$ is more widely documented, although little background information is available to suggest the technical basis on which it was established. The evaluations of cascade equipment are based on the hydrogen being supplied by $\mathrm{HF}$, as opposed to water or oil. $\mathrm{A} \mathrm{H} / \mathrm{U}=0.33$ is assumed in evaluation of cascade freezeouts, but generally not in the evaluation of cascade deposits of $\mathrm{UO}_{2} \mathrm{~F}_{2}$ or $\mathrm{UF}_{4}$ caused, for example, by wet-air inleakage or equipment failure. The moderation level of deposits caused by wet-air or oil inleakage to the cascade may significantly exceed a $\mathrm{H} / \mathrm{U}=0.33$, depending on the nature and location of the deposit. Deposits of this type are generally analyzed on a case-by-case basis and have not been generically studied.
} 
Two requirements in place for the $\mathrm{F} / \mathrm{S}$ are that positive $\mathrm{R}-114 / \mathrm{RCW}$ and $\mathrm{R}-114 / \mathrm{UF}_{6}$ pressure differentials exist during all modes of operation. The purpose of these controls is to prevent inadvertent water entry or $\mathrm{UF}_{6}$ entry into the R-114 tubes. These controls do not directly monitor the integrity of the R-114 boundary in that small leaks, especially in the $C / R$, could exist for long periods of time before differential pressure equalizes. However, they do indicate when the possibility exists for water entry into the R-114 system. At the point differential pressure is lost, it has been assumed that water has entered the R-114 tubes and a single boundary is all that is preventing water entry into a moderation-controlled vessel. Observe that the pressure and temperature ranges for normal operation given in Table 1 indicate a range of conditions that may not satisfy the differential pressure requirements. For the freeze mode and cold standby mode, normal operation could allow the R-114 pressure (17-36 PSIG) to be below the RCW pressure (25-45 PSIG). There is a direct correlation between R-114 pressure and temperature, and the R-114 and RCW temperatures are coupled through the C/R. The minimum RCW temperature must be increased and/or the maximum $R C W$ pressure in the $C / R$ must be decreased from the values in Table 1 in order to satisfy the differential pressure requirements.

Moderation control of HF must also be demonstrated during both normal and abnormal operation of the cascade and the F/S. In the early 1980s at ORGDP, it was shown that HF moderation control could be lost even though the pressure/temperature conditions were such that liquid HF could not condense because of the possibility of surface sorption or monolayer deposition of $\mathrm{HF}$ onto $\mathrm{UF}_{6}$ surfaces. Both condensed-phase and surface-sorbed HF must be controlled such that acceptable moderating levels are not exceeded. It was suggested that controls be placed on the temperature of the RCW system and the pressure of the $\mathrm{UF}_{6}$ in the $\mathrm{F} / \mathrm{S}$ vessel such that pressure/temperature conditions inside the F/S could not exceed two-thirds of the condensation pressure/temperature of pure HF. This procedure allowed demonstration of moderation control independent of the composition of $\mathrm{UF}_{6}$, lights, and $\mathrm{HF}$ entering the $\mathrm{F} / \mathrm{S}$.

In the operation of the F/S, a cascade upset that breaches the integrity of the F/S vessel and triggers the fire sprinklers could result in criticality even though this may be a single unlikely event or a series of events which are not independent. For low-enriched uranium, there are random factors that affect the likelihood of criticality related to the moderation level and the length of time required to supply this moderation. These random factors may have to be used to judge the acceptability of the F/S systems and operation. Procedures for cascade treatment and for emergency response to breach of the cascade (e.g., because of exothermic, explosive reactions, etc.) need to be scrutinized with respect to the location and operational status of the F/S systems. 


\section{FREEZER/SUBLIMER PHYSICS MODEL}

The F/S is a complex geometric assembly. The neutronics model is also complex. Multiple levels of heterogeneity must be addressed in cross-section processing for the model. The purpose of this section is to describe the computer codes, computational methodology, and background calculations that were used to establish an acceptable F/S model.

A brief description of the computer program modules used in this analysis are given in Sect. 4.1. SCALE-4.0 was chosen for the calculational analysis of the F/S. This version has several enhancements over previous versions that allow more appropriate cross sertion processing.

The finned-tube assembly model is discussed in Sect. 4.2. A series of calculations were performed to examine the sensitivity of $k_{\text {eff }}$ to approximations required to model the F/S. The results of these calculations indicate that the reactivity effects of the aluminum fins with soid $\mathrm{UF}_{6}-\mathrm{HF}$ in between could be approximated as a homogeneous mixture of $\mathrm{UF}_{6}-\mathrm{HF}-\mathrm{Al}$ withrsut introducing any nonconservatism into the final results.

The detailed models used to determine the $\mathrm{k}_{\text {eff }}$ of the $\mathrm{F} / \mathrm{S}$ under vatious conditions are given in Sect. 4.3. It is not possible to model all possible loading conditions in the $\mathrm{F} / \mathrm{S}$ vessel. A set of calculational models were chosen such that the calculated $k_{\text {eff }}$ encompasses the range of conditions which could exist in a $\mathrm{F} / \mathrm{S}$. Sect. 4.4.

A discussion of the assumptions and limitations of the physics model are given in

\subsection{CALCULATIONAL METHOD}

The SCALE-4.0 computer program modules used in the criticality evaluations are part of the Standardized Computer Analysis for Licensing Evaluation (SCALE) code system. ${ }^{8}$ The CSAS25 control sequence or the CSAS1X control sequence of the CSAS4 $4^{9}$ control module of SCALE were used for all computations. The CSAS25 control sequence activates the functional modules BONAMI-S, ${ }^{10}$ NITAWL-S, ${ }^{11}$ and KENO V.a. ${ }^{12}$ The CSAS1X control sequence activates the functional modules BONAMI-S, NITAWL-S, and XSDRNPM-S. ${ }^{13}$ The control sequence and functional modules are summarized in the following paragraphs. The 27-group ENDF/B-IV cross-section library in SCALE-4.0 was used for all calculations.

One of the more important enhancements in SCALE-4.0 over previous versions is the implementation of the annular treatment in the LATTICECELL option of the code. In previous versions of SCALE, interchanging the location of the fissile material and moderator regions in the LATTICECELL description resulted in incorrect cross-section processing that could create a bias in the calculations (positive or negative, depending on the specific systems). With the annular treatment, all radial regions in the LATTICECELL description are treated rigorously. This feature of the code is important in the F/S analysis. The control sequences and functional models used in this evaluation are described below.

The CSAS25 control sequence reads user-specified input data, which include the required cross-section library, specification for mixtures, information for resonance processing of nuclides (size, geometry, and temperature), and a detailed geometry model for KENO V.a. Physical and neutronics information not supplied explicitly but required by the functional modules (such as theoretical density, molecular weights, average resonance region background cross sections) is supplied by the Standard Composition Library ${ }^{14}$ or calculated by the Materials Information Processor. ${ }^{15}$ The Standard Composition Library consists of a standard composition directory and 
table, an isotopic distribution directory and table, and a nuclide information table. These data were used to set up the input for BONAMI-S, NITAWL-S, and KENO V.a.

The 27-group ENDF/B-IV master cross-section library in SCALE ${ }^{16}$ is activated in the CSAS25 control sequence by specifying 27GROUPNDF4 (27GR) as the cross-section library name. The 27 -group library is the broad-group companion library to the 218 -group Criticality Safety Reference Library. The Criticality Safety Reference Library master library, which is based on ENDF/B-IV data, was generated as a pseudo-problem-independent fine-group structure library for use in general criticality safety analysis and shipping cask calculations. The 27-group library was collapsed from the 218-group library using a characteristic fission-(1/E)-Maxwellian spectral flux shape. Explicit ENDF/B-IV resonance parameters are carried for resonance nuclides in both the 27- and 218-group master libraries. These resonance parameters are used by NITAWL-S in the CSAS25 control sequence for calculating problem-dependent, self-shielded resonance region cross sections.

BONAMI-S performs resonance shielding through the application of the Bondarenko shielding factor method. BONAMI-S reads the master format library and applies the Bondarenko correction to all nuclides that have Bondarenko data. Input data to BONAMI-S, set up bv the CSAS25 control sequence, include information relating to the physical characteristics (composition of material, size, geometry, temperature) of the system being calculated. BONAMI-S produces a Bondarenko-corrected master format library which is read by NITAWL-S.

For the 27-group master cross-section library used in this study, the primary purpose of the BONAMI functional module is to select the required material cross sections and to create a smaller master cross-section library to be processed by NITAWL. No data processing is performed in BONAMI for the 27-group cross-section library.

NITAWL-S applies the Nordheim Integral Treatment to perform neutron cross-section processing in the resonance energy range for nuclides that have ENDF/B resonance parameter data. This technique involves the numerical integration of ENDF/B resonance parameters using a calculated flux distribution which is based on the calculated collision density across each resonance and subsequent weighting of the reaction cross section to the desired broad group structure. Input data to NITAWL-S, automatically set up by the CSAS25 control sequence, include information relating to the physical and neutronic characteristics of the system being calculated. NITAWL-S uses these data to complete the processing of the problem-dependent master library from BONAMI-S. In the SCALE sequence, NITAWL-S assembles the group-togroup transfer arrays from the elastic and inelastic scattering components, and performs other tasks to produce a problem-dependent, working cross-section library that can be used by KENO V.a.

KENO V.a, a multigroup Monte Carlo computer code, is used to determine $\mathrm{k}_{\mathrm{eff}}$ for multidimensional systems. The geometrical bodies allowed in KENO V.a for defining models include cuboids, spheres, and cylinders. KENO V.a has an enhanced geometry package that (1) allows arrays to be defined and positioned throughout the model, (2) includes a $P_{n}$-scattering treatment, (3) has an extended use of differential albedo reflection, (4) generates printer plots for checking the input model, (5) allows supergrouping of energy-dependent data, (6) has a restart capability, and (7) defines origin specifications for cuboids, spheres, cylinders, hemicylinders, and hemispheres.

XSDRNPM-S is a one-dimensional (1-D) discrete-ordinates multigroup transport code used to determine $k_{\text {eff }}$ for 1-D systems or infinite media systems. The geometric capabilities of XSDRNPM-S include spherical geometry, infinite-length cylinders, and infinite slabs. Options for buckling corrections allow approximation of finite-length two-dimensional (2-D) cylinders and 
finite three-dimensional (3-D) slabs. XSDRNPM-S calculations are useful in evaluating the effects of small changes in cross-section processing or modeling for a system that might be hidden in the statistics of a Monte Carlo code. Default SCALE values for convergence $(1 \times$ $\left.10^{-4}\right)$, quadrature order $\left(\mathrm{S}_{8}\right)$, and Legendre cross-section expansion $\left(\mathrm{P}_{3}\right)$ were used. XSDRNPM-S results were used only for sensitivity analysis, with detailed KENO V.a calculations used for all safety evaluations.

\subsection{FINNED-TUBE ASSEMBLY MODEL}

The F/S has multiple levels of heterogeneity. The first level of heterogeneity is that of the $\mathrm{UF}_{6}-\mathrm{HF}$ fissilc mixture and the aluminum fins. A second level of heterogeneity is the $\mathrm{UF}_{6}-\mathrm{HF}-\mathrm{Al}$ and the cupronickel tube lattice. The computer codes used in this analysis do not allow explicit cross-scction processing for this double heterogeneity. A complicating factor is that the magnitude of hetcrogeneous effects is dependent on the physical characteristics of the system. The purpose of this section is to identify the possible sources of moderation and heterogeneity in the F/S and to establish a calculational model that acceptably accounts for their effects.

Heterogenous effects may exist when the fissile material is separated from a moderating material. The magnitude of the effects depends on several parameters, including the thickness of the fissile region, the density of the fissile material, the type of moderating material, the thickness of the moderating material region, and the enrichment of the uranium. Hydrogen is a good moderator and is generally of greatest concern. Aluminum is not a good moderating material; however, a significant quantity of aluminum is latticed with the fissile material. The heterogeneity presented by the aluminum fins and the $\mathrm{UF}_{6}-\mathrm{HF}$ must be evaluated. The effects are expected to be minor with respect to that of the $\mathrm{UF}_{6}-\mathrm{HF}-\mathrm{Al}$ and the cupronickel tube lattice with the tubes flooded with water. If the heterogeneous effects of aluminum can be demonstrated, then the use of a volume-homogenized $\mathrm{UF}_{6}-\mathrm{HF}-\mathrm{Al}$ mixture will allow explicit treatment of tube lattice effects.

Hydrogen moderation of the $\mathrm{UF}_{6}$ in the $\mathrm{F} / \mathrm{S}$ can be from several sources. During otherwise normal operation, $\mathrm{HF}$, either as a condensed liquid or adsorbed to the surface of the $\mathrm{UF}_{6}$, is a moderator. In the analyses performed here, reference to the $\mathrm{H} / \mathrm{U}$ moderation ratio specifically relates to an assumed quantity of $\mathrm{HF}$ intermixed with the $\mathrm{UF}_{6}$.

The level of moderation of the $\mathrm{UF}_{6}$ in the $\mathrm{F} / \mathrm{S}$ may also be increased if water enters the freon side of the tubes. During normal operation either freon R-114 or R-114 vapor (void) is present on the tube side. In one possible accident scenario, water could flood the freon tubes. This case is specifically addressed in the F/S calculational models. The possibility of water entering the $\mathrm{UF}_{6}$ side of the $\mathrm{F} / \mathrm{S}$ vessel has not been analyzed here because it is accepted $a$ priori that if water is introduced directly into the $\mathrm{F} / \mathrm{S}$ vessel containing enriched $\mathrm{UF}_{6}$, criticality is likely.

A series of infinite media multiplication $\left(\mathrm{k}_{\infty}\right)$ calculations were performed to investigate the heterogeneous and moderating effects of the aluminum fins. This procedure was accomplished by performing calculations for lattices of $\mathrm{UF}_{6}-\mathrm{HF}$ and aluminum with explicit treatment of the geometric effects, and then comparing the results with calculations in which the aluminum was volume homogenized into the $\mathrm{UF}_{6}-\mathrm{HF}$ mixture. Several uranium enrichments and $\mathrm{H} / \mathrm{U}$ atomic ratios were considered. These calculations were performed using the CSAS1X control sequence of SCALE-4.0, described in Sect. 4.1.

The lattice of $\mathrm{UF}_{6}-\mathrm{HF}$ and aluminum was modeled using the SYMMSLABCELL option of the $L A T T I C E C E L L$-type calculation. Figure 4 gives a schematic representation of the 

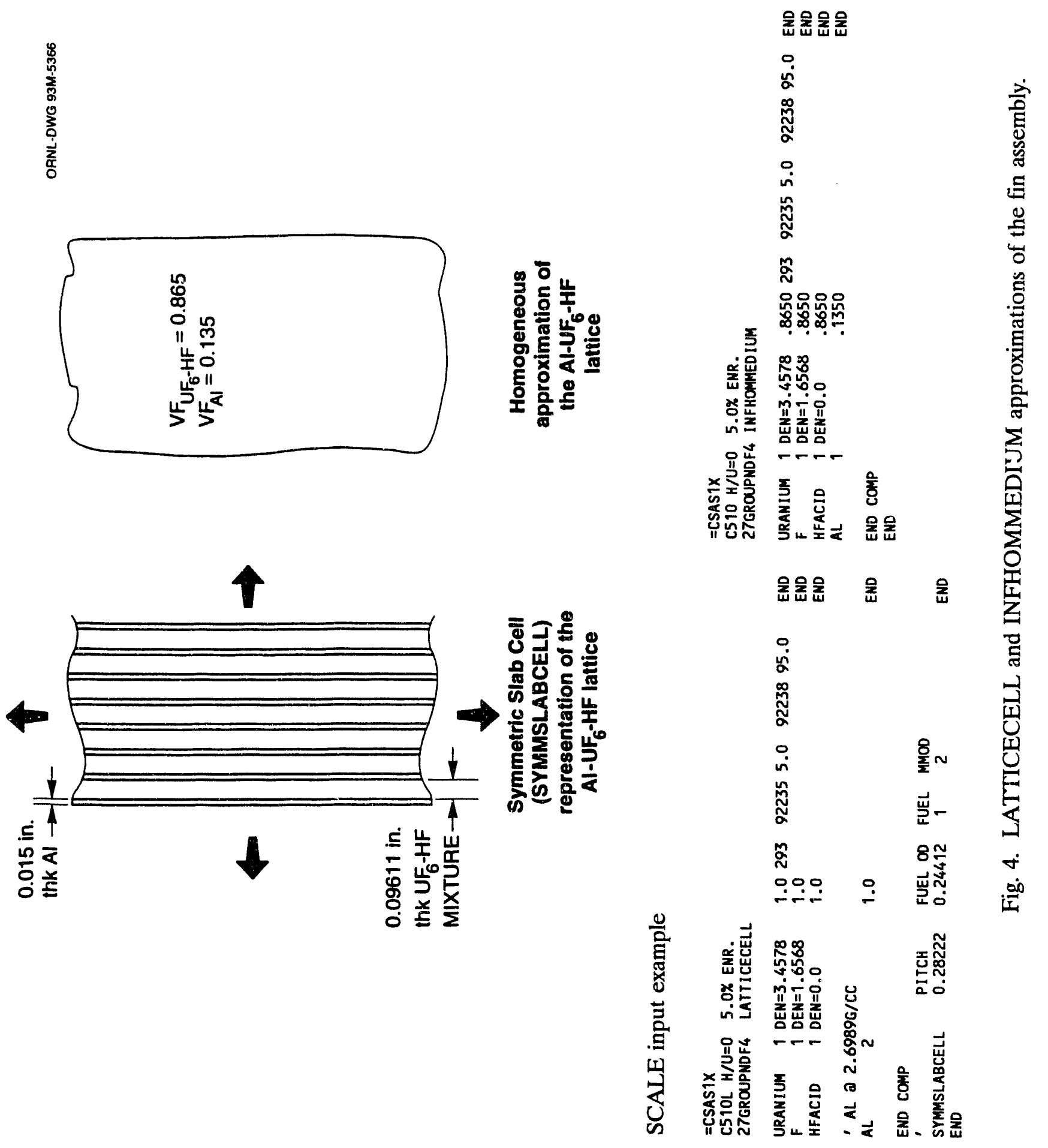
geometry model used to process the cross sections when using this option. The model approximates the horizontal surfaces of the aluminum fins as infinite plates in a configuration of nine 0.015 -in.-thick plates of aluminum per inch. In this model, the minimum fin thickness of 0.015 in. was used instead of the average thickness given in Fig. 3. This maximizes the volume of $\mathrm{UF}_{6}$ and minimizes the volume of aluminum in the model. Three enrichments of uranium were considered in the fuel region: 2,3 , and $5 \mathrm{wt} \%{ }^{235} \mathrm{U}$. The $\mathrm{H} / \mathrm{U}$ in the fuel region was varied from 0 to about 16 for each enrichment. The results are given in Table 2.

Comparison of the LATTICECELL and INFHOMMEDIUM calculational results in Table 2 indicates that the two models are nearly equivalent and that heterogenous effects of the aluminum in the $\mathrm{UF}_{6}-\mathrm{HF}-\mathrm{Al}$ lattice are negligible. A slight amount of conservatism is present for the volume-homogenized cases, which is considered acceptable. Also shown in Table 2 are the calculational results for the homogeneous 5\% enrichment cases with no aluminum. These results indicate that the presence of the aluminum has a small effect on the infinite media multiplication at moderation levels below an $\mathrm{H} / \mathrm{U}=1.0$. As the moderation level is increased, the absence of the aluminum increases the infinite media multiplication by about $3 \%$.

Table 2. Finned-tube modeling effects

\begin{tabular}{|c|c|c|c|c|}
\hline \multirow[b]{2}{*}{ Case } & \multicolumn{4}{|c|}{ Infinite media multiplication $\left(k_{\infty}\right)$} \\
\hline & $\mathrm{H} / \mathrm{U}$ & 1)LATTICECELL & h)INFHOMMEDIUM & $\begin{array}{c}\text { w/o Al } \\
\text { INFHOMMEDIUM }\end{array}$ \\
\hline \multicolumn{5}{|c|}{$5.0 \%$ Enriched } \\
\hline $\operatorname{c5} 10\{1$ or $h\}$ & 0.0 & 0.69594 & 0.69554 & 0.70574 \\
\hline c511 & 0.33 & 0.83408 & 0.83313 & 0.84693 \\
\hline c512 & 1.0 & 1.01520 & 1.01561 & 1.03144 \\
\hline$c 513$ & 2.0 & 1.16497 & 1.16554 & 1.18373 \\
\hline c.514 & 4.0 & 1.29810 & 1.29874 & 1.32153 \\
\hline c515 & 8.0 & 1.37475 & 1.37508 & 1.40762 \\
\hline$c 51 j$ & 10.0 & 1.38185 & 1.38214 & 1.41915 \\
\hline c517 & 12.0 & 1.38025 & 1.38044 & 1.42173 \\
\hline$c 518$ & 14.0 & 1.37326 & 1.37343 & 1.41866 \\
\hline c519 & 16.0 & 1.36289 & 1.36304 & 1.41193 \\
\hline \multicolumn{5}{|c|}{$3.0 \%$ Enriched } \\
\hline c313 & 2.0 & 1.07933 & 1.08013 & \\
\hline c314 & 4.0 & 1.20252 & 1.20308 & \\
\hline c315 & 8.0 & 1.24870 & 1.24908 & \\
\hline c316 & 10.0 & 1.24238 & 1.24270 & \\
\hline c317 & 14.0 & 1.21098 & 1.21125 & \\
\hline c318 & 6.0 & 1.24090 & 1.24134 & \\
\hline \multicolumn{5}{|c|}{$2.0 \%$ Enriched } \\
\hline c213 & 2.0 & 0.99799 & 0.99861 & \\
\hline c214 & 4.0 & 1.10334 & 1.10386 & \\
\hline c215 & 8.0 & 1.12037 & 1.12071 & \\
\hline c216 & 10.0 & 1.10312 & 1.10342 & \\
\hline c217 & 14.0 & 1.05519 & 1.05541 & \\
\hline c218 & 6.0 & 1.12577 & 1.12618 & \\
\hline
\end{tabular}


Case $c 515,5 \%$ enrichment at an $\mathrm{H} / \mathrm{U}=8$, was arbitrarily chosen to further study the effects of the aluminum in the system. The results of these calculations are presented in Table 3. In the first set of calculations presented in Table 3, the volume fraction of $\mathrm{UF}_{6}$ was reduced by factors of $0.7,0.5$, and 0.3 from the initial value to simulate various $\mathrm{UF}_{6}$ loadings. Comparison of the results indicates that as the relative amount of $\mathrm{UF}_{6}$ is reduced, the conservatism introduced by the homogenized (INFHOMMEDIUM) model increases slightly. In the second set of calculations, the volume fraction of aluminum was varied by factors ranging from 0.0 to 2.0. Increasing the volume fraction of aluminum above 1.0 simulates conditions where the fin thickness and/or the aluminum density are greater than that used in the model. The homogenized model exhibits a small amount of conservatism over the lattice model for each of the calculations. In addition, the calculated infinite media multiplication decreases as the relative amount of aluminum is increased. The aluminum is acting as a neutron absorber and not as a moderator for the systems considered.

The results of these calculations indicate that volume homogenization of the $\mathrm{UF}_{6}-\mathrm{Al}$ lattice introduces minor conservatism into the model and is considered acceptable. Approximation of the $\mathrm{UF}_{6}-\mathrm{Al}$ lattice in this manner allows for explicit modeling of the F/S tube lattice.

Table 3. Reactivity effects of aluminum

\begin{tabular}{|c|c|c|c|c|}
\hline \multirow[b]{2}{*}{ Case } & \multirow[b]{2}{*}{$\mathrm{H} / \mathrm{U}$} & \multirow{2}{*}{$\begin{array}{l}U_{6} \\
\text { volume } \\
\text { fraction }\end{array}$} & \multicolumn{2}{|c|}{ Infinite media multiplication $\mathrm{k}_{\infty}$} \\
\hline & & & 1)LATTICECELL & h)INFHOMMEDIUM \\
\hline $\operatorname{c5} 15\{1$ or $\mathrm{h}\}$ & 8.0 & 1.0 & 1.37475 & 1.37508 \\
\hline c525 & & 0.7 & 1.36133 & 1.36763 \\
\hline c525 & & 0.5 & 1.34339 & 1.35239 \\
\hline c525 & & 0.3 & 1.30376 & 1.31779 \\
\hline & & $\begin{array}{c}\mathrm{Al} \\
\text { volume }\end{array}$ & & \\
\hline Case & $\mathrm{H} / \mathrm{U}$ & fraction & 1)LATTICECELL & h)INFHOMMEDIUM \\
\hline al0 $\{1$ or $h\}$ & 8.0 & 0.0 & 1.40761 & 1.40702 \\
\hline al1 & & 0.2 & 1.40090 & 1.40093 \\
\hline al2 & & 0.5 & 1.39097 & 1.39116 \\
\hline al3 & & 0.7 & 1.38444 & 1.38469 \\
\hline al4 & & 1.0 & 1.37475 & 1.37508 \\
\hline al5 & & 1.2 & 1.36838 & 1.36875 \\
\hline al6 & & 1.5 & 1.35893 & 1.35949 \\
\hline al7 & & 1.7 & 1.35270 & 1.35331 \\
\hline al8 & & 2.0 & 1.34347 & 1.34401 \\
\hline
\end{tabular}




\subsection{FREEZER/SUBLIMER CALCULATIONAL MODEL}

Because it is impossible to analyze all possible $\mathrm{UF}_{6}$ loading conditions in the $\mathrm{F} / \mathrm{S}$, an extensive series of calculations were performed for a $20-\mathrm{MW}$ F/S with $5 \%$ enriched uranium to determine a subset of calculations which could be used as a bounding set for analysis of the 10and 20-MW F/S. The subset of calculations, performed for each size F/S unit over a range of enrichments and moderation levels, bounds conditions which could exist in the F/S.

The F/S model was constructed to minimize the changes that would have to be made in the model for the parametric calculations performed. This was accomplished by building a generic geometry model for the 10- and $20-\mathrm{MW}$ vessels and changing the material compositions in the regions to model various conditions, such as freon in the tubes, void in the tubes, water in the tubes, nominal $\mathrm{UF}_{6}$ loading, and complete $\mathrm{UF}_{6}$ loading. Modeling in this manner helps reduce errors inadvertently introduced when the model is cilanged.

Section 4.3.1 describes the generic geometry models used for the 10- and 20-MW F/S vessels. Section 4.3.2 gives the material specifications used in the calculation model. Calculational results for a $20-\mathrm{MW} \mathrm{F} / \mathrm{S}$ with $5 \%$ enriched $\mathrm{UF}_{6}$ are given in Sect. 4.3.3. These results were used to establish the subset of calculations used as bounding calculations for the 10and 20-MW F/S. The results presented in Sect. 4.3.3 allow a "feel" for the reactivity effects of changes in the model.

An error was inadvertently introduced into the resonance processing for the $\mathrm{F} / \mathrm{S}$ calculations in Sect. 4.3.3, where the vessel was modeled as filled with UF $_{6}$. The error was introduced when two regions that contained the same resonance material were modeled adjacent to each other. The SCALE cross-section processing routines are not designed to treat resonance overlap from within a region or between regions. This subtle modeling error introduced a nonconservative bias in the calculated $k_{\text {eff. }}$. The geometric corrections applied by the code caused the resonance absorption in ${ }^{238} U$ to be high. The modeling error was corrected for the calculations presented in Sect. 5 .

\subsubsection{Freezer/sublimer geometry model}

A sketch of the F/S geometry model showing the KENO V.a geometry units is given in Fig. 5. Tables 4 and 5 give the dimensions of the 10 - and $20-\mathrm{MW}$ geometry models, respectively. The geometry models for the 10 - and $20-\mathrm{MW}$ F/S calculations were constructed in a similar manner; the differences were in the diameter and length of the vessel.

Each model consists of a lattice of finned tubes surrounded by a cylindrical steel shell. Solid 2.6-in.(6.604-cm)-thick steel tube sheets were modeled at each end of the finned tube region. The heads were modeled as a segment of a spherical shell which approximates the curvature, thickness, and depth of the actual ellipsoidal heads. A minimum of $30 \mathrm{~cm}$ of water was modeled outside the sides and top of the F/S to account for reflective effects of adjacent equipment, structures, or housings which might exist. Sixty centimeters of concrete was modeled as the bottom reflector.

The 0.5 -in. nominal wall thickness $F / S$ vessel was modeled with a reduced wall thickness of about $0.375 \mathrm{in}$. This adjustment was made to account for any undertolerance in the wall of the vessel and to add a slight amount of conservatism to the model because of the increased effectiveness of the external water reflector. 
ORNL.DWG 92M-13562
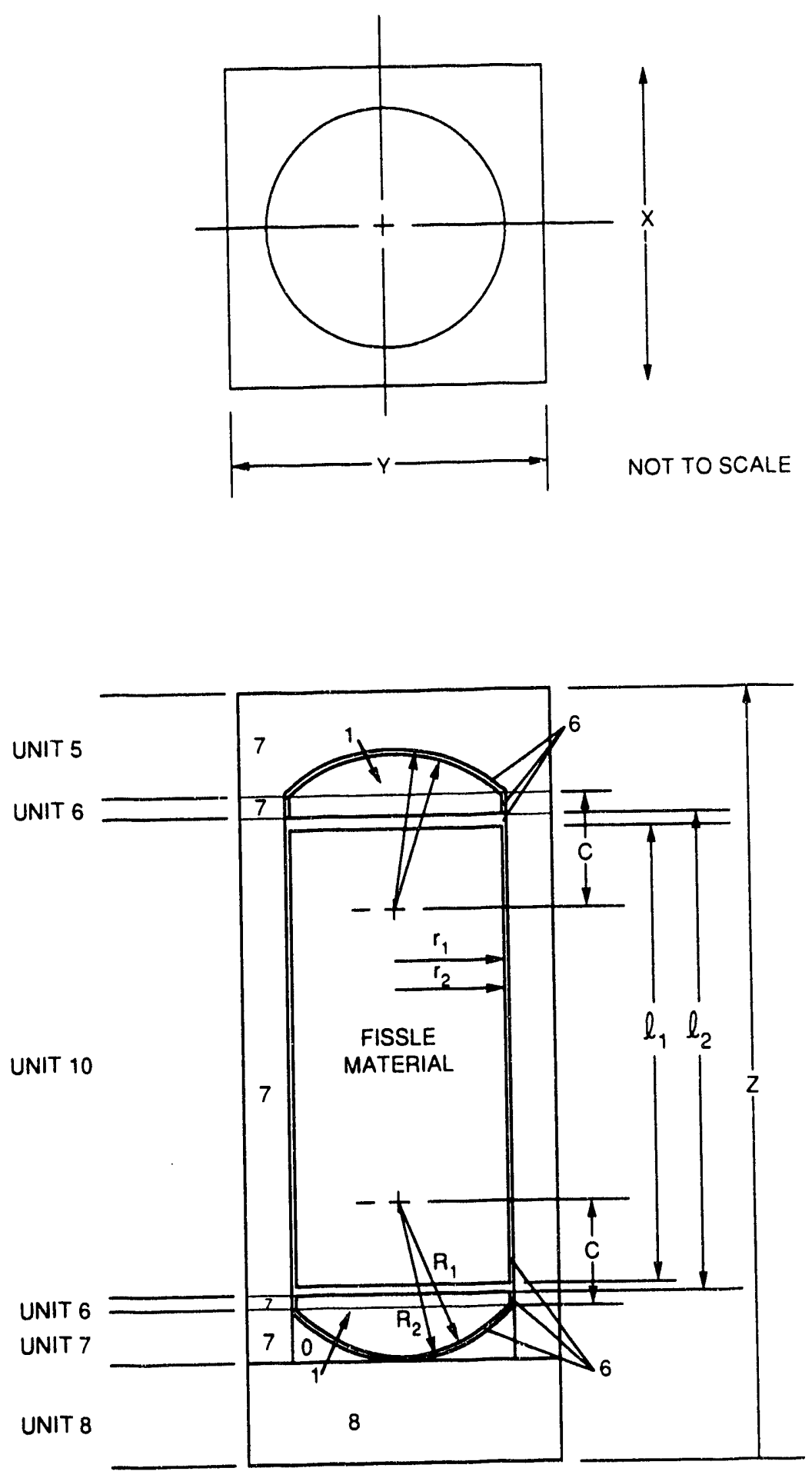

Fig. 5. F/S geometry model. 
Table 4. $10-\mathrm{MW} \mathrm{F/S}$ geometry model

\begin{tabular}{|c|c|c|c|c|c|}
\hline \multirow{2}{*}{$\frac{\text { Unit }}{8}$} & \multirow{2}{*}{$\begin{array}{l}\text { Description } \\
\text { Lower concrete } \\
\text { reflector }\end{array}$} & \multicolumn{2}{|c|}{$\begin{array}{l}\text { Geometry } \\
\text { (all dimensions in } \mathrm{cm} \text { ) }\end{array}$} & \multirow{2}{*}{$\begin{array}{c}\text { Material } \\
\text { region }\end{array}$} & \multirow{2}{*}{$\frac{\text { Material }}{\text { Reg. concrete }}$} \\
\hline & & Cuboid & $x=y=181.92, z=60.48$ & & \\
\hline 7 & Lower head & $\begin{array}{l}\text { Spheroida } \\
\text { Spheroida } \\
\text { Cylinder } \\
\text { Cuboid }\end{array}$ & $\begin{array}{ll}\text { l segment } & R_{1}=81.5775, C=55.633 \\
\text { l segment } & R_{2}=82.5290, C=55.633 \\
& r=60.9600, Z=26.896 \\
& x=y=181.92, Z=26.896\end{array}$ & $\begin{array}{l}1 \\
6 \\
0 \\
7\end{array}$ & $\begin{array}{l}\text { Void/freon/water } \\
\text { Steel; SA-516 GR55 } \\
\text { Void } \\
\text { Water reflector }\end{array}$ \\
\hline 6 & $\begin{array}{l}\text { Head } \\
\text { straight flange }\end{array}$ & $\begin{array}{l}\text { Cylinder } \\
\text { Cylinder } \\
\text { Cuboid }\end{array}$ & $\begin{array}{l}r_{1}=60.0088, z=2.948 \\
r_{2}=60.9600, z=2.948 \\
x=y=181.92, z=2.948\end{array}$ & $\begin{array}{l}1 \\
6 \\
7\end{array}$ & $\begin{array}{l}\text { Void/freon/water } \\
\text { Steel; SA-516 GR55 } \\
\text { Water reflector }\end{array}$ \\
\hline 10 & $\begin{array}{l}\text { Finned-tube } \\
\text { region and upper } \\
\text { and lower } \\
\text { tube sheets }\end{array}$ & $\begin{array}{l}\text { Cylinder } \\
\text { Cylinder } \\
\text { Cuboid }\end{array}$ & $\begin{array}{l}r_{1}=60.0088, l_{1}=198.12 \\
r_{2}=60.9600, l_{2}=211.3280 \\
x=y=181.92, z=211.3280\end{array}$ & $\begin{array}{l}- \\
6 \\
7\end{array}$ & $\begin{array}{l}\text { Fissile material region } \\
\text { Steel; SA-516 GR55 } \\
\text { Water reflector }\end{array}$ \\
\hline 5 & Upper head & $\begin{array}{l}\text { Spheroida } \\
\text { Spheroida } \\
\text { Cuboid }\end{array}$ & $\begin{array}{ll}\text { l segment } & R_{1}=81.5775, C=55.633 \\
\text { al segment } & R_{2}=82.5290, C=55.633 \\
& x=y=181.92, z=57.367\end{array}$ & $\begin{array}{l}1 \\
6 \\
7\end{array}$ & $\begin{array}{l}\text { Void/freon/water } \\
\text { Steel; SA-516 GR55 } \\
\text { Water reflector }\end{array}$ \\
\hline \multicolumn{6}{|c|}{ Reference Drawings } \\
\hline & $\begin{array}{ll}\text { M5E17202 } & \text { R } \\
\text { M5E17202 } & \text { T } \\
\text { M5E17202 } & \text { V }\end{array}$ & \multicolumn{4}{|c|}{$\begin{array}{l}\text { Rev D Freezer/Sublimer } 10 \mathrm{MW}^{17} \\
\text { Rev C Head }-10 \mathrm{MW} \text { upper and lower } 18 \\
\text { Rev A Tube sheet, } 10 \mathrm{MW} \text { upper and lower }{ }^{19}\end{array}$} \\
\hline
\end{tabular}

Table 5. 20-MW F/S geometry model

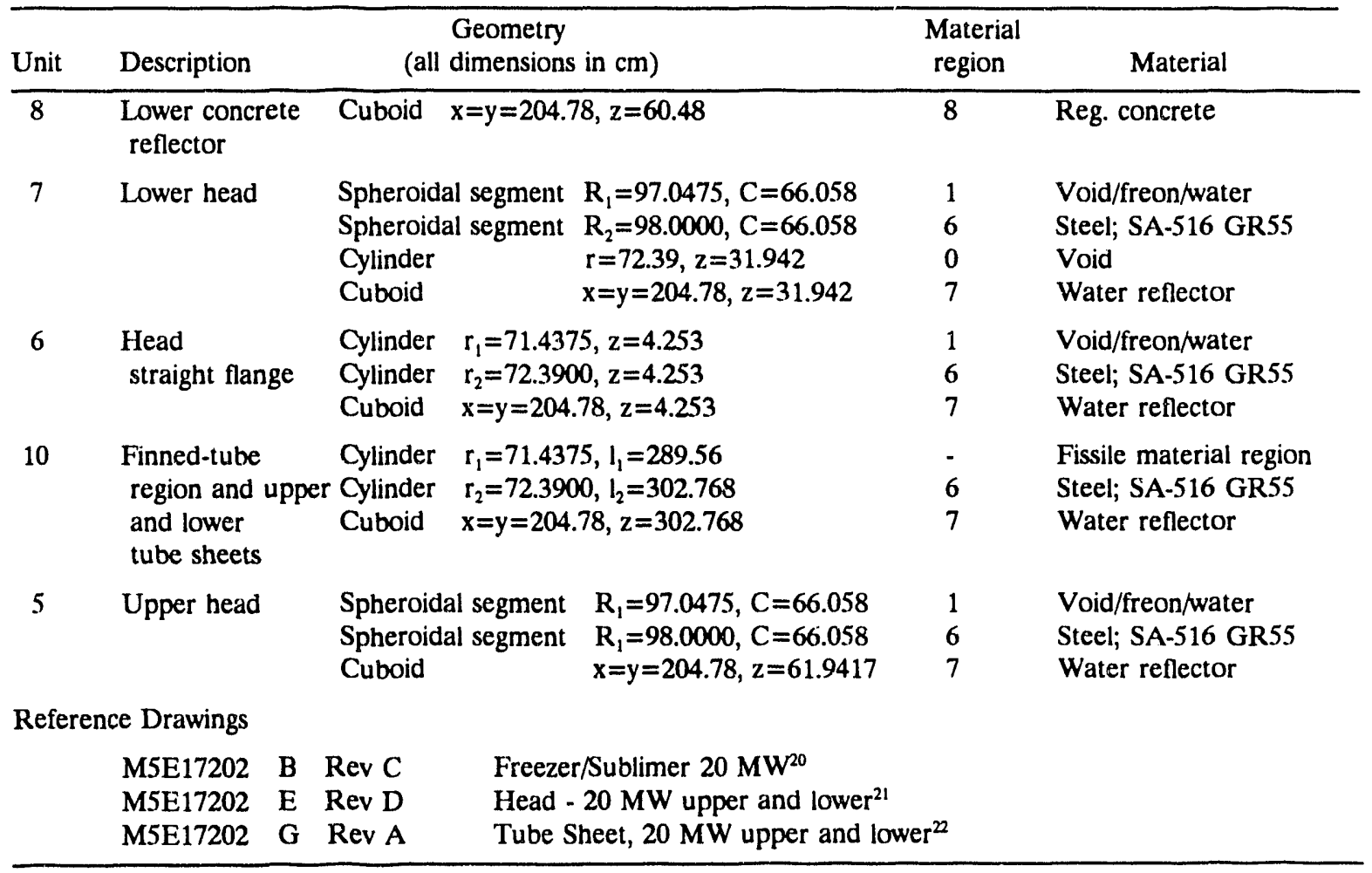


The interior region of the F/S contains the fissile material. The model of this region was constructed by first modeling the finned tubes and then constructing a "base array." The base array was the largest square array of tubes that could be modeled within the F/S shell. Finned tube positions outside of the base array were modeled using the KENO V.a HOLE feature.

The Wolverine ${ }^{23}$ finned-tube assembly was modeled radially as a 1.0 -in. OD by 0.055 -in. wall thickness $(1.1303-\mathrm{cm}$ inside radius $\times 1.27-\mathrm{cm}$ outside radius) cupronickel tube with an integral contact 1.07 -in. OD (1.3589-cm outside radius) aluminum tube. The finned region was modeled with an OD of 2.25 in. (2.8575-cm outside radius). A homogeneous mixture of $\mathrm{UF}_{6}-\mathrm{HF}-\mathrm{Al}$ was modeled. The volume fraction of $\mathrm{UF}_{6}-\mathrm{HF}$ and $\mathrm{Al}$ were 0.865 and 0.135 , respectively. This corresponds to a finned-tube assembly with 9 uniform 0.015 -in.-thick fins per inch. The tubes were modeled on a 2.75 -in. $(6.9850 \mathrm{~cm})$-center-to-center pitch. The region external to the finned region was modeled as a void or filled with $U_{6}-\mathrm{HF}$. Figure 6 shows a sketch of the finned-tube geometry model. The dimensions for the F/S finned tube model are given in Table 6.

The 0.065 -in. minimum wall thickness of the cupronickel tube was modeled with a reduced wall thickness of 0.055 in. This adjustment was made to account for corrosion which might reduce the wall thickness. This modeling increases the volume available for water in the tubes and reduces the amount of absorbing material in the vessel model. The aluminum fin thickness and diameter were taken to be the minimum specification values. This modeling increased the volume available for $\mathrm{UF}_{6}-\mathrm{HF}$ and decreased the amount of absorbing material in the vessel model.

\subsubsection{Material compositions used in the F/S analysis}

The material compositions used in the F/S analysis are described in this section. Nominal material compositions and nominal material densities were specified initially. Subsequently, the volume fractions for the aluminum and cupronickel were reduced to build a degree of conservatism into the model. The material composition descriptions presented in this section include this built-in conservatism. These modeling optimizations are discussed in detail in Sect. 4.4.

A description of the SCALE standard compositions used in the calculations are given in Table 7. These standard compositions were used in the specification of the mixtures used in the calculational models. The standard composition volume fraction was used to adjust the relative amounts of materials in mixtures containing more than one standard composition. The mixture compositions used in the calculations are given in Table 8.

Mixture 1 in the $\mathrm{F} / \mathrm{S}$ is the material inside the cupronickel tube. This mixture could be freon, a void, or water, depending on the specific case being modeled. In order to facilitate simple modifications of the model, all three of these materials were included in the material description of each case.

For cases in which R-114 was considered in the tubes, the physical and chemical properties of 1,1 dichloro 1,2,2,2 tetraflouroethane were used. The chemical formulation can be expressed in simplest form as $\mathrm{C}_{2} \mathrm{Cl}_{2} \mathrm{~F}_{4}$. $\mathrm{R}-114$ was modeled in SCALE using the arbitrary material option for a compound. A theoretical density of $1.455 \mathrm{~g} / \mathrm{cc}$ was used, corresponding to the density of $\mathrm{R}-114$ at $25^{\circ} \mathrm{C}$ and atmospheric pressure.

A void inside the tube was modeled as R-114 at a density of $1 \times 10^{-15}$. Even though this is not a true void, calculationally it is an insignificant density. 


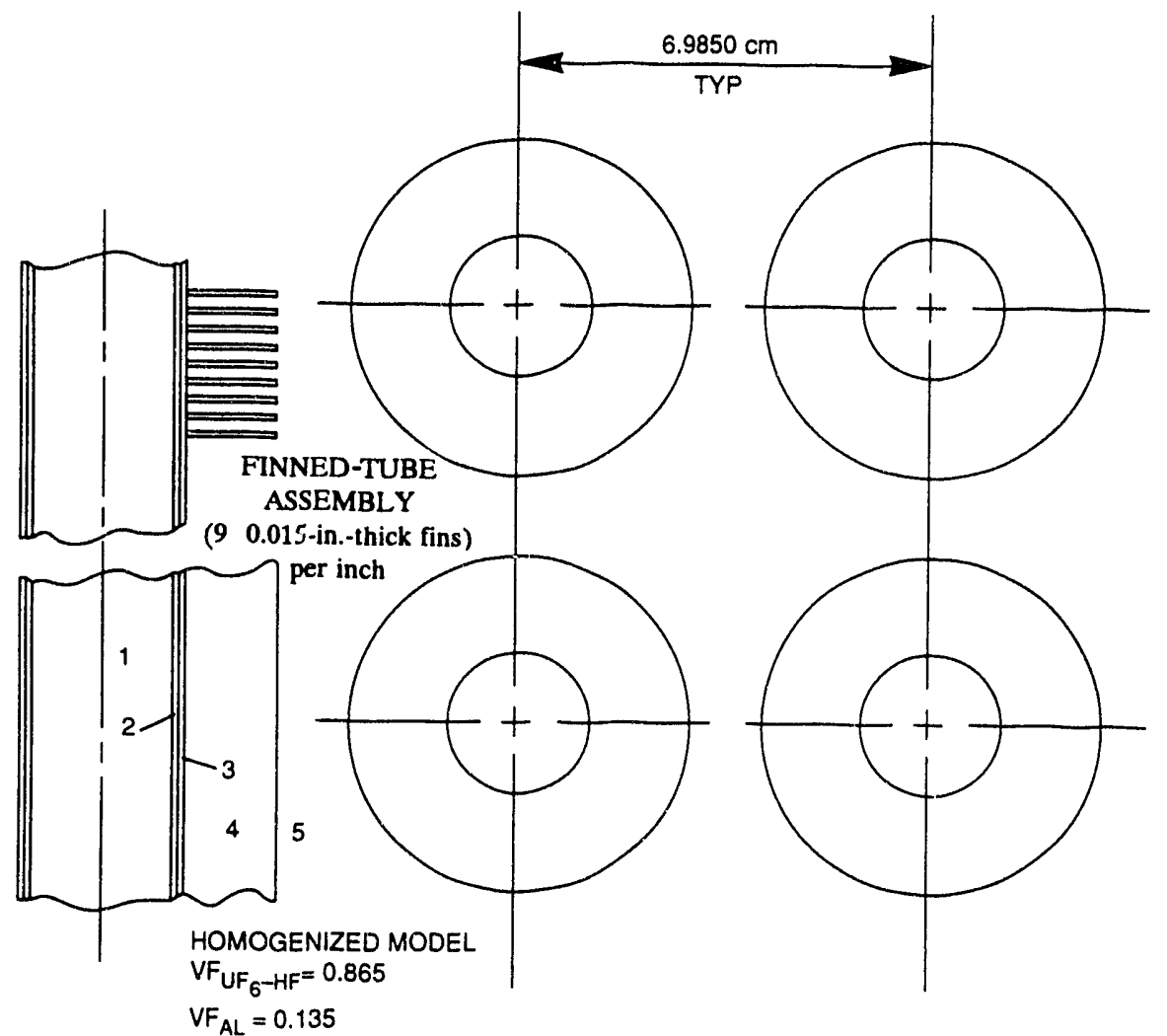

Fig. 6. Finned-tube assembly model.

Table 6. Finned-tube assembly model

\begin{tabular}{|c|c|c|c|c|}
\hline Unit & Description & $\begin{array}{l}\text { Geometry } \\
\text { (all dimensions in } \mathrm{cm} \text { ) }\end{array}$ & & $\begin{array}{l}\text { Material } \\
\text { region }\end{array}$ \\
\hline 1 & $\begin{array}{l}\text { Finned-tube } \\
\text { assembly } \\
\text { "HOLE" model }\end{array}$ & $\begin{array}{l}\text { Cylinder } r=1.1303 \\
\text { Cylinder } r=1.2700 \\
\text { Cylinder } r=1.3589 \\
\text { Cylinder } r=2.8575 \\
\text { Cylinder } r=2.8575\end{array}$ & $\begin{array}{l}1 \\
2 \\
3 \\
4 \\
5^{b}\end{array}$ & $\begin{array}{l}\text { Void/freon/water } \\
\text { Cupronickel } \\
\mathrm{Al} \\
\mathrm{UF}_{6} \text {-HF/AL } \\
\mathrm{UF}_{6} \text { in overloaded region }\end{array}$ \\
\hline 4 & $\begin{array}{l}\text { Finned-tube } \\
\text { assembly } \\
\text { "Base Array" } \\
\text { model }\end{array}$ & $\begin{array}{l}\text { Cylinder } r=1.1303 \\
\text { Cylinder } r=1.2700 \\
\text { Cylinder } r=1.3589 \\
\text { Cylinder } r=2.8575 \\
\text { Cylinder } r=2.857 \\
\text { Cuboid } \quad x=y=6.9850\end{array}$ & $\begin{array}{l}1 \\
2 \\
3 \\
4 \\
5^{b} \\
5\end{array}$ & $\begin{array}{l}\text { Void/freon/water } \\
\text { Cupronickel } \\
\mathrm{Al} \\
\mathrm{UF}_{6}-\mathrm{HF} / \mathrm{Al} \\
\mathrm{UF}_{6} \text { in overloaded region } \\
\mathrm{UF}_{6} \text { in overloaded region }\end{array}$ \\
\hline
\end{tabular}

-The length of the finned-tube assembly model is $198.12 \mathrm{~cm}$ for the $10-\mathrm{MW}$ F/S and $289.56 \mathrm{~cm}$ for the $20-\mathrm{MW}$ F/S.

'The model was constructed in a manner that would allow for calculating overloading conditions that were less than "complete filling"; however, this feature was not used in the F/S analysis.

Sources: Dwg. M5E17202 H Rev A Tube, $10 \mathrm{MW}$ and $20 \mathrm{MW}$ finned, ${ }^{24}$

Wolverine Tube INC - Wolverine Trufin type L/C specifications. ${ }^{23}$ 
Table 7. Standard composition descriptions

\begin{tabular}{|c|c|c|c|}
\hline $\begin{array}{l}\text { Composition name } \\
\text { (material) }\end{array}$ & $\begin{array}{l}\text { Material } \\
\text { density } \\
\text { g/cc }\end{array}$ & Constituent & $\begin{array}{l}\text { wt } \% \text { in composition } \\
\text { (or number of atoms } \\
\text { per molecule) }\end{array}$ \\
\hline $\begin{array}{l}\text { ARBMR114 } \\
\text { (freon R-114) }\end{array}$ & 1.455 & $\begin{array}{l}\mathrm{C} \\
\mathrm{F} \\
\mathrm{Cl}\end{array}$ & $\begin{array}{l}\text { (2) } \\
\text { (4) } \\
(2)\end{array}$ \\
\hline $\begin{array}{l}\text { ARBMVOID } \\
\text { (void) }\end{array}$ & $1 \times 10^{-15}$ & $\begin{array}{l}\mathrm{C} \\
\mathrm{F} \\
\mathrm{Cl}\end{array}$ & $\begin{array}{l}\text { (2) } \\
\text { (4) } \\
\text { (2) }\end{array}$ \\
\hline $\begin{array}{l}\mathrm{H}_{2} \mathrm{O} \\
\text { (water) }\end{array}$ & 0.9982 & $\begin{array}{l}\mathrm{H} \\
\mathrm{O}\end{array}$ & $\begin{array}{l}\text { (2) } \\
\text { (1) }\end{array}$ \\
\hline $\begin{array}{l}\text { ARBMC71500 } \\
\text { (cupronickel) }\end{array}$ & 8.94 & $\begin{array}{l}\mathrm{Cu} \\
\mathrm{Ni} \\
\mathrm{Fe} \\
\mathrm{Mn}\end{array}$ & $\begin{array}{r}67.80 \\
31.00 \\
0.70 \\
0.50\end{array}$ \\
\hline $\begin{array}{l}\mathrm{AL} \\
\text { (aluminum) }\end{array}$ & 2.6989 & $\mathrm{Al}$ & 100.00 \\
\hline $\begin{array}{l}\text { UF6 } \\
\text { (uranium hexaflu sride) }\end{array}$ & $5.11591^{\star}$ & $\begin{array}{l}\mathrm{U} \\
\mathrm{F}\end{array}$ & $\begin{array}{l}(1) \\
(6)\end{array}$ \\
\hline $\begin{array}{l}\text { HFACID } \\
\text { (hydrofluoric acid) }\end{array}$ & $0.0000^{\circ}$ & $\begin{array}{l}\mathrm{H} \\
\mathrm{F}\end{array}$ & $\begin{array}{l}\text { (1) } \\
\text { (1) }\end{array}$ \\
\hline $\begin{array}{l}\text { ARBMSA516 } \\
\text { (SA-516 GR55 steel) }\end{array}$ & 7.85 & $\begin{array}{l}\mathrm{Fe} \\
\mathrm{Mn} \\
\mathrm{Si} \\
\mathrm{C}\end{array}$ & $\begin{array}{r}98.855 \\
0.765 \\
0.29 \\
0.900\end{array}$ \\
\hline $\begin{array}{l}\text { RFCONCRETE } \\
\text { (Rocky Flats concrete) }\end{array}$ & & $\begin{array}{l}\mathrm{O} \\
\mathrm{Ca} \\
\mathrm{Si} \\
\mathrm{C} \\
\mathrm{Al} \\
\mathrm{K} \\
\mathrm{Mg} \\
\mathrm{Fe} \\
\mathrm{H} \\
\mathrm{Na} \\
\mathrm{S} \\
\mathrm{Ti} \\
\mathrm{N}\end{array}$ & $\begin{array}{r}48.49 \\
23.00 \\
15.50 \\
5.52 \\
2.17 \\
1.37 \\
1.25 \\
1.01 \\
0.75 \\
0.63 \\
0.19 \\
0.10 \\
0.02\end{array}$ \\
\hline
\end{tabular}

- The density of $\mathrm{UF}_{6}$ and HFACID are determined by using a volume additive density formulation given in Appendix B. The density stown is for $2 \%$ enriched $\mathrm{UF}_{6}$ at an $\mathrm{H} / \mathrm{U}=0.0$ and a temperature of $15^{\circ} \mathrm{C}$. 
Table 8. Mixture compositions used in the calculations

\begin{tabular}{|c|c|c|c|c|}
\hline $\begin{array}{l}\text { Mixture } \\
\text { No. } \\
\end{array}$ & $\begin{array}{l}\text { Compositions used } \\
\text { in the mixture }\end{array}$ & $\begin{array}{l}\text { Volume fraction } \\
\text { in the mixture }\end{array}$ & Constituent & $\begin{array}{l}\text { Atom } \\
\text { density }\end{array}$ \\
\hline \multirow[t]{8}{*}{1} & ARBMR114 & 1.0 & $\mathrm{C}$ & $1.02543-2$ \\
\hline & & & F & $2.05086-2$ \\
\hline & or & & $\mathrm{Cl}$ & $1.02543-2$ \\
\hline & ARBMVOID & 1.0 & C & $7.04764-18$ \\
\hline & & & $F$ & $1.40953-17$ \\
\hline & or & & $\mathrm{Cl}$ & $7.04764-18$ \\
\hline & $\mathrm{H} 2 \mathrm{O}$ & 1.0 & $\mathrm{H}$ & $6.67514-2$ \\
\hline & & & o & $3.33757-2$ \\
\hline \multirow[t]{4}{*}{2} & ARBMC71500 & $0.5^{\mathrm{a}}$ & $\mathrm{Cu}$ & $2.84743-2$ \\
\hline & & & $\mathrm{Ni}$ & $1.42193-2$ \\
\hline & & & $\mathrm{Fe}$ & $3.37422-4$ \\
\hline & & & $\mathrm{Mn}$ & $2.44994-4$ \\
\hline \multirow[t]{2}{*}{3} & AL & $0.5^{n}$ & Al & $3.01187-2$ \\
\hline & & & ${ }^{235} \mathrm{U}^{\mathrm{b}}$ & $1.53324-4$ \\
\hline \multirow[t]{4}{*}{4} & UF6 & 0.8650 & ${ }^{228} \mathrm{U}^{b}$ & $7.41801-3$ \\
\hline & HFACID & 0.8650 & $\mathrm{~F}$ & $4.5428-2$ \\
\hline & $\mathrm{AL}$ & $0.0675^{\star}$ & $\mathrm{H}$ & 0.00000 \\
\hline & & & Al & $4.06602-3$ \\
\hline \multirow[t]{4}{*}{5} & UF6 & $1.0\left(\text { or } 1 \times 10^{-5}\right)^{c}$ & ${ }^{235} \mathrm{U}^{\mathrm{b}}$ & $1.77253-4$ \\
\hline & HFACID & $1.0\left(\text { or } 1 \times 10^{-5}\right)^{c}$ & ${ }^{238} \mathrm{U}^{\mathrm{b}}$ & $8.57573-3$ \\
\hline & & & $\mathrm{F}$ & $5.25179-2$ \\
\hline & & & $\mathrm{H}$ & 0.00000 \\
\hline \multirow[t]{4}{*}{6} & ARBMSA516 & 1.0 & $\mathrm{Fe}$ & $8.36829-2$ \\
\hline & & & $\mathrm{Mn}$ & $6.58277-4$ \\
\hline & & & Si & $4.88134-4$ \\
\hline & & & C & $3.54553-3$ \\
\hline \multirow[t]{2}{*}{7} & $\mathrm{H} 2 \mathrm{O}$ & 1.0 & $\mathrm{H}$ & $6.67514-2$ \\
\hline & & & o & $3.33757-2$ \\
\hline \multirow[t]{13}{*}{8} & RFCONCRETE & 1.0 & 0 & $4.23723-2$ \\
\hline & & & $\mathrm{Ca}$ & $8.02088-3$ \\
\hline & & & $\mathrm{Si}$ & $7.71397-2$ \\
\hline & & & C & $6.42958-3$ \\
\hline & & & Al & $1.12412-3$ \\
\hline & & & K & $4.8972-4$ \\
\hline & & & Mg & $7.18849-4$ \\
\hline & & & $\mathrm{Fe}$ & $2.52792-4$ \\
\hline & & & $\mathbf{H}$ & $1.04019-2$ \\
\hline & & & $\mathrm{Na}$ & $3.83033-4$ \\
\hline & & & $\mathbf{S}$ & $8.28260-5$ \\
\hline & & & $\mathrm{Ti}$ & $2.91932-5$ \\
\hline & & & $\mathrm{N}$ & $1.99629-5$ \\
\hline
\end{tabular}

-Scoping calculations were performed at volume fractions of $1.0,0.7$, and 0.5 . The results indicated that this material of construction is important to the reactivity of the system. A volume fraction of 0.5 was used in all of the subsequent calculations.

${ }^{6}$ The ${ }^{235} \mathrm{U}$ and ${ }^{250} \mathrm{U}$ atom densities depend on the enrichment and $\mathrm{H} / \mathrm{U}$ moderation ratio being calculated. These values are for $2 \%$ enriched $\mathrm{UF}_{6}$ at an $\mathrm{H} / \mathrm{U}=0.0$ and at $15^{\circ} \mathrm{C}$.

'Mixture 5 is the UF $_{6}$ modeled in the region between the finned tubes. For the nominal loaded cases, a volume fraction of $1 \times$ $10^{-5}$ was used; for fully loaded cases, a volume fraction of 1.0 was used. 
The SCALE default specifications corresponding to water at a density of $0.9982 \mathrm{~g} / \mathrm{cc}$ were used for cases having water inside the tubes.

Mixture 2 is the cupronickel tubing. The nominal composition used for cupronickel was that specified for SB-359 C71500 from ASME Section II, Part B. ${ }^{25}$ The material was defined as $67.8 \mathrm{wt} \% \mathrm{Cu}, 31 \mathrm{wt} \% \mathrm{Ni}$, with minor quantities of iron and manganese. A density of $8.94 \mathrm{~g} / \mathrm{cc}$ was used.

Mixture 3 is the aluminum in the tube portion of the Wolverine trufin type L/C finned tube. The SCALE default for $\mathrm{Al}$ was used for this material which corresponds to $\mathrm{Al}$ at a density of $2.6989 \mathrm{~g} / \mathrm{cc}$.

Mixture 4 is the $\mathrm{UF}_{6}-\mathrm{HF} / \mathrm{Al}$ mixture used to represent the $\mathrm{UF}_{6}-\mathrm{HF}$ and $\mathrm{Al}$ fins. The mixture was created using SCALE standard compositions for $\mathrm{UF}_{6}, \mathrm{HF}$, and $\mathrm{Al}$. The volume fractions of the $\mathrm{UF}_{6}$ and $\mathrm{HF}$ were specified at 0.8650 , and the aluminum was specified at a volume fraction of 0.1350 . This maintained the proper proportions of $\mathrm{UF}_{6}-\mathrm{HF}-\mathrm{Al}$ in the finned region. The density of a mixture of $\mathrm{UF}_{6}-\mathrm{HF}$ is a function of the temperature, the $\mathrm{H} / \mathrm{U}$ atomic ratio of the mixture, and, to a lesser extent, the enrichment of the uranium. The theoretical densities of $\mathrm{UF}_{6}$ and $\mathrm{HF}$ at $15^{\circ} \mathrm{C}$ were used in a volume additive density formula to determine the densities of $\mathrm{UF}_{6}$ and $\mathrm{HF}$ in a mixture at a given $\mathrm{H} / \mathrm{U}$. The density formulation used is given in Appendix $A$ with the calculated $U_{6}-\mathrm{HF}$ densities for each enrichment and $\mathrm{H} / \mathrm{U}$ considered in the $\mathrm{F} / \mathrm{S}$ analysis.

Mixture 5 is the $\mathrm{UF}_{6}-\mathrm{HF}$ in the overloaded region of the F/S. Mixture 5 was the same as mixture 4, except the aluminum was omitted and the volume fractions of the $\mathrm{UF}_{6}$ and $\mathrm{HF}$ were changed. For calculations in which nominal $\mathrm{UF}_{6}$ loading was considered, the volume fraction of mixture 5 was specified as $1 \times 10^{-15}$, which represents a near void. For cases in which overloading was considered, a volume fraction of 1 was used.

Mixture 6 is the steel in the F/S steel, tube sheets, and head. The nominal composition for steel was taken to be that specified for SA-516 GR55 from ASME Section II Part $\mathrm{A}^{26}$ A density of $7.85 \mathrm{~g} / \mathrm{cc}$ was used for this material.

\subsubsection{Preliminary F/S calculations}

The 20-MW F/S model and material compositions described in Sects. 4.3.1 and 4.3.2 were used for preliminary calculations considering $5 \mathrm{wt} \%$ enriched $\mathrm{UF}_{6}$. A range of $\mathrm{H} / \mathrm{U}$ moderation ratios from 0.0 to 30 have been analyzed. Cases with freon, void, or water on the tube side of the finned tube were calculated for a nominally loaded F/S and for a fully loaded F/S. Several calculations were performed to demonstrate the reactivity effects of the materials of construction.

The model for a nominal loaded $\mathrm{F} / \mathrm{S}$ was based on $\mathrm{UF}_{6}$ on the tubes extending radially to the edge of the fin $(2.8575 \mathrm{~cm})$. The corresponding mass of $\mathrm{UF}_{6}$ in the models is dependent on the $\mathrm{H} / \mathrm{U}$ ratio being considered. The mass of $\mathrm{UF}_{6}$ at an $\mathrm{H} / \mathrm{U}=0.0$ is $3,619 \mathrm{~kg}$ for the 10 MW model and 7,628 kg for the 20-MW model. The fully loaded model was based on the entire free volume of the $\mathrm{F} / \mathrm{S}$ vessel being filled with $\mathrm{UF}_{6}$. The corresponding mass of $\mathrm{UF}_{6}$ at an $\mathrm{H} / \mathrm{U}=0.0$ is $9,676 \mathrm{~kg}$ for the $10-\mathrm{MW}$ model and $19,974 \mathrm{~kg}$ for the $20-\mathrm{MW}$ model. The mass of $\mathrm{UF}_{6}$ is about $9 \%$ smaller for a $\mathrm{H} / \mathrm{U}=0.33$ than for a $\mathrm{H} / \mathrm{U}=0.0$.

This rather extensive series of calculations demonstrate the reactivity of the $F / S$ for various normal and abnormal operating conditions. The general trends that exist as a function of $\mathrm{H} / \mathrm{U}$, tube side material, and loading conditions are expected to be similar for all uranium enrichments and for both the 10- and 20-MW F/S. 
The results of these analyses are given in Tables 9 through 12 and presented in Figs. 7 and 8. A consistent naming convention was used for the case names of the $\mathrm{F} / \mathrm{S}$ calculations. In Tables 9 and 10, the first character of the name defines the loading. Roman numeral "I" designates that nominal loading was modeled. Roman numeral "II" designates that full loading was modeled. A two-digit number corresponds to an $\mathrm{H} / \mathrm{U}$ value shown in Tables 9 and 10. Case variations for given $\mathrm{H} / \mathrm{U}$ ratios are presented in Tables 11 and 12. These case names start with a letter and a number designating the type of variation. The nominal loading cases have a twodigit number corresponding to the $\mathrm{H} / \mathrm{U}$. The full loading cases have the letter " $\mathrm{F}$ " followed by a single-digit number corresponding to the H/U. For example, R201 is a case name for nominal loading, and R2F1 is the corresponding case for full loading. The headings in Tables 9-12 designate which material was considered in the freon tubes. An "a" corresponds to R-114 in the tube, a "b" corresponds to void, and a "c" corresponds to water in the freon tube. The actual case name includes this designation as the last character of the case name. This naming convention was also used in Sect. 5.

The calculational results in Tables 9 and 10 indicate that the R-114 acts as an absorber. The reactivity effects of $\mathrm{R}-114$, as compared to a void increase with $\mathrm{H} / \mathrm{U}$ moderating ratio varying from about a $6 \%$ negative reactivity at $\mathrm{H} / \mathrm{U}=0.0$ to more than $30 \%$ negative reactivity at $\mathrm{H} / \mathrm{U}$ around 5 for the nominally loaded cases. For the fully loaded cases, the reactivity effects of $\mathrm{R}-114$ compared to a void are smaller, varying from abut $2.5 \%$ at $\mathrm{H} / \mathrm{U}=0.33$ to about $16 \%$ at $\mathrm{H} / \mathrm{U}=7$.

The moderating effects of water in the tube significantly increase the reactivity of both the nominally loaded and fully loaded F/S. The reactivity effects are larger at the lower $\mathrm{H} / \mathrm{U}$ moderating ratios. The positive reactivity increase is much larger for the nominally loaded $\mathrm{F} / \mathrm{S}$ than for the fully loaded vessel.

Table 9. Preliminary calculated $k_{\text {eff }}$ for 20-MW 1 s nominal loading, $5 \mathrm{wt} \%{ }^{235} \mathrm{U}$ enrichment ${ }^{\mathrm{a}}$

\begin{tabular}{llccc}
\hline & & \multicolumn{3}{c}{$\mathrm{k}_{\mathrm{eff}} \pm \sigma$} \\
\cline { 3 - 5 } Case & $\mathrm{H} / \mathrm{U}$ & (a) R-114 & (b) Void & (c) Water \\
\hline I01 $\{\mathrm{a}, \mathrm{b}$, or $\mathrm{c}\}$ & 0 & $0.4354 \pm 0.0020$ & $0.4621 \pm 0.0023$ & $0.8730 \pm 0.0024$ \\
I02 & 0.088 & $0.4508 \pm 0.0018$ & - & $0.8820 \pm 0.0025$ \\
I03 & 0.33 & $0.4861 \pm 0.0020$ & $0.5128 \pm 0.0023$ & $0.8966 \pm 0.0028$ \\
I04 & 1.0 & $0.5444 \pm 0.0019$ & $0.6027 \pm 0.0023$ & $0.9269 \pm 0.0026$ \\
I05 & 3 & $0.6067 \pm 0.0020$ & $0.7243 \pm 0.0023$ & $0.9485 \pm 0.0028$ \\
I06 & 5 & $0.5971 \pm 0.0022$ & $0.7659 \pm 0.0026$ & $0.9280 \pm 0.0026$ \\
I07 & 7 & $0.5826 \pm 0.0017$ & $0.7633 \pm 0.0025$ & $0.9019 \pm 0.0023$ \\
I08 & 10 & $0.5398 \pm 0.0020$ & $0.7524 \pm 0.0023$ & $0.8456 \pm 0.0022$ \\
I09 & 15 & $0.4743 \pm 0.0018$ & $0.6942 \pm 0.0020$ & $0.7799 \pm 0.0021$ \\
I10 & 20 & $0.4170 \pm 0.0013$ & -- & $0.7045 \pm 0.0021$ \\
I11 & 30 & $0.3405 \pm 0.0012$ & -- & $0.8944 \pm 0.0017$ \\
\hline
\end{tabular}

${ }^{\mathrm{a} C a l c u l a t i o n s}$ performed wtih $100 \%$ of nominal aluminum and cupronickel. 
Table 10. Preliminary calculated $k_{\text {eff }}$ for $20-\mathrm{MW} \mathrm{F/S}$ fully loaded, 5 wt $\%{ }^{235} \mathrm{U}$ enrichment ${ }^{\mathrm{a}}$

\begin{tabular}{llcll}
\hline & & \multicolumn{3}{c}{$\mathrm{k}_{\text {efi }} \pm \sigma$} \\
\cline { 3 - 5 } Case & $\mathrm{H} / \mathrm{U}$ & (a) R-114 & (b) Void & (c) Water \\
\hline II01 $\{\mathrm{a}, \mathrm{b}$, or $\mathrm{c}\}$ & 0 & $0.5791 \pm 0.0015$ & -- & $0.9110 \pm 0.0027$ \\
II02 & 0.088 & $0.6120 \pm 0.0013$ & - & $0.9300 \pm 0.0023$ \\
II03 & 0.33 & $0.6730 \pm 0.0018$ & $0.6898 \pm 0.0020$ & $0.9586 \pm 0.0023$ \\
II04 & 1.0 & $0.7937 \pm 0.0021$ & $0.8346 \pm 0.0023$ & $1.0395 \pm 0.0027$ \\
II05 & 3 & $0.9367 \pm 0.0022$ & $1.0360 \pm 0.0024$ & $1.1417 \pm 0.0024$ \\
II06 & 5 & $0.9793 \pm 0.0022$ & $1.1073 \pm 0.0027$ & $1.1737 \pm 0.0027$ \\
II07 & 7 & $0.9799 \pm 0.0025$ & $1.1375 \pm 0.0026$ & $1.1762 \pm 0.0028$ \\
I108 & 10 & $0.9562 \pm 0.0019$ & $1.1358 \pm 0.0025$ & $1.1629 \pm 0.0024$ \\
I109 & 15 & $0.8946 \pm 0.0023$ & $1.1007 \pm 0.0026$ & $1.1055 \pm 0.0021$ \\
II10 & 20 & $0.8302 \pm 0.0021$ & -- & $1.0593 \pm 0.0024$ \\
II11 & 30 & $0.7233 \pm 0.0017$ & -- & $0.9520 \pm 0.0019$ \\
\hline
\end{tabular}

${ }^{a}$ Calculations performed with $100 \%$ of nominal aluminum and cupronickel.

Table 11. Preliminary calculated $\mathrm{k}_{\text {eff }}$ for $20-\mathrm{MW} \mathrm{F/S}$ nominal loading, $5 \mathrm{wt} \%{ }^{235} \mathrm{U}$ enrichment reduced structural density

\begin{tabular}{llcc}
\hline & & \multicolumn{2}{c}{$\mathrm{k}_{\text {eff }} \pm \sigma$} \\
\cline { 3 - 4 } Case $^{\mathrm{a}}$ & $\mathrm{H} / \mathrm{U}$ & (b) Void & (c) Water \\
\hline R201 & 0.0 & $0.4145 \pm 0.0023$ & $0.8965 \pm 0.0026$ \\
R103 & 0.33 & $0.5185 \pm 0.0023$ & $0.9066 \pm 0.0025$ \\
R203 & & $0.5240 \pm 0.0023$ & $0.9308 \pm 0.0028$ \\
R303 & & $0.5343 \pm 0.0023$ & $0.9678 \pm 0.0031$ \\
R104 & 1.0 & $0.6065 \pm 0.0023$ & $0.9390 \pm 0.0024$ \\
R204 & & $0.6160 \pm 0.0023$ & $0.9684 \pm 0.0030$ \\
R304 & & $0.6310 \pm 0.0026$ & $1.0076 \pm 0.0027$ \\
R105 & 3.0 & $0.7346 \pm 0.0023$ & $0.9714 \pm 0.0025$ \\
R205 & & $0.7585 \pm 0.0026$ & $0.9971 \pm 0.0026$ \\
R305 & & $0.7794 \pm 0.0029$ & $1.0701 \pm 0.0029$ \\
\hline
\end{tabular}

${ }^{2}$ Prefix R1 - 80\% of nominal aluminum and cupronickel. $\mathrm{R} 2-50 \%$ of nominal aluminum and cupronickel. R3 - $0 \%$ of nominal aluminum and cupronickel. 
Table 12. Preliminary calculated $\mathrm{k}_{\mathrm{eff}}$ for $20-\mathrm{MW} \mathrm{F} / \mathrm{S}$ fully loaded, $5 \mathrm{wt} \%{ }^{235} \mathrm{U}$ enrichment reduced structural density

\begin{tabular}{llcc}
\hline & & \multicolumn{2}{c}{$k_{\text {eff }} \pm \sigma$} \\
\cline { 3 - 4 } Case $^{\mathrm{a}}$ & $\mathrm{H} / \mathrm{U}$ & (b) Void & (c) Water \\
\hline R2F1 & 0.0 & - & $0.9622 \pm 0.0024$ \\
R1F3 & 0.33 & $0.7160 \pm 0.0023$ & $1.0037 \pm 0.0026$ \\
R2F3 & & $0.7250 \pm 0.0021$ & $1.0154 \pm 0.0025$ \\
R3F3 & & -- & $1.0362 \pm 0.0027$ \\
R1F4 & 1.0 & $0.8717 \pm 0.0023$ & $1.0841 \pm 0.0026$ \\
R2F4 & & $0.8859 \pm 0.0022$ & $1.1005 \pm 0.0024$ \\
R1F5 & 3.0 & $1.0800 \pm 0.0024$ & $1.1836 \pm 0.0026$ \\
R2F5 & & $1.0893 \pm 0.0029$ & $1.2090 \pm 0.0027$ \\
\hline
\end{tabular}

${ }^{2}$ Prefix R1 - 80\% of nominal aluminum and cupronickel. R2 - $50 \%$ of nominal aluminum and cupronickel. R3 - $0 \%$ of nominal aluminum and cupronickel.

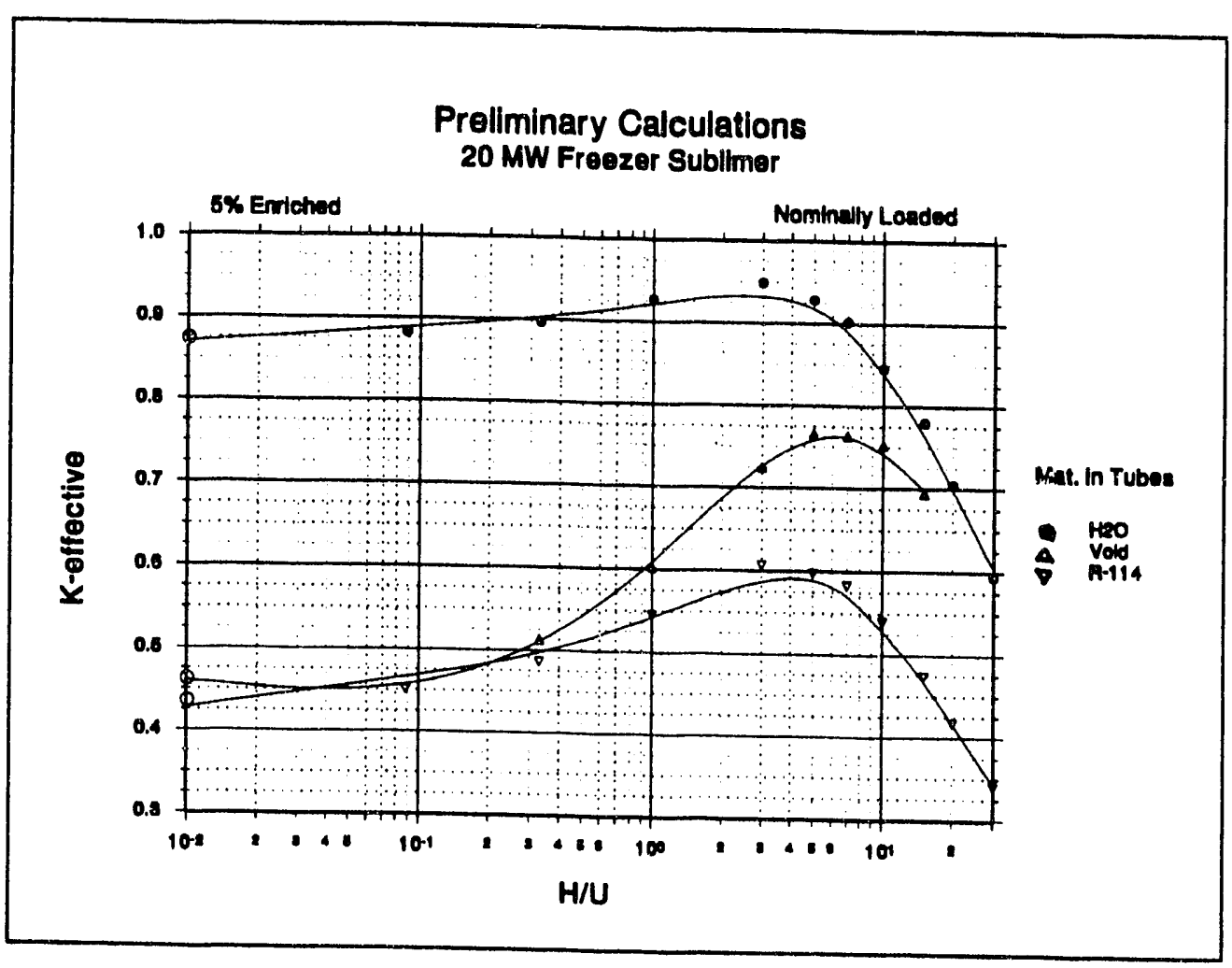

Fig. 7. Preliminary calculations from Table $7-20-\mathrm{MW}$ nominally loaded F/S 


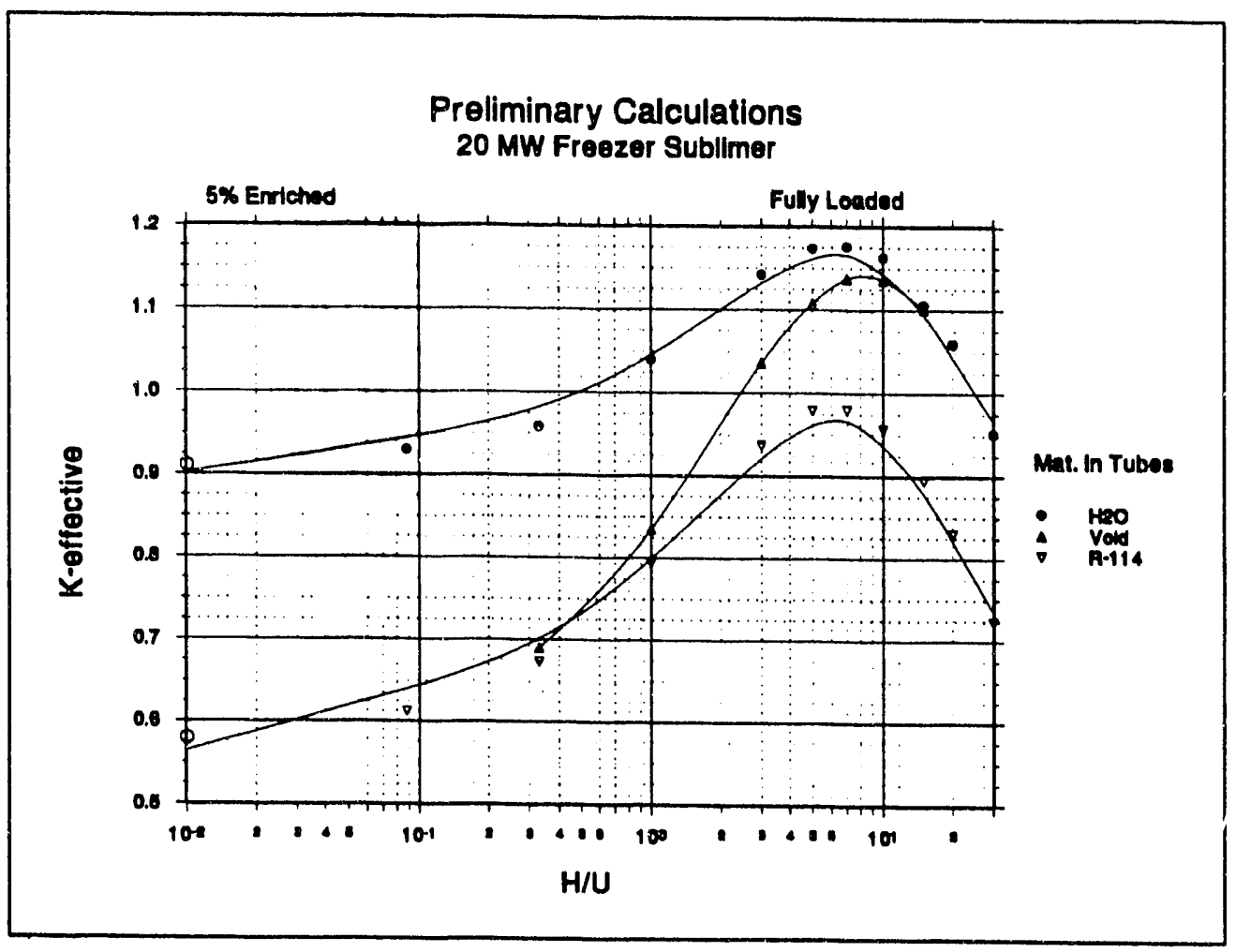

Fig. 8. Preliminary calculations from Table $10-20-\mathrm{MW}$ fully loaded F/S

For every case, the $k_{\text {eff }}$ calculated for the fully loaded $F / S$ is larger than that for the nominally loaded vessel. The reactivity differences range from about $7 \%$ at an $\mathrm{H} / \mathrm{U}=0.33$ to more than $40 \%$ at the higher $\mathrm{H} / \mathrm{U}$ moderating ratios.

The results in Tables 11 and 12 indicate the relative importance of the effect of the structural aluminum and cupronickel on calculated $k_{\text {eff }}$. The results indicate that the reactivity is linearly related to the quantity of structural material modeled. The structural material reduces reactivity by about $8 \%$ for an $\mathrm{H} / \mathrm{U}=0.33$ and about $13 \%$ for an $\mathrm{H} / \mathrm{U}=3.0$ for both the fully loaded and nominally loaded conditions.

One purpose of the extensive preliminary calculations was to identify a smaller subset of calculations that could be used to evaluate the F/S. The calculations of the fully loaded F/S with water in the tubes yield the highest $k_{\text {eff }}$ of the calculations performed. The presence of water in the tubes is one of the accident cases which must be evaluated for the F/S.

The F/S is equipped with load cells to prevent the occurrence of a fully loaded vessel. However, the distribution of $\mathrm{UF}_{6}$ in the vessel is not directly controlled, and the $\mathrm{UF}_{6}$ may be unevenly distributed in the vessel. ${ }^{27}$ There is a significant increase in $k_{\text {eff }}$ for the fully loaded $F / S$ compared with the nominally loaded $\mathrm{F} / \mathrm{S}$. The use of the $\mathbf{k}_{\text {eff }}$ for a nominally loaded vessel to evaluate the safety of the F/S would be nonconservative under conditions of nonuniform loading. The fully loaded condition is one that cannot be exceeded and has the highest calculated $\mathrm{k}_{\text {eff }}$. 
A fully loaded vessel with water in the tubes would appear to be an appropriate subset for evaluating the safety of the vessel.

The moderating ratios of interest are those in the range 0.0 to 1.0 , such that a reasonable subset might be an $\mathrm{H} / \mathrm{U}$ of $0.0,0.088,0.33,1.0$, and 3.0. Extension of the calculations to an $\mathrm{H} / \mathrm{U}=3.0$ allows the trends in reactivity as a function of the moderation ratio to be evaluated. Calculations for a fully loaded $\mathrm{F} / \mathrm{S}$ at these $\mathrm{H} / \mathrm{U}$ values with water in the tubes should provide sufficient information for the criticality safety evaluation of the F/S.

The structural aluminum and cupronickel are important in the calculated reactivity of the F/S. Nominal densities were initially used in the material descriptions, and the models were based upon uniform, evenly distributed fins. The use of nominal densities for the structural materials could result in a nonconservative model because of overestimating the quantity of absorbing material in the F/S. In addition, the model does not account for regions where the aluminum fin has been deformed or removed. Reduction of the effective density of the structural material by a few percent would adequately cover the range of variation in material density. The absence or displacement of the fins in a region of the F/S is a localized effect. Applying a reduction in density over the entire model would conservatively address the absence of fins in a region. A volume fraction of $50 \%$ for the aluminum and cupronickel was chosen for use in the final calculations. This represents a reduction of the density of these absorbing materials to $50 \%$ of their nominal quantities. Modeling in this manner is considered to conservatively account for the possible variations of material density and location in the $\mathrm{F} / \mathrm{S}$ model.

Several additional cases of interest were chosen to be included in the set of calculations performed for each F/S loading configuration analyzed. These cases were variations of the F/S model with an $\mathrm{H} / \mathrm{U}$ moderating ratio of 0.33 . These included a fully loaded $\mathrm{F} / \mathrm{S}$ with void in the tubes and a nominally loaded $\mathrm{F} / \mathrm{S}$ with a void and with water in the tubes. Calculations taking $100 \%$ credit and no credit for aluminum and cupronickel were also chosen to be included.

During the review of the preliminary calculations, it was noted that the LATTICECELL specifications for the fully loaded F/S model adjacent regions had been modeled with nearly the same fissile material. Because the SCALE codes do not account for resonance overlap, modeling adjacent regions with the same fissile material would cause both regions to be resonance selfshielded incorrectly and could produce nonconservative results because of excessive ${ }^{238} \mathrm{U}$ resonance absorption. The magnitude of the error is related to the amount of intermixed moderator in the fissile region. It was not expected that the error introduced by this modeling method would be significant for the F/S calculations; however, the magnitude of the effect on $\mathrm{k}_{\text {eff }}$ is undefined so it was decided to redefine the model for resonance processing.

The LATTICECELL specifications were modified for the calculations performed for Sect. 5 to eliminate any nonconservatism introduced in the resonance processing. Resonance processing for the $\mathrm{UF}_{6}-\mathrm{HF}-\mathrm{Al}$ was performed by modeling the entire region external to the cupronickel tubes as being filled with this material. The resonance processing of the $\mathrm{UF}_{6}-\mathrm{HF}$ in the overfilled region was treated with the lattice effects omitted. This modeling methodology yields cross sections which are slightly over self-shielded and which give slightly conservative results. 


\subsection{MODELING APPROXIMATIONS}

The F/S model is discussed in Sects. 4.2 and 4.3. The purpose of this section is to identify optimizations and approximations used to ensure conservative calculational results. Some optimization is required because of variability in the dimensions and fabrications of the vessel. Other optimizations deal with the cross-section processing; others are related to uncertainties in the actual configuration of the fissile material in the vessel.

The specifications for the finned-tube assembly give a range for the thickness of the fins and nominal and minimum dimensions for the tube materials. The code geometry model used minimum dimensions for the thickness of the aluminum fins and the tube material. This minimizes the absorption by the structural materials and maximizes the volume available for $\mathrm{UF}_{6}$. No conservatism is claimed for these optimizations in that they reflect a normal range of fabrication that the manufacturer may choose to approach in order to minimize material costs.

A volume additive formulation was used to estimate the density of the $\mathrm{UF}_{6}-\mathrm{HF}$ mixture as a function of $\mathrm{H} / \mathrm{U}$. The theoretical densities for $\mathrm{UF}_{6}$ and $\mathrm{HF}$ are required parameters. The density of $\mathrm{UF}_{6}$ and $\mathrm{HF}$ are both functions of temperature. The theoretical densities of $\mathrm{UF}_{6}$ and $\mathrm{HF}$ were taken at $15^{\circ} \mathrm{C}$ for these calculations. This temperature is lower than the operating temperature of the $\mathrm{F} / \mathrm{S}$ during any normal mode of operation. As a result, the $\mathrm{UF}_{6}-\mathrm{HF}$ density is higher for the models than could actually exist in the F/S. This represents a small degree of conservatism in the model.

Calculations in which the $\mathrm{F} / \mathrm{S}$ was considered completely full of $\mathrm{UF}_{6}$ with water in the tubes were chosen as the bounding cases. Weight safety systems on the F/S prevent the actual mass in the F/S from reaching this amount. However, the distribution of $\mathrm{UF}_{6}$ within the $\mathrm{F} / \mathrm{S}$ is not controlled. $\mathrm{UF}_{6}$ will tend to preferentially freeze onto surfaces that do not already have a layer of $\mathrm{UF}_{6}$, but testing with prototype vessels has indicated that there may be significant variations in the distribution of the $\mathrm{UF}_{6}$ loading of the vessel during freezeout.

The reactivity of the $F / S$ is sensitive to the distribution of $U_{6}$ in the vessel. The reactivity of a nominally loaded $F / S$ is lower if the $U F_{6}$ is uniformly distributed than if all of the $\mathrm{UF}_{6}$ were at full density in one location in the vessel. This is due to the change in neutron migration area and leakage from the fissile system. Modeling the $\mathrm{F} / \mathrm{S}$ completely full of $\mathrm{UF}_{6}$ conservatively bounds conditions of nonuniform distribution. No conservatism is claimed for this modeling assumption.

The models that have water in the freon tubes represent an upset condition in which there has been a breach in the condenser/reboiler which has allowed water to displace the freon. The reactivity effect of the water in the freon tubes varies, depending on the intermixed $\mathrm{H} / \mathrm{U}$ in the $\mathrm{UF}_{6}$ and the $\mathrm{UF}_{6}$ loading. Under nominal loading conditions, water in the freon tubes is equivalent to an increase of about 1.76 in the $\mathrm{H} / \mathrm{U}$ of the $\mathrm{UF}_{6}$ in the system. Under fully loaded conditions, water in the freon tubes is equivalent to an increase of about 0.76 in the $\mathrm{H} / \mathrm{U}$ of the $\mathrm{UF}_{6}$ in the system. The presence of water in the freon tubes results in a larger reactivity effect for the nominally loaded F/S than for the fully loaded F/S. The reactivity of the nominally filled vessel remains lower, however, because of the high neutron leakage from the system.

An infinite variety of loading conditions could exist in the F/S. Under the abnormal condition of water in the freon tubes, the smaller the $\mathrm{F} / \mathrm{S}$ inventory the greater the positive reactivity effect of the water. The reactivity gain due to the increase in the $\mathrm{H} / \mathrm{U}$ moderating ratio is countered by a smaller inventory having greater neutron leakage from the vessel. It appears that the neutron leakage effects are of greater importance and drive the overall reactivity of the vessel. As the $\mathrm{H} / \mathrm{U}$ increases because of intermixed HF, the water in the tubes becomes less important to the overall reactivity of the vessel. 
A uniform lattice of finned tubes was used in the model of the F/S. In reality, the central region of the $\mathrm{F} / \mathrm{S}$ vessel is used as a flow path for $\mathrm{UF}_{6}$ and does not have finned tubes in this region. Modeling of the F/S in this manner adds some degree of conservatism to the calculations performed with water in the tubes and at low intermixed $\mathrm{H} / \mathrm{U}$ values. This is due to replacing a central void important to the reactivity of the vessel with fissile material. As the moderating ratio of the intermixed hydrogen increases, the model will become nonconservative because of the decrease in importance of the moderation provided by the water in the tubes and increase in absorption in the structural material in the finned tube assembly. The $\mathrm{H} / \mathrm{U}$ ratio at which the model becomes nonconservative has not been determined, but is believed to be significantly greater than an $\mathrm{H} / \mathrm{U}=0.33$.

In order to ensure conservatism of the model, the volume fraction of the structural mat rials of the finned tube were taken to be $50 \%$ of their nominal value. The model contains approximately onc-half the mass of aluminum and cupronickel that is actually present in the F/S. 


\section{CALCULATIONAL RESULTS AND CONCLUSIONS}

\subsection{RESULTS}

The results of the calculations performed for 10- and 20-MW F/S vessels are presented in this section. The models were based on the geometry descriptions given in Tables 4 and 5 and the material specifications given in Table 8. Input CSAS25 examples for a 10- and a 20-MW F/S calculation at $5 \%$ enrichment and an $\mathrm{H} / \mathrm{U}=0.0$ are given in Appendix $\mathrm{B}$ for reference.

The results for the 10- and $20-\mathrm{MW}$ F/S vessels are presented in Tables 13 and 14 respectively. Presented for each calculation are the case identifier, the enrichment, the $H / U$, the calculation results ( $k_{\text {eff }}$ and $\sigma$ ), and the average energy group of neutrons causing fission. The results are presented graphically in Figs. 9-11 for a 10-MW F/S and in Figs. 12-14 for a 20-MW $\mathrm{F} / \mathrm{S}$.

Figures 9 and 12 show the variation of $k_{\text {eff }}$ as a function of $H / U$ for a fully loaded $F / S$ with water in the tubes at four enrichments. The curve represents a smooth spline through the calculated $k_{\text {eff }}$. The reactivity of the F/S is extremely sensitive to even small changes in the amount of hydrogen intermixed with the $\mathrm{UF}_{6}$.

Figures 10 and 13 show the variation of $\mathrm{k}_{\text {eff }}$ as a function of enrichment for a fully loaded $\mathrm{F} / \mathrm{S}$ with water in the tubes for $\mathrm{H} / \mathrm{U}$ ratios of $0.0,0.088$, and 0.33 . The solid curves are a smooth spline through the calculated $k_{\text {eff }}$, and the dashed curves are a smooth spline through the set of points of calculated $k_{\text {eff }}+2 \sigma$.

Figures 11 and 14 show $k_{\text {eff }}$ as a function of enrichment for a fully loaded and nominally loaded $\mathrm{F} / \mathrm{S}$ at an $\mathrm{H} / \mathrm{U}=0.33$. The $\Delta \mathrm{k}$ between the fully loaded and nominally loaded calculations is about 0.12 for the $10-\mathrm{MW}$ model and about 0.10 for the $20-\mathrm{MW}$ model. The smaller change for the larger vessel is because of smaller overall neutron leakage from the 20MW model. No credit for conservatism is taken for the fully loaded model over the nominally loaded model because nonuniform loading (which is known to occur) could result in $\mathrm{k}_{\text {eff }}$ greater than the nominally loaded values. It is believed that the calculated $k_{\text {eff }}$ for the fully loaded vessel is a bounding case for all loading conditions which could occur in the vessel.

Cases IIN3C (no structural material) and IIF3C (full structural material) show the reactivity effects of the aluminum and cupronickel in the model and allow an estimate of the conservatism introduced into the model due to using a volume fraction of 0.5 for these materials. The IIN3C cases may be compared directly with the cases used to establish the acceptable operating criteria in Taylor's report. The ANISN homogenized model used by Taylor appears to be slightly conservative relative to the KENO V.a model for the same loading and moderation conditions. Good agreement is noted between previous KENO IV and KENO V.a calculations. The use of a volume fraction of 0.5 for the structural materials results in a slight reduction ( $\sim 2 \%$ for the $10-\mathrm{MW} \mathrm{F} / \mathrm{S}$ and $\sim 3 \%$ for the $20-\mathrm{MW} \mathrm{F} / \mathrm{S}$ ) in the amount of conservatism of the current $\mathrm{F} / \mathrm{S}$ models compared with that used previously for acceptance.

The 10-MW F/S will be used in the cascade in locations that will exceed the enrichment criteria of $2.35 \mathrm{wt} \%{ }^{235} \mathrm{U}$ established by Taylor for acceptable operation. Several calculations were performed to allow a more detailed study of the reactivity as a function of $\mathrm{H} / \mathrm{U}$ for enrichme ts between 3 and $4 \%$ enrichment. The results of these calculations are shown graphically in Figs. 15-20. The $\mathrm{H} / \mathrm{U}$ at which $k_{\text {eff }}+2 \sigma=0.90$ was read from each of these figures and is plotted graphically as a function of enrichment in Fig. 21. The dashed curve in Fig. 21 is the $95 \%$ confidence on the least-squares fit through the data. 


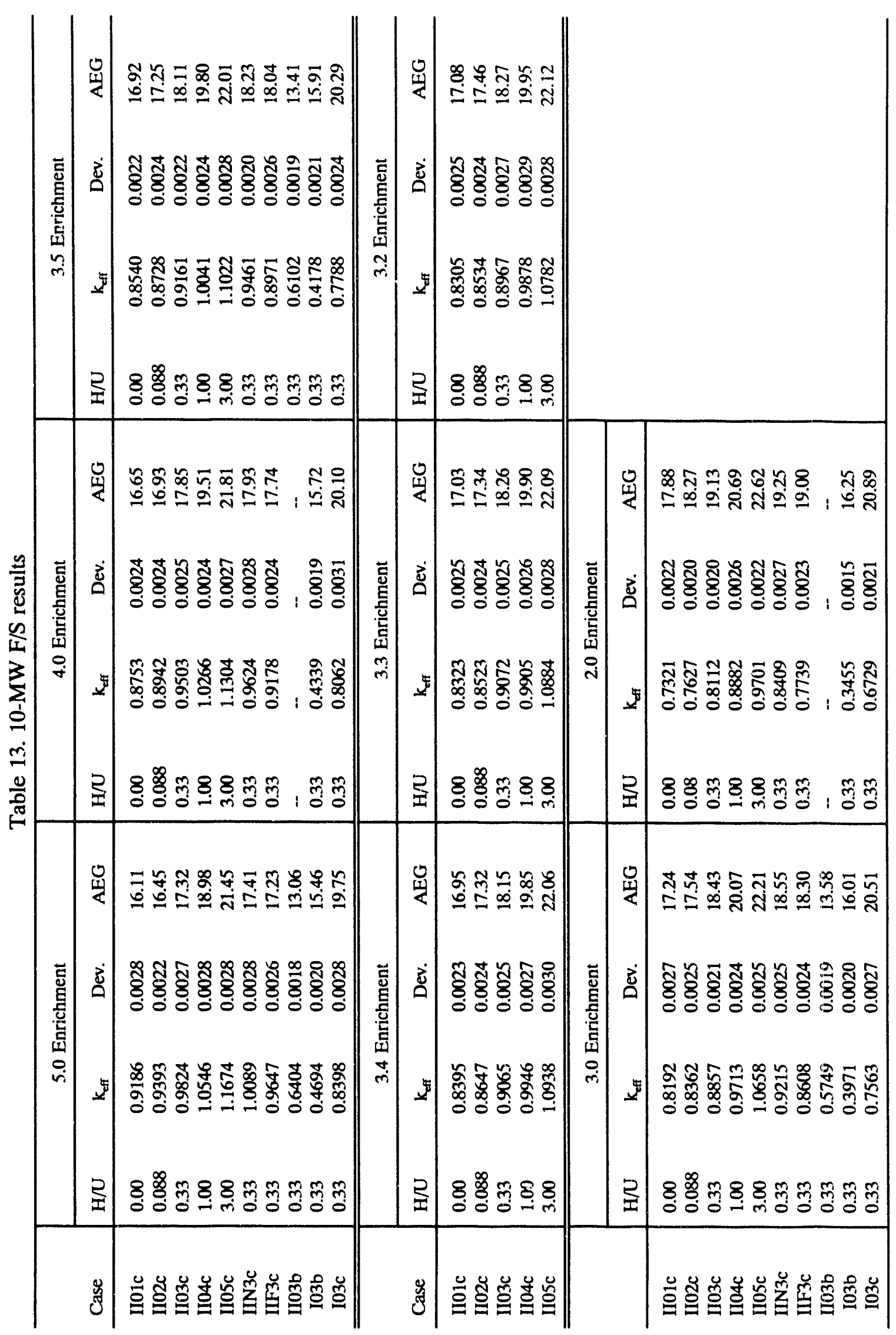




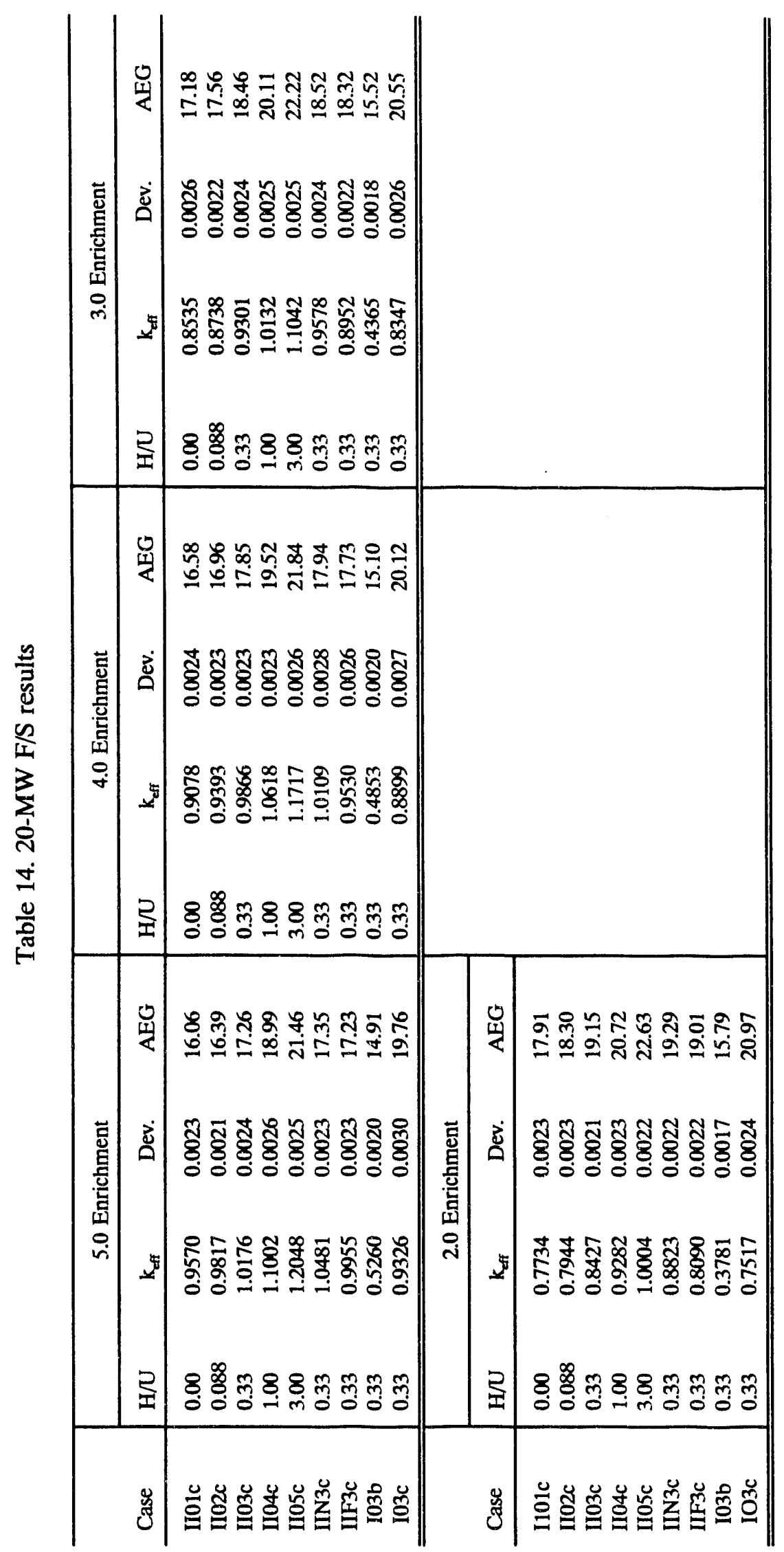




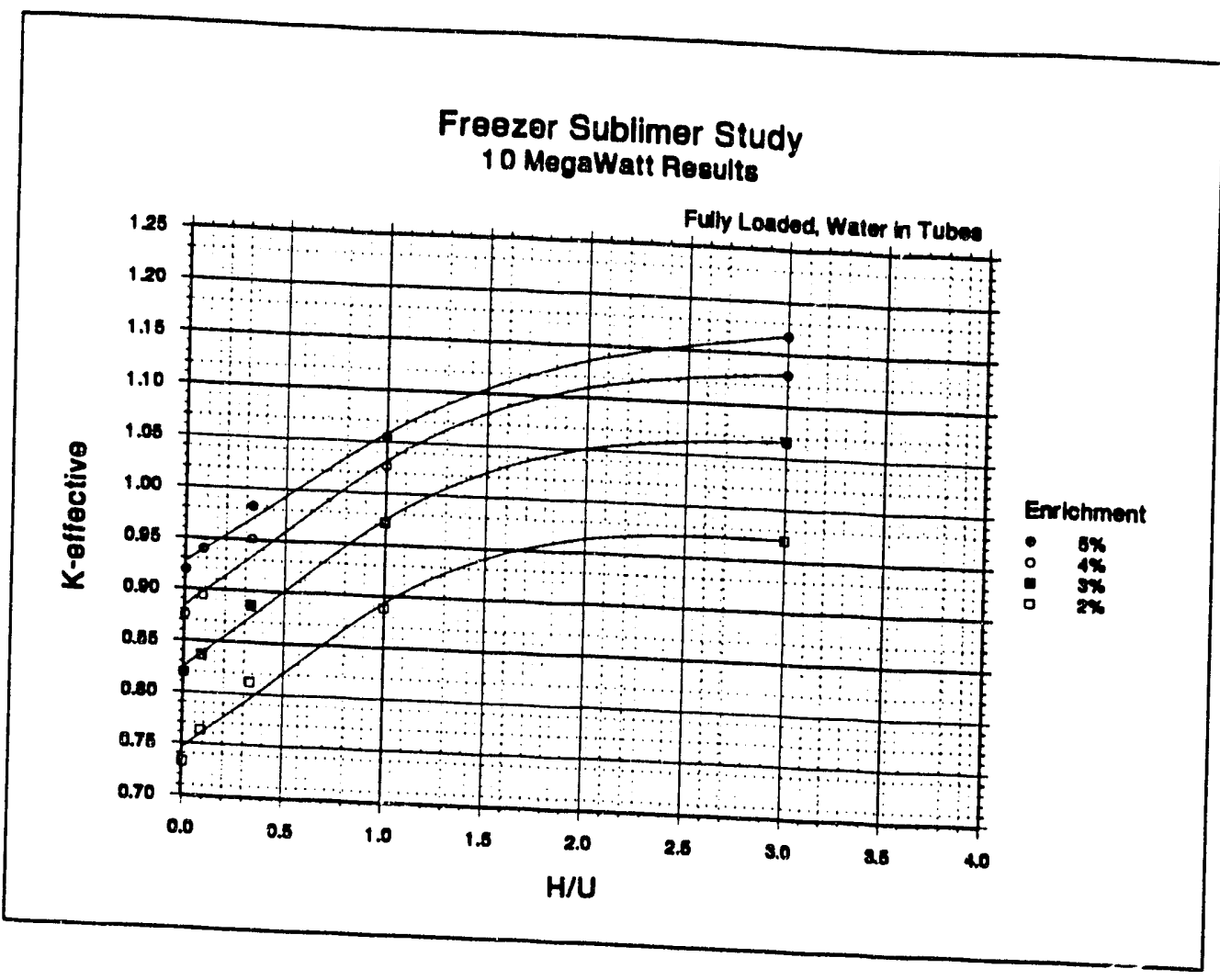

Fig. 9. $\mathrm{k}_{\text {eff }}$ vs $\mathrm{H} / \mathrm{U}$ for a $10-\mathrm{MW}$ fully loaded $\mathrm{F} / \mathrm{S}$ with water in the tubes.

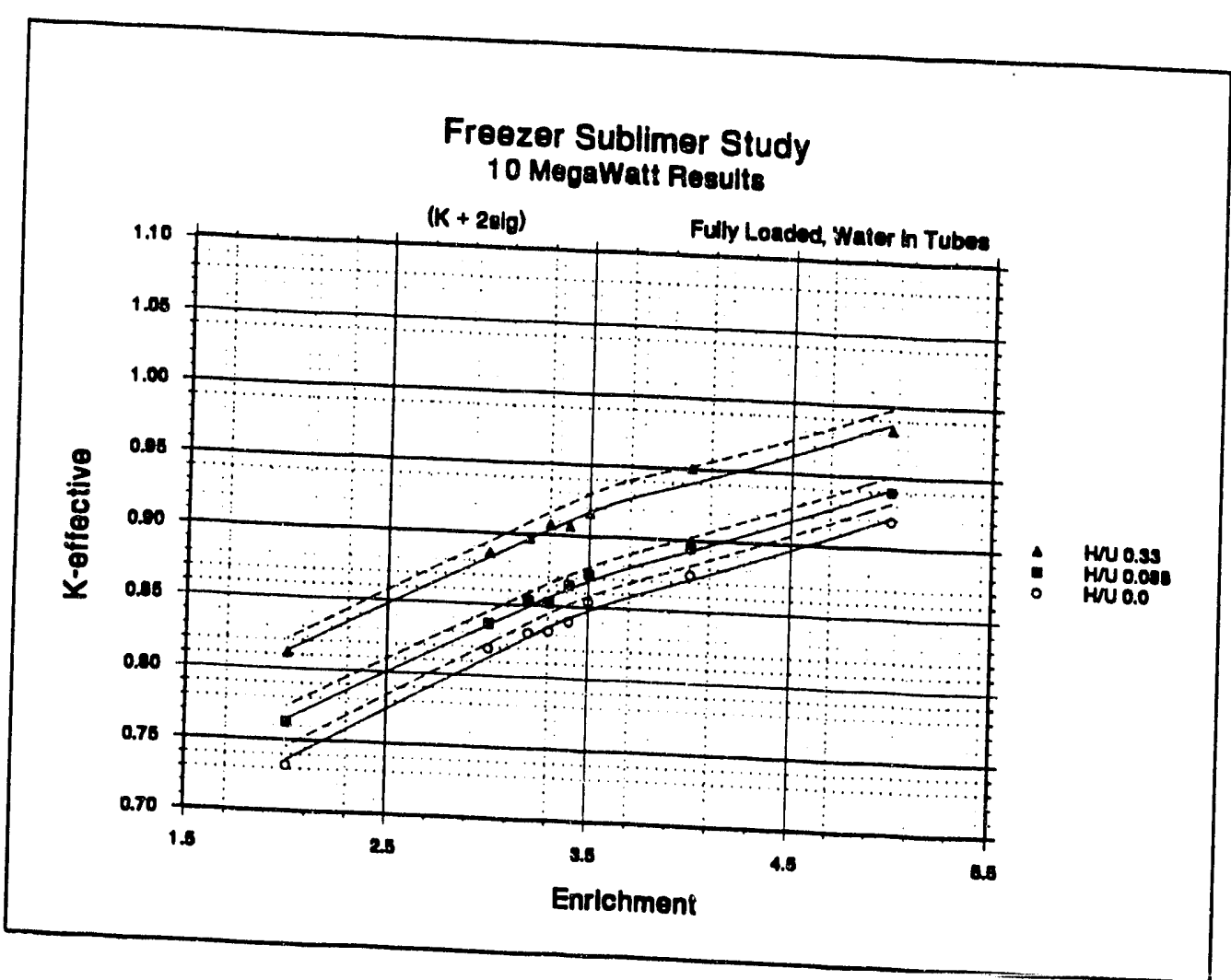

Fig. 10. $\mathrm{k}_{\text {eff }}$ vs enrichment for a 10-MW fully loaded $\mathrm{F} / \mathrm{S}$ with water in the tubes. 


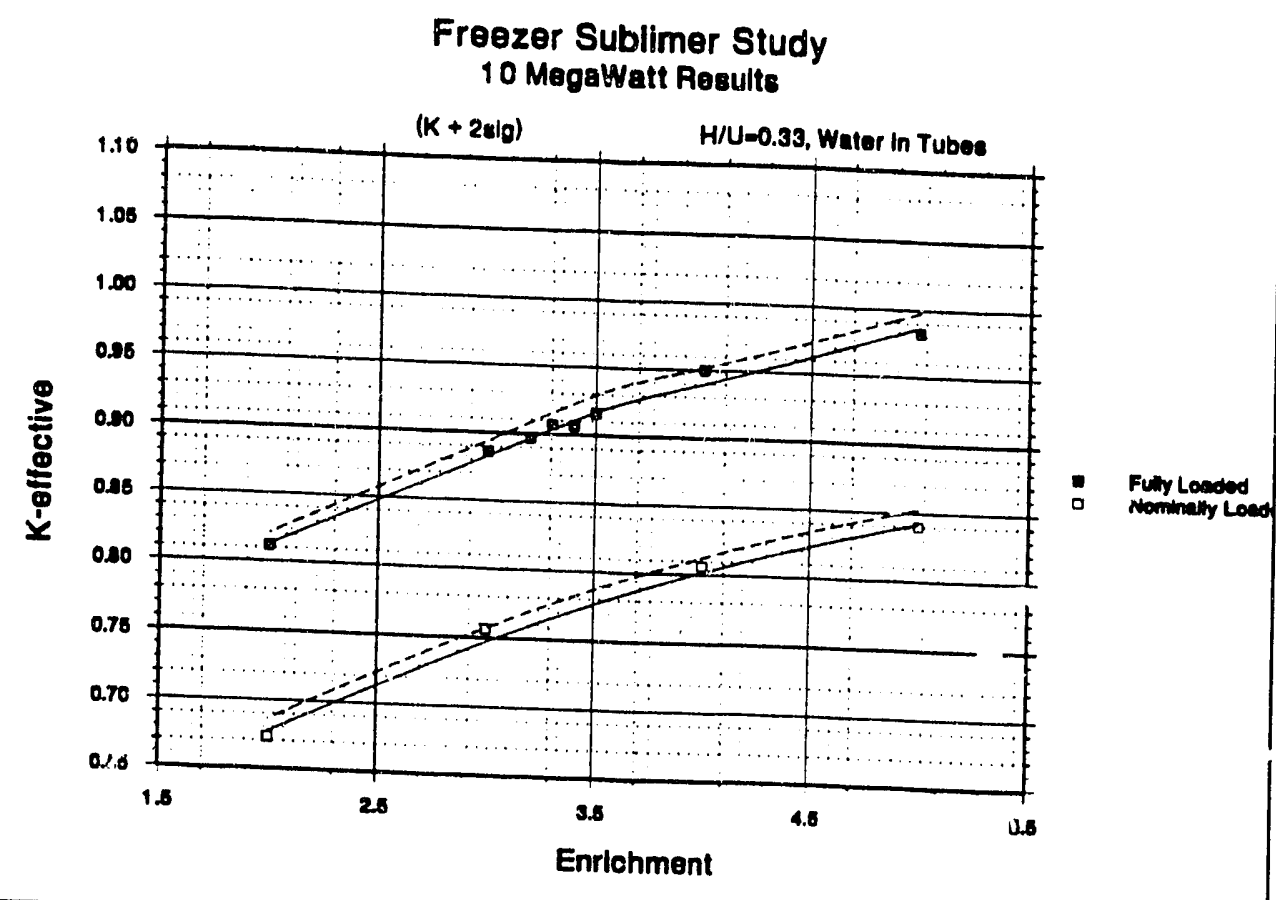

Fig. 11. $k_{\text {eff }}$ vs enrichment for a 10-MW F/S fully loaded and nomiıally loaded.



Fig. 12. $\mathrm{k}_{\mathrm{eff}}$ vs $\mathrm{H} / \mathrm{U}$ for a $2 \mathrm{U}-\mathrm{MW}$ fully loaded $\mathrm{F} / \mathrm{S}$ with water in the tubes. 


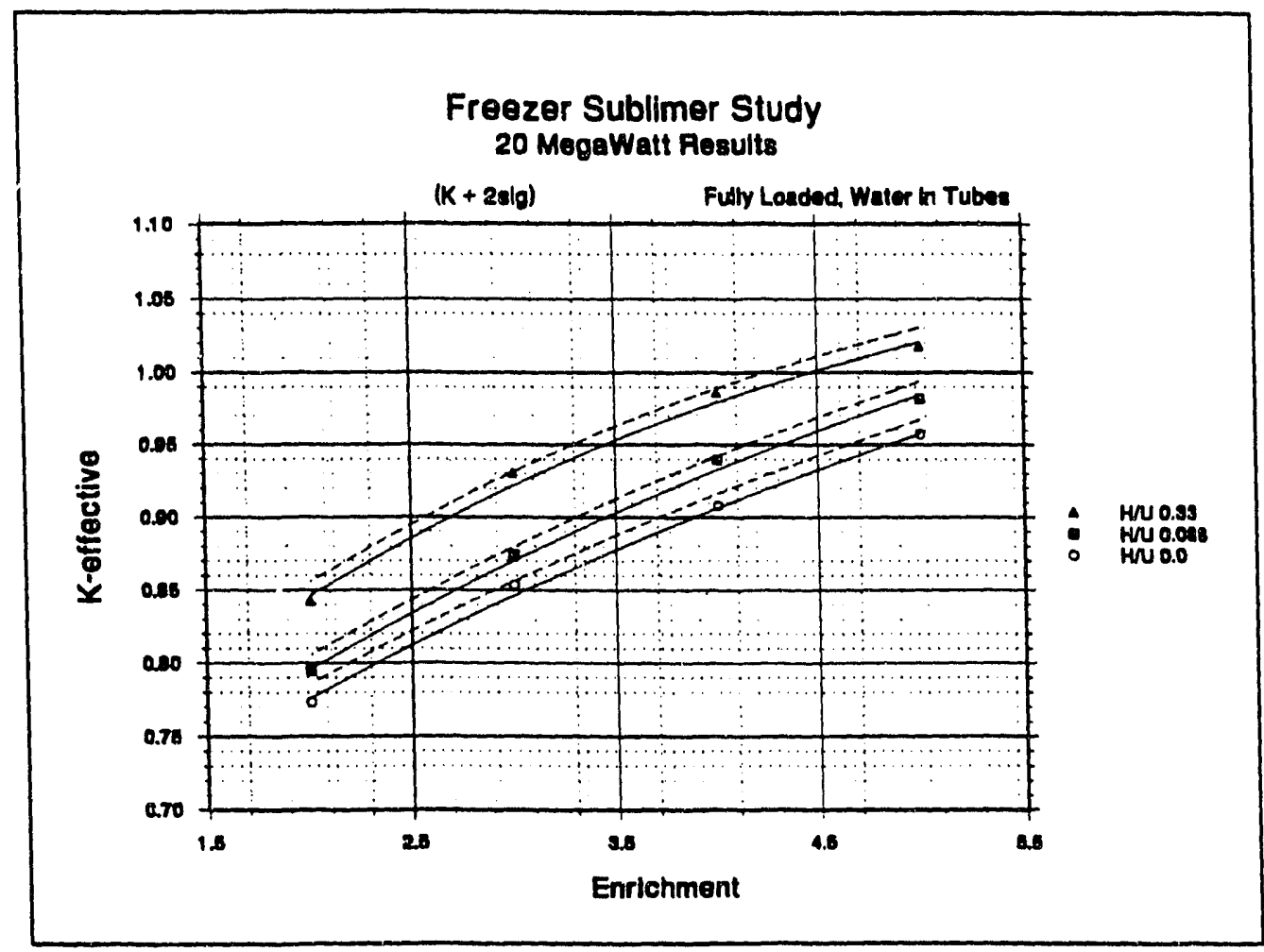

Fig. 13. $\mathrm{k}_{\text {eff }}$ vs enrichment for a $20-\mathrm{MW}$ fully loaded $\mathrm{F} / \mathrm{S}$ with water in the tubes.

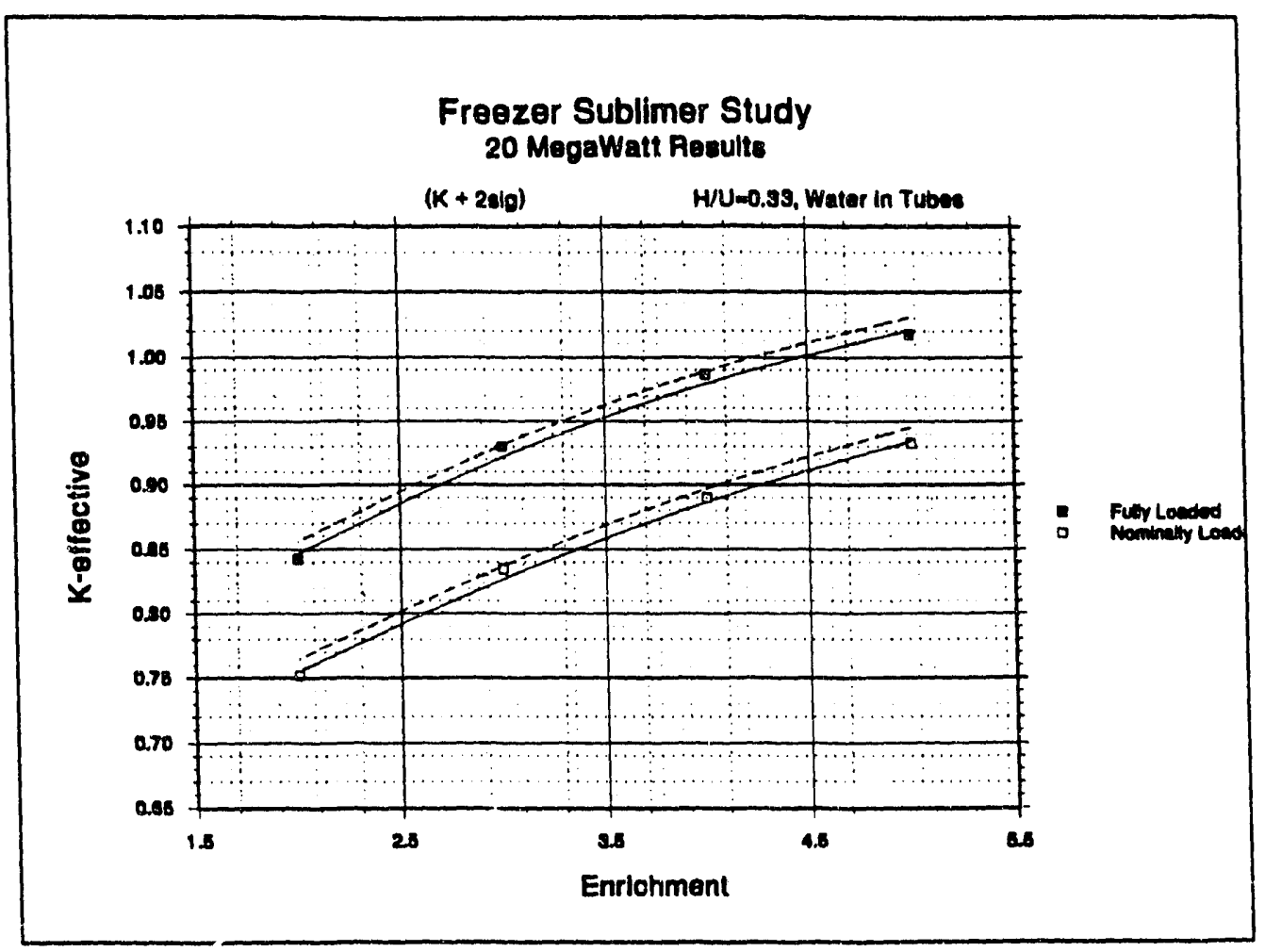

Fig. 14. $k_{\text {eff }}$ vs enrichment for a $20-\mathrm{MW}$ F/S fully loaded and nominally loaded. 


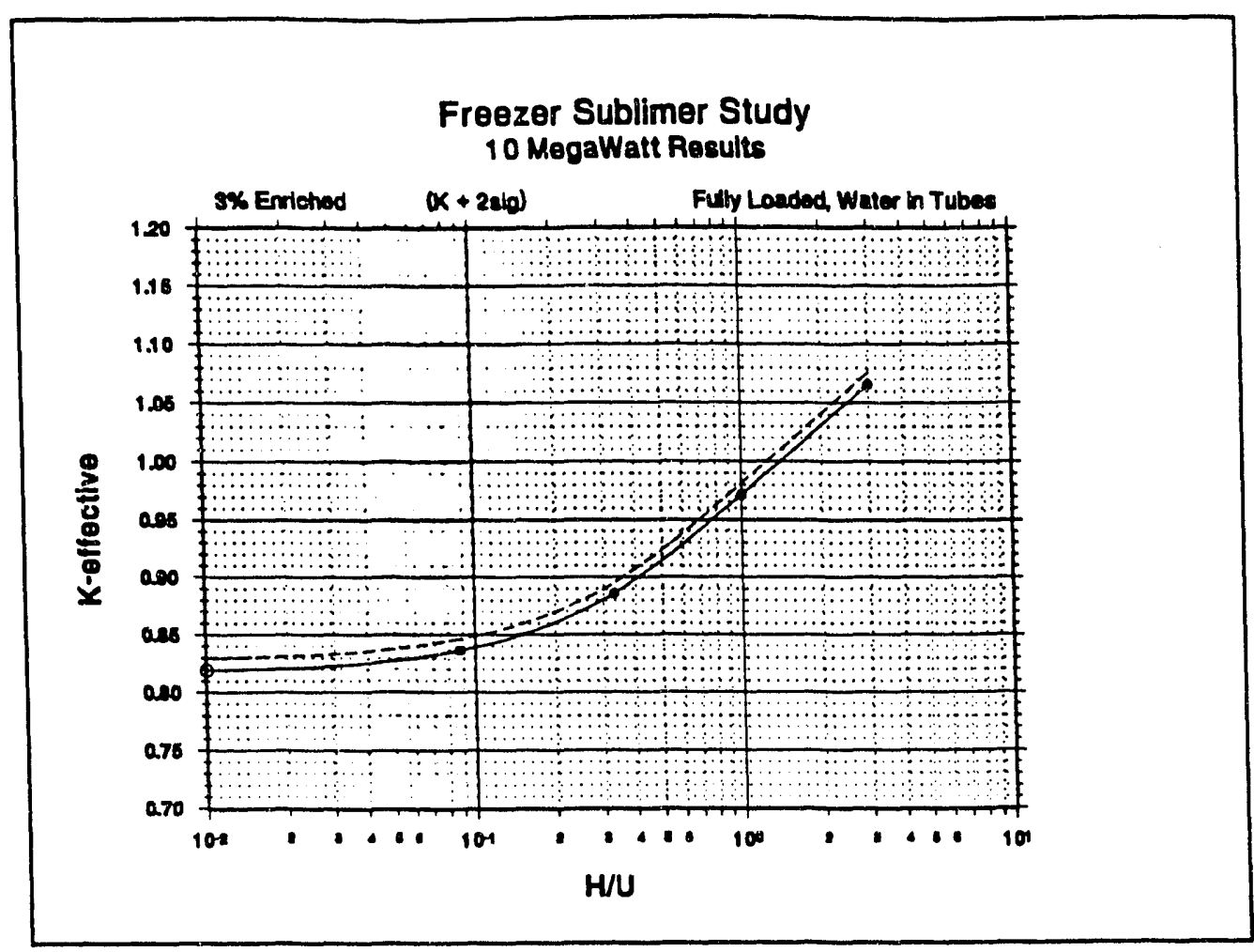

Fig. 15. $\mathrm{k}_{\text {eff }}$ vs $\mathrm{H} / \mathrm{U}$ for a $10-\mathrm{MW} \mathrm{F} / \mathrm{S}-\mathbf{3 . 0 \%}$ enrichment.

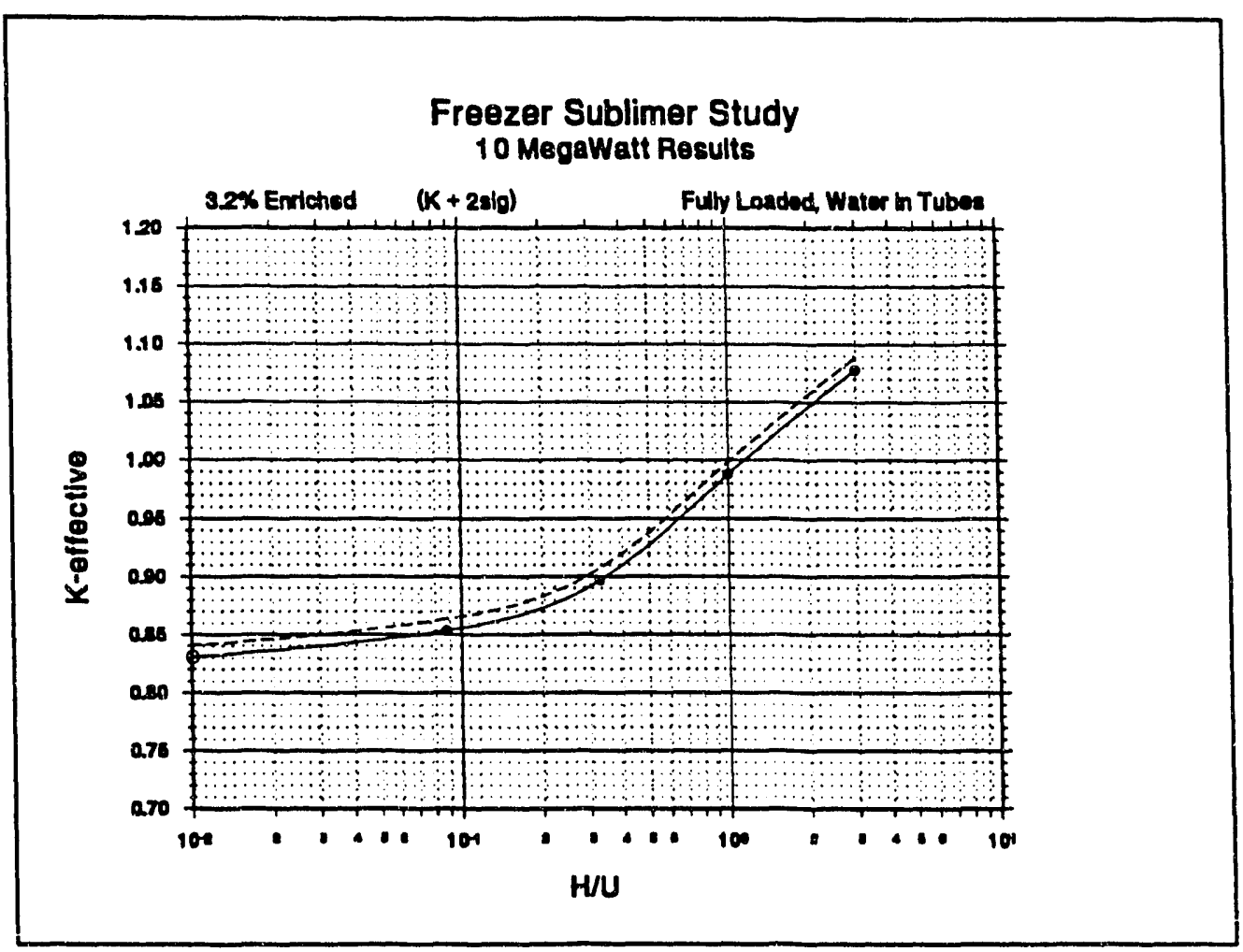

Fig. 16. $k_{\text {eff }}$ vs $\mathrm{H} / \mathrm{U}$ for a $10-\mathrm{MW} \mathrm{F} / \mathrm{S}-3.2 \%$ enrichment. 


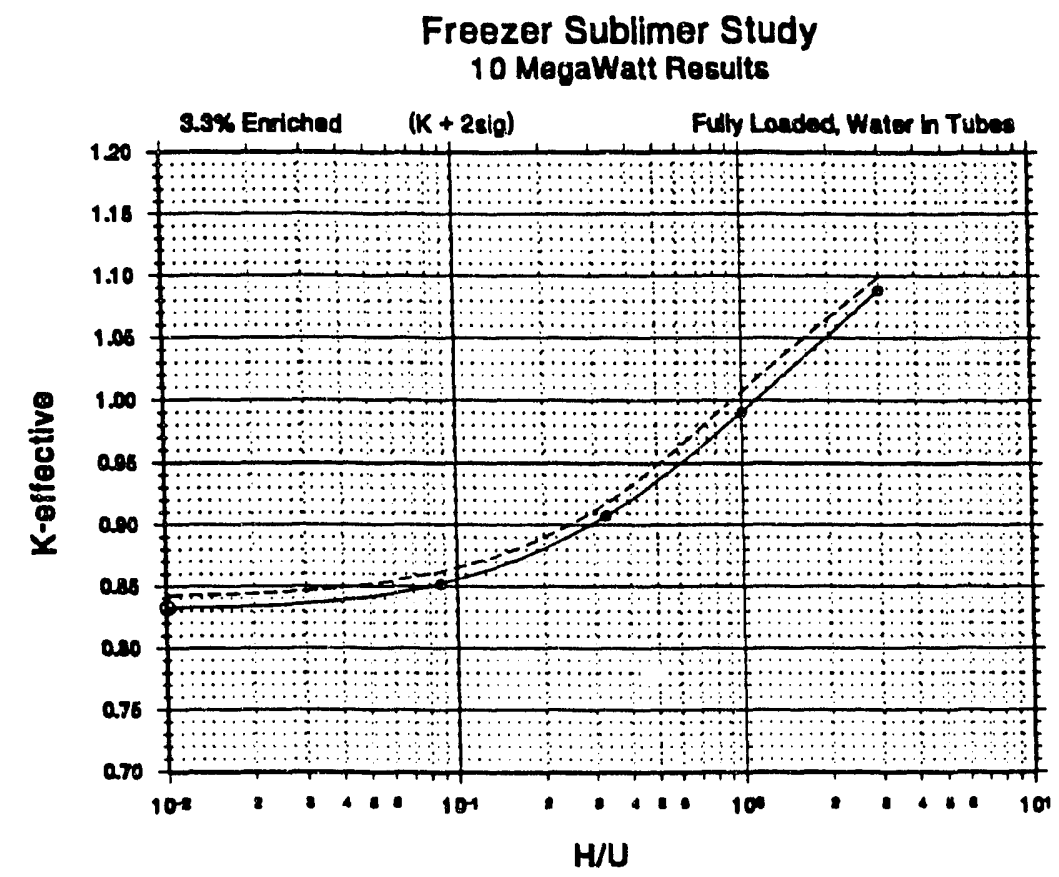

Fig. 17. $\mathrm{k}_{\text {eff }}$ vs $\mathrm{H} / \mathrm{U}$ for a $10-\mathrm{MW} \mathrm{F} / \mathrm{S}-3.3 \%$ enrichment.

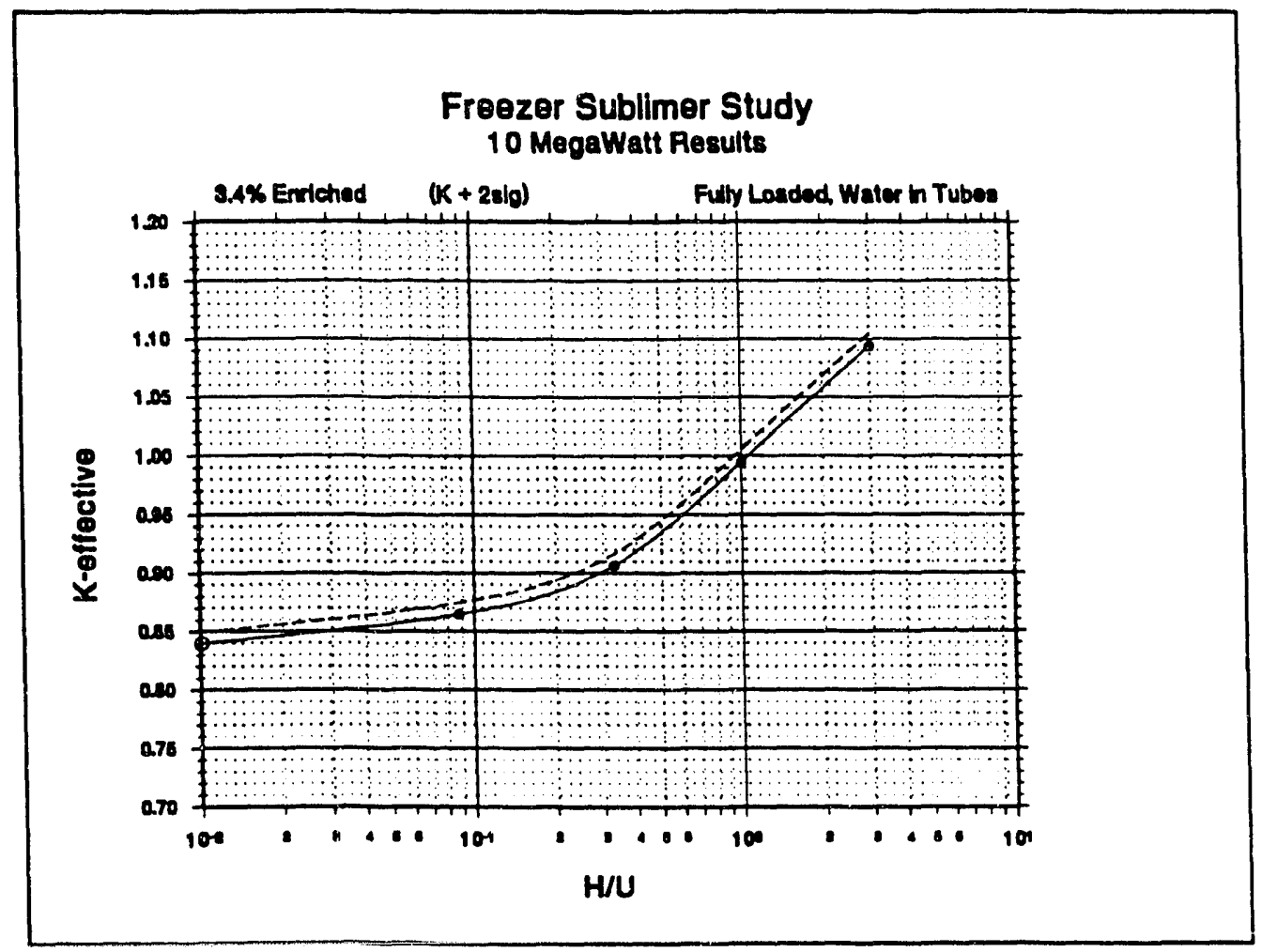

Fig. 18. $\mathrm{k}_{\text {eff }}$ vs $\mathrm{H} / \mathrm{U}$ for a $10-\mathrm{MW} \mathrm{F} / \mathrm{S}-3.4 \%$ enrichment. 


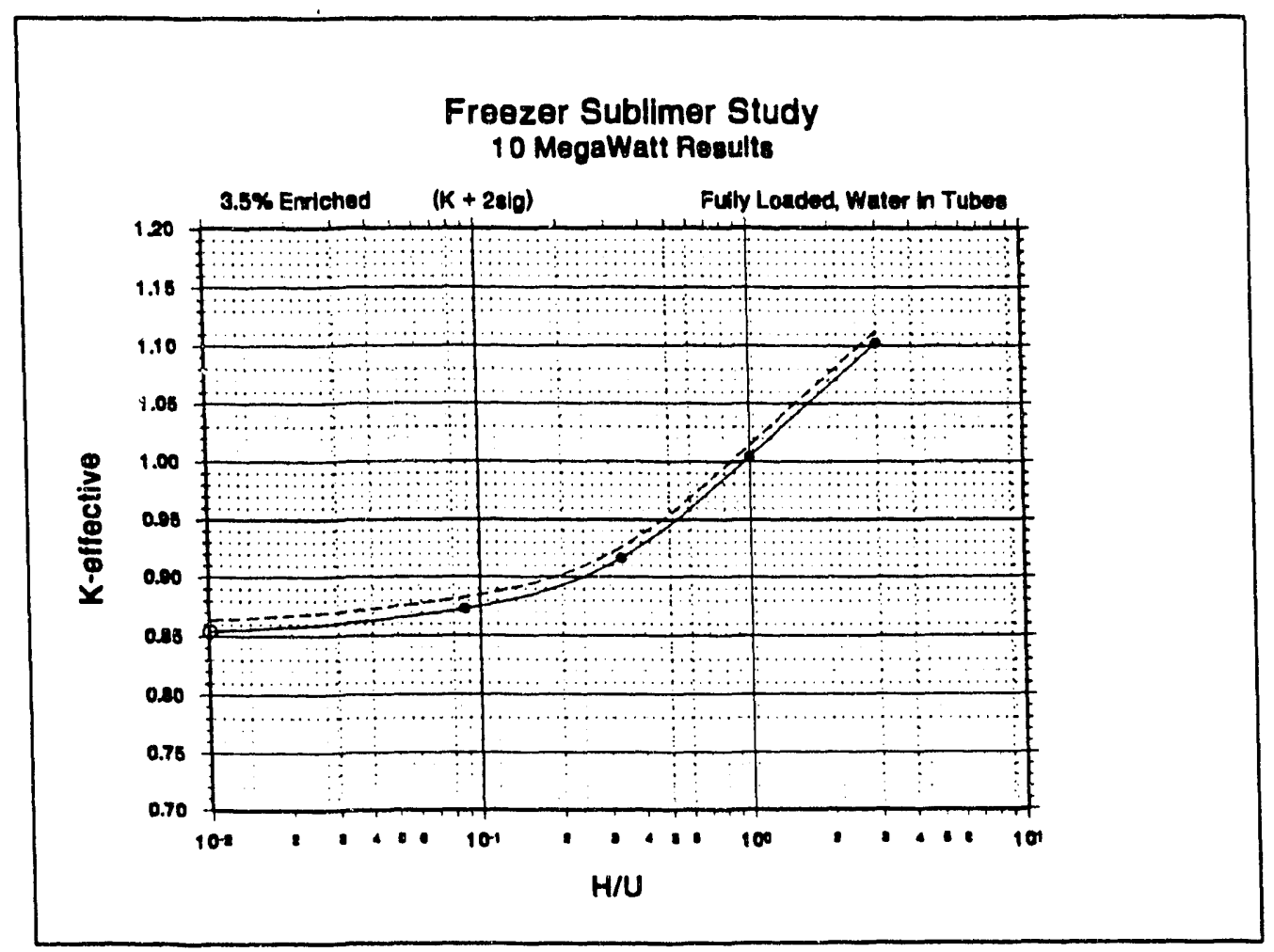

Fig. 19. $\mathrm{k}_{\text {eff }}$ vs $\mathrm{H} / \mathrm{U}$ for a $10-\mathrm{MW}$ F/S $-3.5 \%$ enrichment.

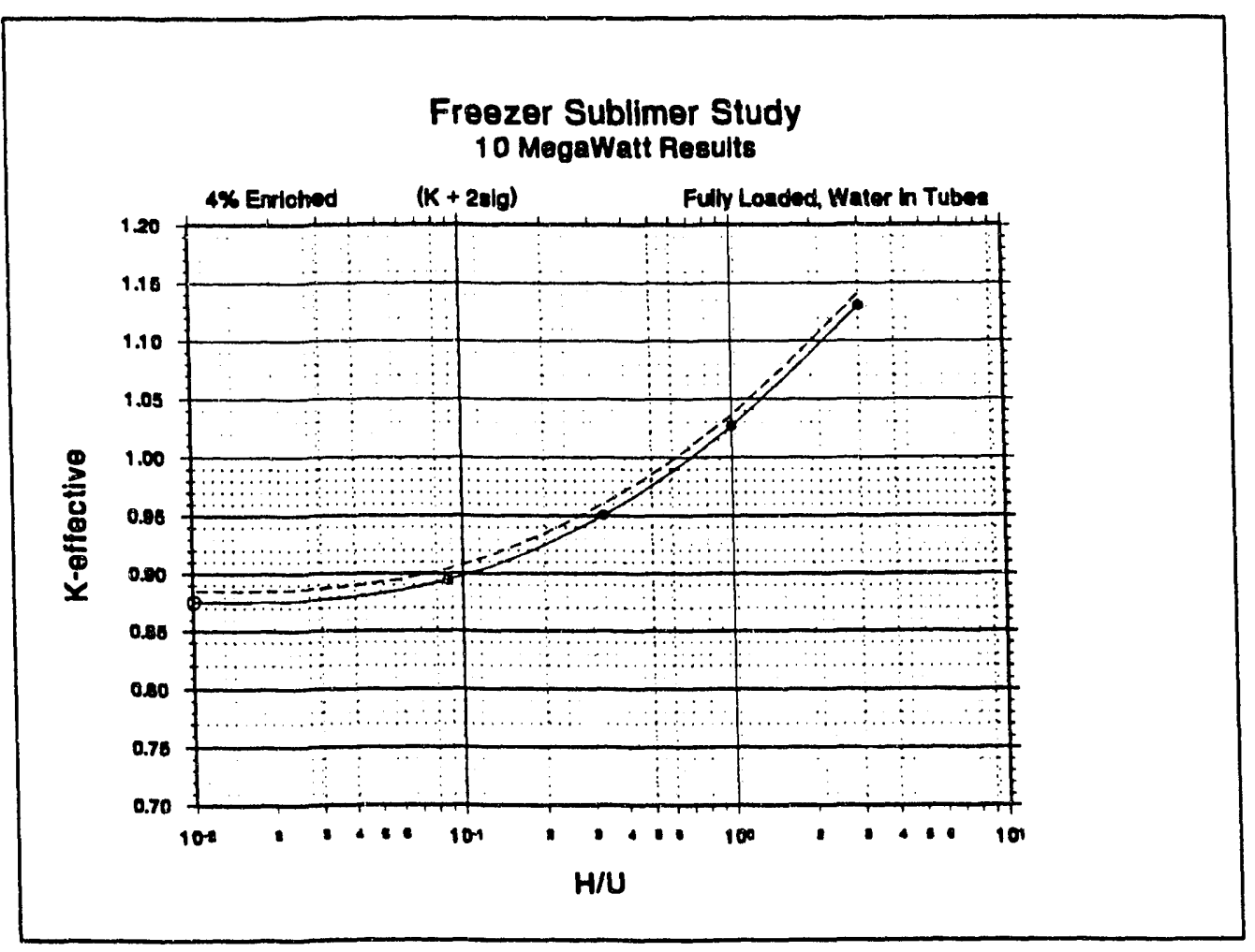

Fig. 20. $\mathrm{k}_{\text {eff }}$ vs $\mathrm{H} / \mathrm{U}$ for a $10-\mathrm{MW} \mathrm{F} / \mathrm{S}-4.0 \%$ enrichment. 


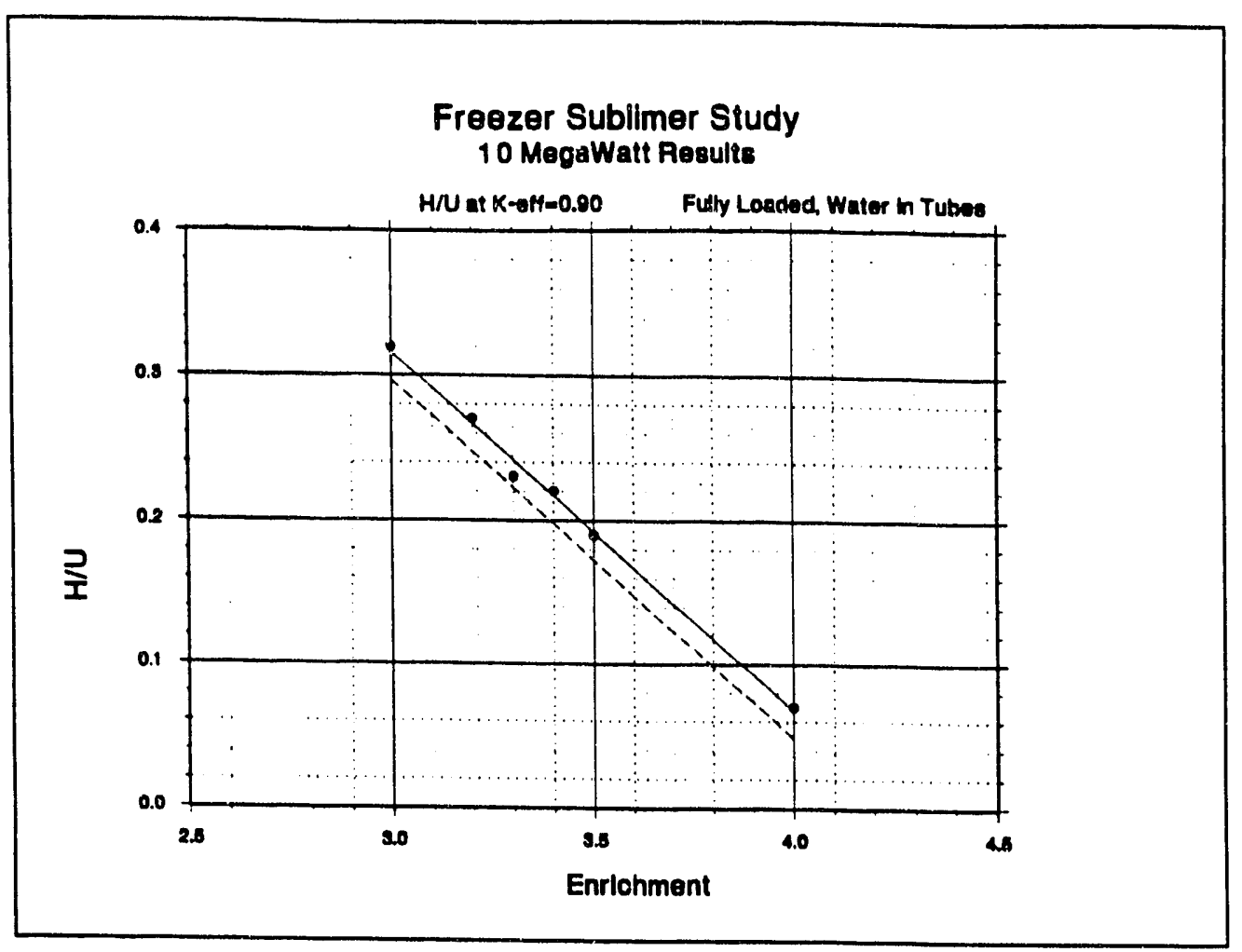

Fig. 21. $\mathrm{H} / \mathrm{U}$ vs enrichment to yield a $\mathrm{k}_{\mathrm{eff}}+2 \sigma=0.90$ (for a $10-\mathrm{MW} \mathrm{F} / \mathrm{S}$ ).

For an $\mathrm{F} / \mathrm{S}$ that is controlled to $\mathrm{H} / \mathrm{U}=0.33$, Figs. 11 and 14 may be used to establish an acceptable enrichment limit for the 10 - and $20-\mathrm{MW} \mathrm{F/S}$, respectively. If these figures are used directly, some allowance should be given for the curve fit of the data.

For a 10-MW F/S controlled to a $\mathrm{H} / \mathrm{U}<0.33$, Fig. 21 may be used to establish the acceptable enrichment limit based on $k_{\text {eff }}+2 \sigma=0.90$ and water in the tubes.

\subsection{CONCLUSIONS}

Several criticality safety considerations for the operating cascade, the compression liquefaction withdrawal system, and the F/S system have been identified. A comparison of the operations has been presented, identifying important differences and similarities. In each system, the purpose of the criticality safety controls are to prevent the occurrence of a moderated mass of uranium in unsafe geometry. In the cascade, uranium density control is the first criticality control, with moderation control as a second control. In the withdrawal system, geometry control is the primary control at the front of the system, with demonstrated moderation control before the $\mathrm{UF}_{6}$ is transferred to unsafe geometry. In the $\mathrm{F} / \mathrm{S}$, moderation control is the only control and must be demonstrated for every mode of operation because $\mathrm{UF}_{6}$ is being moved directly from the cascade (which is under density control) into unsafe geometry. 
A conservative model of the F/S has been developed. Each of the assumptions used to build the model has been identified, and the justification or reasons leading to these assumptions has been given. The model may be used with confidence to establish the safety of the F/S over the range of enrichments up to $5 \%$ and moderation ratios up to $\mathrm{H} / \mathrm{U}=1$.

A set of calculations has been performed for the 10- and 20-MW F/S which covers the range of enrichment and moderation encompassing safe operating conditions. The possibility of water moderation being present in the R-114 tubes has been explicitly addressed in the calculations.

The results demonstrate that the calculations originally performed for the $10-\mathrm{MW} \mathrm{F} / \mathrm{S}$ are conservative and the enrichment limits established at a $\mathrm{H} / \mathrm{U}=0.33$ are acceptable. The enrichment limits for safe operation may be increased slightly under the same acceptance criteria used previously. The results also allow safe enrichment limits to be established for the 10-MW $\mathrm{F} / \mathrm{S}$ at different levels of $\mathrm{H} / \mathrm{U}$ moderation, provided these levels are demonstrated to exist during all modes of operation. The results allow the safe enrichment to be determined for the $20-\mathrm{MW}$ $\mathrm{F} / \mathrm{S}$. 


\section{CODE VALIDATION}

A code validation was performed to support the F/S calculation study. Fifty-nine critical experiments were chosen to demonstrate the functionality and ability of the SCALE-4.0 codes and cross sections to accurately calculate critical experiments. The validation is documented in ORNL/CSD/TM-287..$^{28}$ Presented here is a brief discussion of the results of this validation and its use and applicability for F/S criticality safety calculational analysis. The CSAS25 sequence and the 27-group library of SCALE-4.0 were validated. The majority of the experiments used in the validation were low-enriched uranium systems. These experiments validate low-enriched uranium at several moderation ratios in spherical, cylindrical, and slab geometry. A series of lattice experiments were included to demonstrate the ability of the CSAS25 sequence to calculate these systems. The uranium materials considered were uranium metal, $\mathrm{UO}_{2}, \mathrm{U}_{3} \mathrm{O}_{8}, \mathrm{UF}_{4}$, and $\mathrm{UO}_{2} \mathrm{~F}_{2}$.

Several highly enriched uranium experiments were included in the validation, primarily to demonstrate the ability of the codes to properly process resonance cross sections for lowmoderated or unmoderated systems.

A statistical analysis of the validation results was performed to establish an upper calculational acceptance criteria. The technique described by Dyer et al. ${ }^{29}$ was used to calculate a one-sided, closed-interval, lower tolerance band for the low-enriched experiments as a function of the average energy group of the neutron-causing fission. The results of this analysis are presented graphically in Fig. 22.

Based on the statistical analysis, systems similar to those validated (within the range of validation) may be considered safely subcritical if the calculated $k_{\text {eff }}$ plus the uncertainty in the calculation is less than about 0.945 .

The application of the validation to the F/S must include consideration of the following four important observations:

1. The F/S geometry is highly unusual in its heterogeneous characteristics. The moderator is inside the tube with near-dry fissile material on the outside. The tubes have a significant negative reactivity effect because of neutron absorption. The calculational analysis is sensitive to the assumption used to describe this unusual lattice.

2. The systems considered in the F/S analysis are highly undermoderated. Even with this low level of moderation, some of the systems analyzed have unacceptably high reactivity. The calculations are especially sensitive to the scattering cross sections and the ${ }^{238} \mathrm{U}$ absorption cross sections. There are no critical experiments using water or HFmoderated, low-enriched $\mathrm{UF}_{6}$ systems, so the code and cross-section performance cannot be evaluated for these systems. Few experiments of any sort have moderation levels in the region of interest in the F/S analysis.

3. The calculational analysis of the F/S is sensitive to the distribution of the material in the vessel.

4. At nominal loading conditions, with water in the tubes, the uranium in the F/S is significantly undermoderated. As $\mathrm{UF}_{6}$ is removed from around the tubes, the infinite media multiplication of the $\mathrm{F} / \mathrm{S}$ tube lattice increases because the uranium becomes more optimumly moderated. The F/S reactivity decreases, however, due to an increase in leakage. Because of this tradeoff in increased leakage versus increased reactivity, the analysis of the $F / S$ is sensitive to the assumed distribution of the $U_{6}$ in the vessel. $A$ 


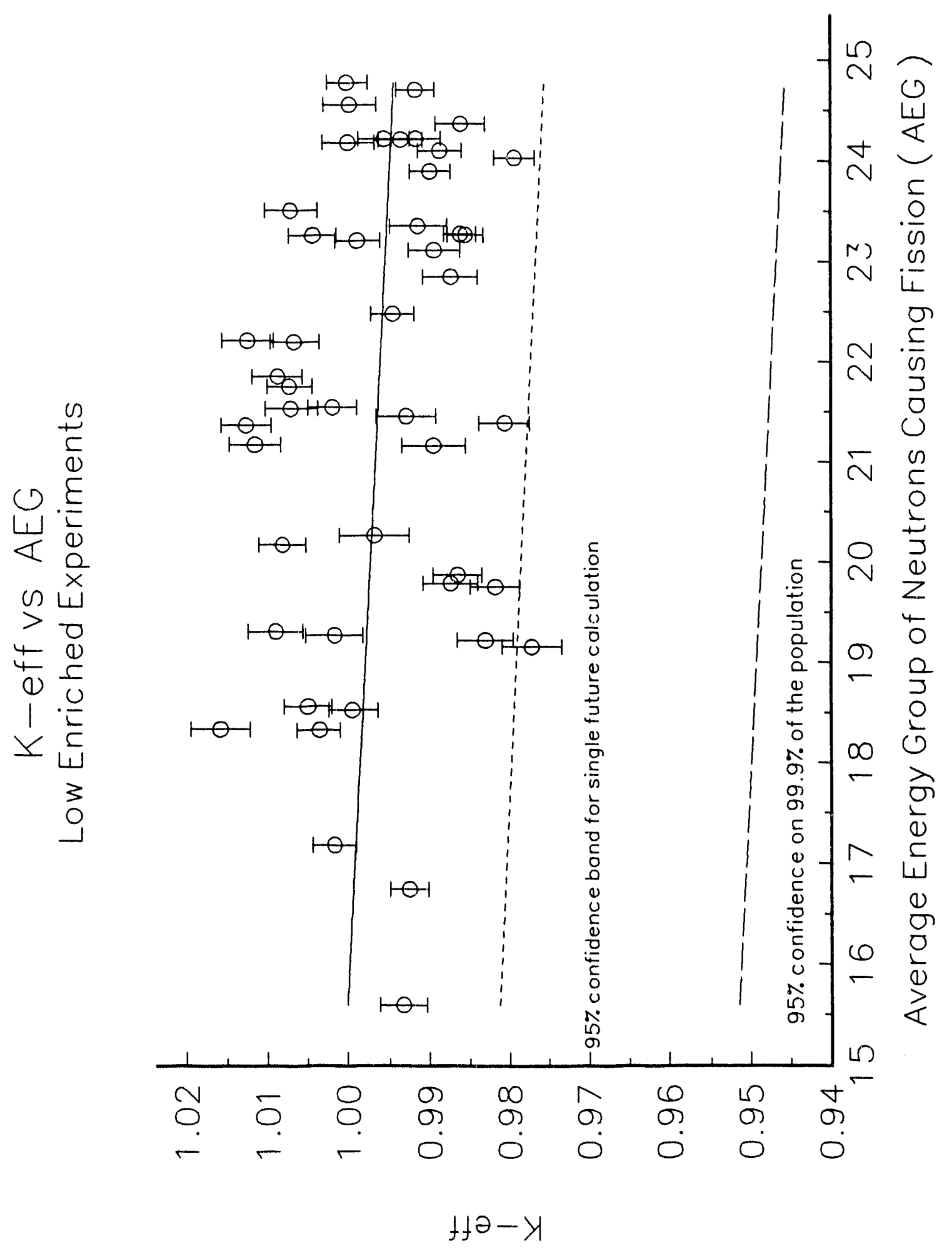

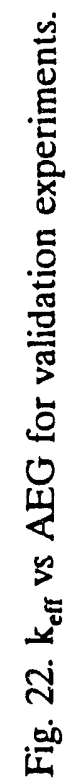


vessel with significantly less than nominal inventory with a nonuniform distribution of material in the vessel can approach the $k_{\text {eff }}$ calculated for a fully loaded vessel. No attempt has been made in the current analysis to determine optimum loading conditions and the maximum $k_{\text {eff }}$

In the establishment of an acceptance criteria, one must consider not only the results of the validation but also the system to which the validation is being applied. Because there are several assumptions and limitations in the $\mathrm{F} / \mathrm{S}$ criticality analysis and the validation, there should be some additional conservatism factored into the acceptance criteria. This level of additional conservatism is quite arbitrary. The value originally established by Taylor of $k+2 \sigma$ less than 0.90 seems reasonable and has been adopted here. 


\section{REFERENCES}

1. R. G. Taylor, Criticality Safety Analysis of a Uranium Hexafluoride Freezer/Sublimer, K/DD-1003, Union Carbide Corp., Nucl. Div., Oak Ridge Gaseous Diffusion Plant (May 1978).

2. R. G. Taylor, Criticality Safety Survey Computations of Uranium Hexafluoride Freezer/Sublimer Tube Lattices, K/DD-1003, Union Carbide Corp., Nucl. Div., Oak Ridge Gaseous Diffusion Plant (July 1977).

3. Final Safety Analysis Report for the Paducah Gaseous Diffusion Plant, KY-734, Union Carbide Corp., Nucl. Div., Paducah Gaseous Diffusion Plant (March 29, 1985).

4. H. F. Henry et al., Criticality Data and Nuclear Safety Guide Applicable to the Oak Ridge Gaseous Diffusion Plant, K-1019, Rev. 5, Union Carbide Corp., Nucl. Div., Oak Ridge Gaseous Diffusion Plant (May 22, 1959).

5. J. L. Feuerbacher, Nuclear Criticality Safety Guide for the Portsmouth Gaseous Diffusion Plant, GAT-225, Rev. 4, Portsmouth Gaseous Diffusion Plant (March 15, 1981).

6. Nuclear Criticality Safety in Operations with Fissionable Materials Outside Reactors, ANSI/ANS-8.1, American Nuclear Society, 1983.

7. Uranium Hexafluoride: A Manual of Good Handling Practices, ORO-651, Rev. 6 (October 1991).

8. SCALE: A Modular Code System for Performing Standardized Computer Analyses for Licensing Evaluation, NUREG/CR-0200, Rev. 4 (ORNL/NUREG/CSD-2/R4), Vols. I, II, and III (draft February 1990). Available from Radiation Shielding Information Center as CCC-545.

9. N. F. Landers and L. M. Petrie, "CSAS4: An Enhanced Criticality Safety Analysis Module with an Optimum Pitch Search Option," Sect. C4 of SCALE: A Modular Code System for Performing Standardized Computer Analyses for Licensing Evaluation, NUREG/CR-0200, Rev. 4 (ORNL/NUREG/CSD-2/R4), Vols. I, II, and III (draft February 1990). Available from Radiation Shielding Information Center as CCC-545.

10. N. M. Greene, "BONAMI-S: Resonance Self-Shielding by the Bondarenko Method," Sect. F1 of SCALE: A Modular Code System for Performing Standardized Computer Analyses for Licensing Evaluation, NUREG/CR-0200, Rev. 4 (ORNL/NUREG/CSD2/R4), Vols. I, II, and III (draft February 1990). Available from Radiation Shielding Information Center as CCC-545. 
11. N. M. Greene, L. M. Petrie and R. M. Westfall, "NITAWL-II: SCALE System Module for Performing Resonance Shielding and Working Library Production," Sect. F2 of SCALE: A Modular Code System for Performing Standardized Computer Analyses for Licensing Evaluation, NUREG/CR-0200, Rev. 4 (ORNL/NUREG/CSD-2/R4), Vols. I, II, and III (draft February 1990). Available from Radiation Shielding Information Center as CCC-545.

12. L. M. Petrie and N. F. Landers, "KENO V.a: An Improved Monte Carlo Criticality Program with Supergrouping," Sect. F11 of SCALE: A Modular Code System for Performing Standardized Computer Analyses for Licensing Evaluation, NUREG/CR-0200, Rev. 4 (ORNL/NUREG/CSD-2/R4), Vols. I, II, and III (draft February 1990). Available from Radiation Shielding Information Center as CCC-545.

13. N. M. Greene and L. M. Petrie, "XSDRNPM-S: A One-Dimensional Discrete-Ordinates Code for Transport Analysis," Sect. F3 of SCALE: A Modular Code System for Performing Standardized Computer Analyses for Licensing Evaluation, NUREG/CR-0200, Rev. 4 (ORNL/NUREG/CSD-2/R4), Vols. I, II, and III (draft February 1990). Available from Radiation Shielding Information Center as CCC-545.

14. J. A. Bucholz et al., "Standard Composition Library," Sect. M8 of SCALE: A Modular Code System for Performing Standardized Computer Analyses for Licensing Evaluation, NUREG/CR-0200, Rev. 4 (ORNL/NUREG/CSD-2/R4), Vols. I, II, and III (draft February 1990). Available from Radiation Shielding Information Center as CCC-545.

15. N. F. Landers, L. M. Petrie, and J. A. Bucholz, "The Material Information Processor for SCALE," Sect. M7 of SCALE: A Modular Code System for Performing Standardized Computer Analyses for Licensing Evaluation, NUREG/CR-0200, Rev. 4 (ORNL/NUREG/CSD-2/R4), Vols. I, II, and III (draft February 1990). Available from Radiation Shielding Information Center as CCC-545.

16. W. C. Jordan, "SCALE Cross-Section Libraries," Sect. M4 of SCALE: A Modular Code System for Performing Standardized Computer Analyses for Licensing Evaluation, NUREG/CR-0200, Rev. 4 (ORNL/NUREG/CSD-2/R4), Vols. I, II, and III (draft February 1990). Available from Radiation Shielding Information Center as CCC-545.

17. MMES Drawing, MSE17202 R Rev. D, Freezer/Sublimer $10 \mathrm{MW}$.

18. MMES Drawing, MSE17202 T Rev. C, Head - 10 MW Upper and Lower.

19. MMES Drawing, MSE17202 V Rev. A, Tube Sheet 10 MW Upper and Lower.

20. MMES Drawing, MSE17202 B Rev. C, Freezer/Sublimer 20 MW.

21. MMES Drawing, MSE17202 E Rev. D, Head - 20 MW Upper and Lower.

22. MMES Drawing, MSE17202 G Rev. A, Tube Sheet, 20 MW Upper and Lower. 
23. Wolverine Tube, Inc., Specifications for Wolverine Trufin Type L/C Integral Finned Tube.

24. MMES Drawing, MSE17202 H Rev. A, Tube, $10 \mathrm{MW}$ and $20 \mathrm{MW}$ Finned.

25. 1986 ASME Boiler and Pressure Vessel Code, Sect. II, Part B, Specification SB-359, C71500.

26. 1986 ASME Boiler and Pressure Vessel Code, Sect. II, Part A, Specification SA516 GR55.

27. G. W. Hoffman, Prototype Testing of 20-MW Freezer-Sublimer, KYL-1462, Martin Marietta Energy Systems, Inc., Paducah Gaseous Diffusion Plant (December 1987).

28. W. C. Jordan, Validation of CSAS25 and the 27-Group Library in SCALE 4.0 for LowEnriched Uranium, ORNL/CSD/TM-287, Martin Marietta Energy Systems, Inc., Oak Ridge Natl. Lab. (to be published).

29. H. R. Dyer et al., A Technique for Code Validation for Criticality Calculations," TANSAO 63-1-464, p. 238, 1991. 


\section{APPENDIX A}

\section{$\mathrm{UF}_{6}$-HF DENSITIES}

The $\mathrm{UF}_{6}-\mathrm{HF}$ densities used in the evaluation of the $\mathrm{F} / \mathrm{S}$ are based on a theoretical volume additive formulation. The theoretical densities for solid $\mathrm{UF}_{6}$ and liquid HF were calculated from Eqs. (A.1) and (A.2) for a temperature of $15^{\circ} \mathrm{C}$. The volume additive formulation for uranium density as a function of $\mathrm{H} / \mathrm{U}$ moderation ratio is given in Eq. (A.3). The data sheets used to generate the input for the F/S analysis are included in Tables $A 1$ through A8.

$$
\begin{gathered}
\rho_{U F_{6}}=5.194-0.005168 * t \\
\rho_{H F}=1.0020-0.0022625 * t+3.125-6 * t^{2} \\
\rho_{U}=\frac{\text { molecular weight of uranium }}{68.80091+H / U * 20.65102}
\end{gathered}
$$

\begin{tabular}{|c|c|c|c|}
\hline \multicolumn{4}{|c|}{ Density of components in a theoretical mixture } \\
\hline $\mathrm{H} / \mathrm{U}$ & Uranium & $\mathrm{UF}_{6}$ & HF \\
\hline 0.00000 & 3.45779 & 5.11458 & 0.00000 \\
\hline 0.08800 & 3.36880 & 4.98297 & 0.02493 \\
\hline 0.33000 & 3.14615 & 4.65363 & 0.08731 \\
\hline 1.00000 & 2.65952 & 3.9338 & 0.2236 \\
\hline 3.00000 & 1.81944 & 2.6912 & 0.4590 \\
\hline 5.00000 & 1.38268 & 2.0451 & 0.5813 \\
\hline 7.00000 & 1.11502 & 1.6492 & 0.6563 \\
\hline 10.00000 & 0.86411 & 1.2781 & 0.7266 \\
\hline 15.00000 & 0.62842 & 0.92953 & 0.79270 \\
\hline 20.00000 & 0.49375 & 0.73033 & 0.83043 \\
\hline 30.00000 & 0.34562 & 0.51122 & 0.87193 \\
\hline
\end{tabular}

Table A.1. UF - -HF Density - 5.0\% Enrichment 
Table A.2. $\mathrm{UF}_{6}-\mathrm{HF}$ Density - 4.0\% Enrichment

\begin{tabular}{|c|c|c|c|}
\hline \multicolumn{4}{|c|}{ Density of components in $:$ theoretical mixture } \\
\hline $\mathrm{H} / \mathrm{U}$ & Uranium & $\mathrm{UF}_{6}$ & $\mathrm{HF}$ \\
\hline 0.00000 & 3.45823 & 5.11503 & 0.00000 \\
\hline 0.08800 & 3.36923 & 4.98340 & 0.02493 \\
\hline 0.33000 & 3.14656 & 4.65404 & 0.08731 \\
\hline 1.00000 & 2.65986 & 3.93416 & 0.22365 \\
\hline 3.00000 & 1.81967 & 2.69145 & 0.45901 \\
\hline 5.00000 & 1.38286 & 2.04537 & 0.58138 \\
\hline 7.C0000 & 1.11516 & 1.64943 & 0.65637 \\
\hline 10.00000 & 0.86422 & 1.27826 & 0.72667 \\
\hline 15.00000 & 0.62850 & 0.92961 & 0.79270 \\
\hline 20.00000 & 0.49381 & 0.73039 & 0.83043 \\
\hline $30.0002 n$ & 0.34566 & 0.51126 & 0.87193 \\
\hline
\end{tabular}

Table A.3. $\mathrm{UF}_{6}$-HF Density - 3.5\% Enrichment

${ }^{235} \mathrm{U}$ enrichment $=\mathbf{3 . 5 0 0}$

Molecular weight of uranium $=237.94450$

Temperature of mixture $=15.00^{\circ} \mathrm{C}$

Density of components in a theoretical mixture

\begin{tabular}{llll}
\hline $\mathrm{H} / \mathrm{U}$ & Uranium & $\mathrm{UF}_{6}$ & $\mathrm{HF}$ \\
\hline 0.00000 & 3.45845 & 5.11525 & 0.00000 \\
0.08800 & 3.36945 & 4.98361 & 0.02493 \\
0.33000 & 3.14676 & 4.65424 & 0.08731 \\
1.00000 & 2.66003 & 3.93433 & 0.22365 \\
3.00000 & 1.81979 & 2.69157 & 0.45901 \\
5.00000 & 1.38295 & 2.04546 & 0.58138 \\
7.00000 & 1.11524 & 1.61950 & 0.65637 \\
10.00000 & 0.86427 & 1.27831 & 0.72667 \\
15.00000 & 0.62854 & 0.92965 & 0.79270 \\
20.00000 & 0.49384 & 0.73042 & 0.83043 \\
$30.0000 \mathrm{~V}$ & 0.34568 & 0.51129 & 0.87193 \\
\hline
\end{tabular}


Table A.4. $\mathrm{UF}_{6}-\mathrm{HF}$ Density - $3.4 \%$ Enrichment

${ }^{235} \mathrm{U}$ enrichment $=3.400$

Molecular weight of uranium $=237.94750$

Temperature of mixture $=15.00^{\circ} \mathrm{C}$

Density of components in a theoretical mixture

\begin{tabular}{rccc}
\hline $\mathrm{H} / \mathrm{U}$ & Uranium & $\mathrm{UF}_{6}$ & $\mathrm{HF}$ \\
\hline 0.00000 & 3.45849 & 5.11529 & 0.00000 \\
0.08800 & 3.36949 & 4.98365 & 0.02493 \\
0.33000 & 3.14680 & 4.65428 & 0.08731 \\
1.00000 & 2.66006 & 3.93437 & 0.22365 \\
3.00000 & 1.81981 & 2.69159 & 0.45901 \\
5.00000 & 1.38297 & 2.04548 & 0.58138 \\
7.00000 & 1.11525 & 1.64951 & 0.65637 \\
10.00000 & 0.86429 & 1.27832 & 0.72667 \\
15.00000 & 0.62855 & 0.92966 & 0.79270 \\
20.00000 & 0.49385 & 0.73043 & 0.83043 \\
30.00000 & 0.34569 & 0.51129 & 0.87193 \\
\hline
\end{tabular}

Table A.5. UF $_{6}-$ HF Density - 3.3\% Enrichment

${ }^{235} \mathrm{U}$ enrichment $=3.300$

Molecular weight of uranium $=237.95050$

Temperature of mixture $=15.00^{\circ} \mathrm{C}$

Density of components in a theoretical mixture

\begin{tabular}{lccc}
\hline $\mathrm{H} / \mathrm{U}$ & Uranium & $\mathrm{UF}_{6}$ & $\mathrm{HF}$ \\
\hline 0.00000 & 3.45854 & 5.11534 & 0.00000 \\
0.08800 & 3.36954 & 4.98370 & 0.02493 \\
0.33000 & 3.14684 & 4.65432 & 0.08731 \\
1.00000 & 2.66009 & 3.93440 & 0.22365 \\
3.00000 & 1.81983 & 2.69162 & 0.45901 \\
5.00000 & 1.38298 & 2.04550 & 0.58138 \\
7.00000 & 1.11526 & 1.64953 & 0.65637 \\
10.00000 & 0.86430 & 1.27833 & 0.72667 \\
15.00000 & 0.62856 & 0.92966 & 0.79270 \\
20.00000 & 0.49386 & 0.73044 & 0.83043 \\
30.00000 & 0.34569 & 0.51129 & 0.87193 \\
\hline
\end{tabular}


Table A.6. $\mathrm{UF}_{6}$-HF Density - 3.2\% Enrichment

\begin{tabular}{|c|c|c|c|}
\hline \multicolumn{4}{|c|}{ Density of components in a theoretical mixture } \\
\hline $\mathrm{H} / \mathrm{U}$ & Uranium & $\mathrm{UF}_{6}$ & HF \\
\hline 0.00000 & 3.45858 & 5.11538 & 0.00000 \\
\hline 0.08800 & 3.36958 & 4.98374 & 0.02493 \\
\hline 0.33000 & 3.14688 & 4.65436 & 0.08731 \\
\hline 1.00000 & 2.66013 & 3.93443 & 0.22365 \\
\hline 3.00000 & 1.81986 & 2.69164 & 0.45901 \\
\hline 5.00000 & 1.38300 & 2.04551 & 0.58138 \\
\hline 7.00000 & 1.11528 & 1.64954 & 0.65637 \\
\hline 10.00000 & 0.86431 & 1.27835 & 0.72667 \\
\hline 15.00000 & 0.62857 & 0.92967 & 0.79270 \\
\hline 20.00000 & 0.49386 & 0.73044 & 0.83043 \\
\hline 30.00000 & 0.34570 & 0.51130 & 0.87193 \\
\hline
\end{tabular}

Table A.7. $\mathrm{UF}_{6}$-HF Density - 3.0\% Enrichment

${ }^{235} \mathrm{U}$ enrichment $=3.000$

Molecular weight of uranium $=237.95970$

Temperature of mixture $=15.00^{\circ} \mathrm{C}$

Density of components in a theoretical mixture

\begin{tabular}{lccc}
\hline $\mathrm{H} / \mathrm{U}$ & Uranium & $\mathrm{UF}_{6}$ & $\mathrm{HF}$ \\
\hline 0.00000 & 3.45867 & 5.11547 & 0.00000 \\
0.08800 & 3.36966 & 4.98383 & 0.02493 \\
0.33000 & 3.14696 & 4.65444 & 0.08731 \\
1.00000 & 2.66020 & 3.93450 & 0.22365 \\
3.00000 & 1.81990 & 2.69169 & 0.45901 \\
5.00000 & 1.38304 & 2.04555 & 0.58138 \\
7.00000 & 1.11531 & 1.64957 & 0.65637 \\
10.00000 & 0.86433 & 1.27837 & 0.72667 \\
15.00000 & 0.62858 & 0.92969 & 0.79270 \\
20.00000 & 0.49388 & 0.73046 & 0.83043 \\
30.00000 & 0.34571 & 0.51131 & 0.87193 \\
\hline
\end{tabular}


Table A.8. $\mathrm{UF}_{6}-\mathrm{HF}$ Density - $2.0 \%$ Enrichment

${ }^{235} \mathrm{U}$ enrichment $=2.000$

Molecular weight of uranium $=237.99010$

Temperature of mmixture $=15.00^{\circ} \mathrm{C}$

Density of components in a theoretical mixture

\begin{tabular}{lccc}
\hline $\mathrm{H} / \mathrm{U}$ & Uranium & $\mathrm{UF}_{6}$ & $\mathrm{HF}$ \\
\hline 0.00000 & 3.45911 & 5.11591 & 0.00000 \\
0.08800 & 3.37010 & 4.98426 & 0.02493 \\
0.33000 & 3.14736 & 4.65484 & 0.08731 \\
1.00000 & 2.66054 & 3.93484 & 0.22365 \\
3.00000 & 1.82014 & 2.69192 & 0.45901 \\
5.00000 & 1.38321 & 2.04573 & 0.58138 \\
7.00000 & 1.11545 & 1.64971 & 0.65637 \\
10.00000 & 0.86444 & 1.27848 & 0.72667 \\
15.00000 & 0.62866 & 0.92977 & 0.79270 \\
20.00000 & 0.49394 & 0.73052 & 0.83043 \\
30.00000 & 0.34575 & 0.51135 & 0.87193 \\
\hline
\end{tabular}




\section{APPENDIX B}

\section{F/S INPUT EXAMPLES}

Sample input for the F/S calculations are included in this appendix. The input for the first calculation presented in Tables 13 and 14 is given. The modifications required for the other calculations performed involve changes in the uranium enrichment and component densities in the fissile mixtures and the titles of the cases. 
$10 \mathrm{MH} \mathrm{F} / \mathrm{S}$ Calculational Input for $5 \%$ Enrichment, $H / U=0$.






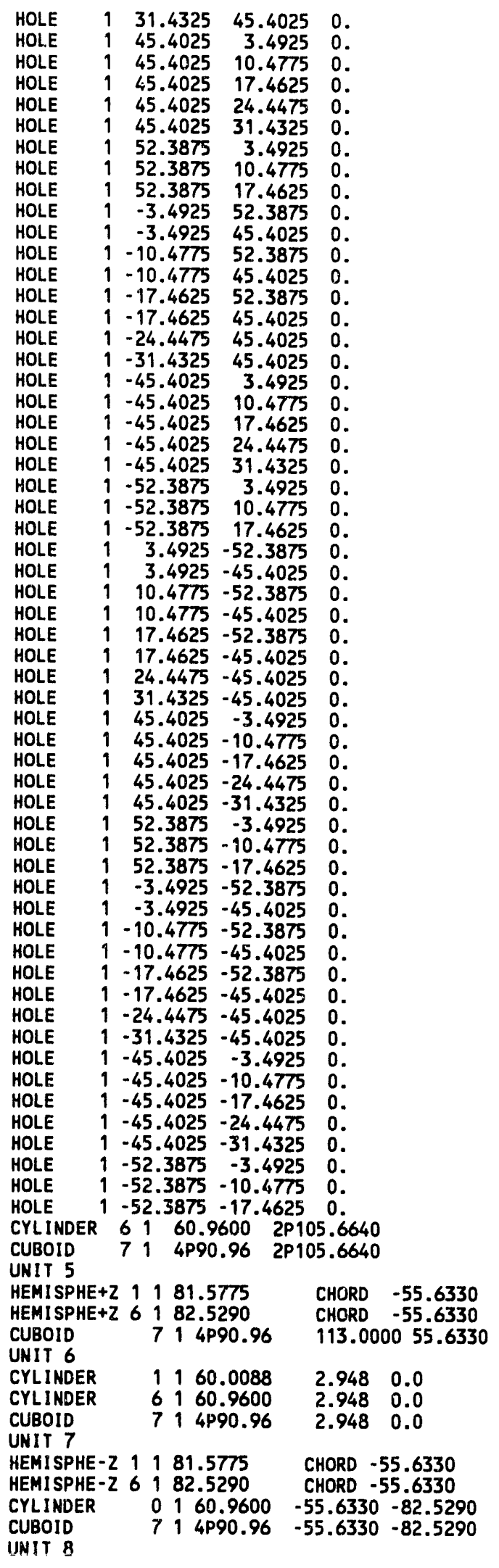




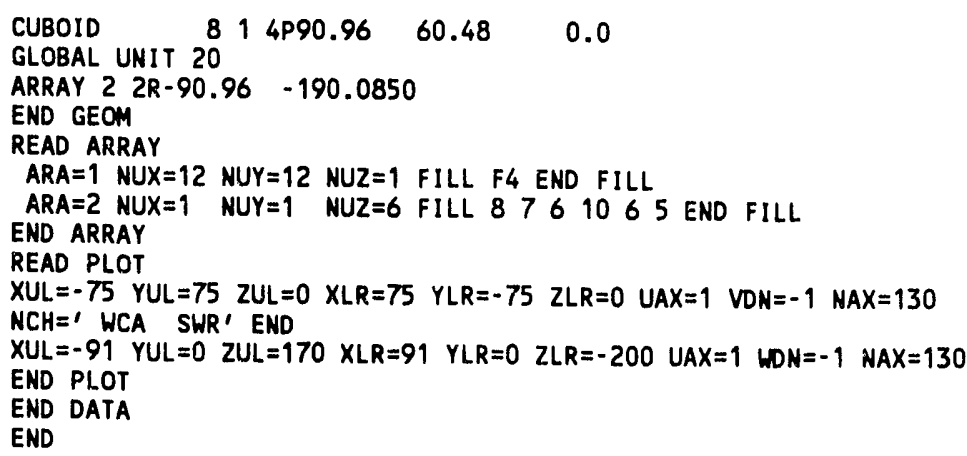


$20 \mathrm{MW} F / \mathrm{S}$ Calculational Input for $5 \%$ Enrichment, $H / U=0$.

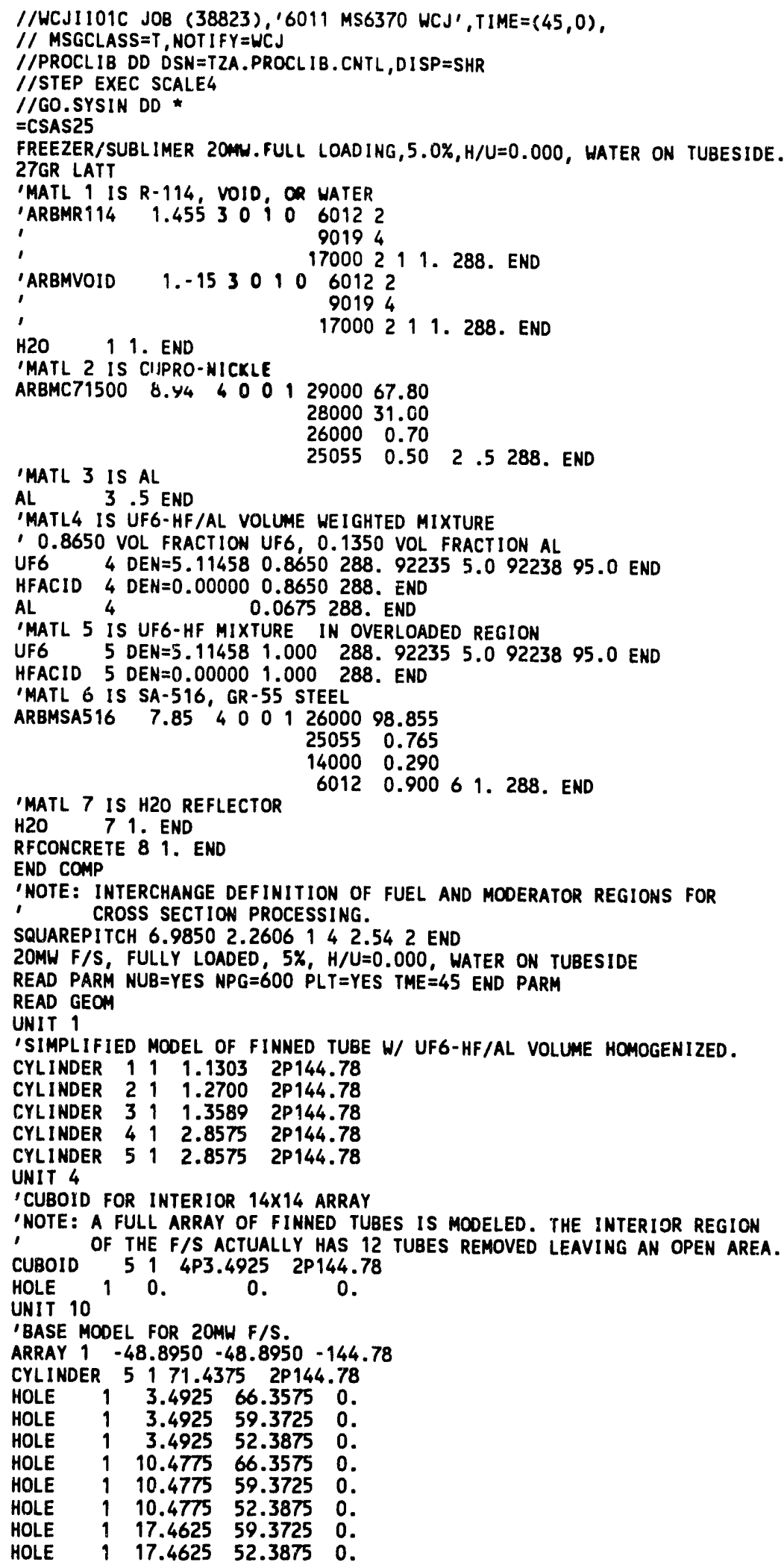




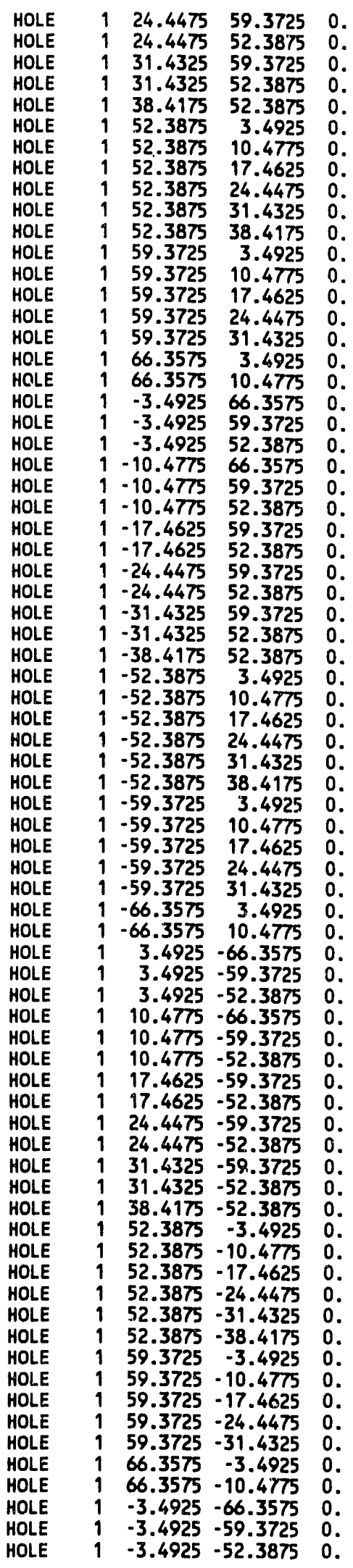




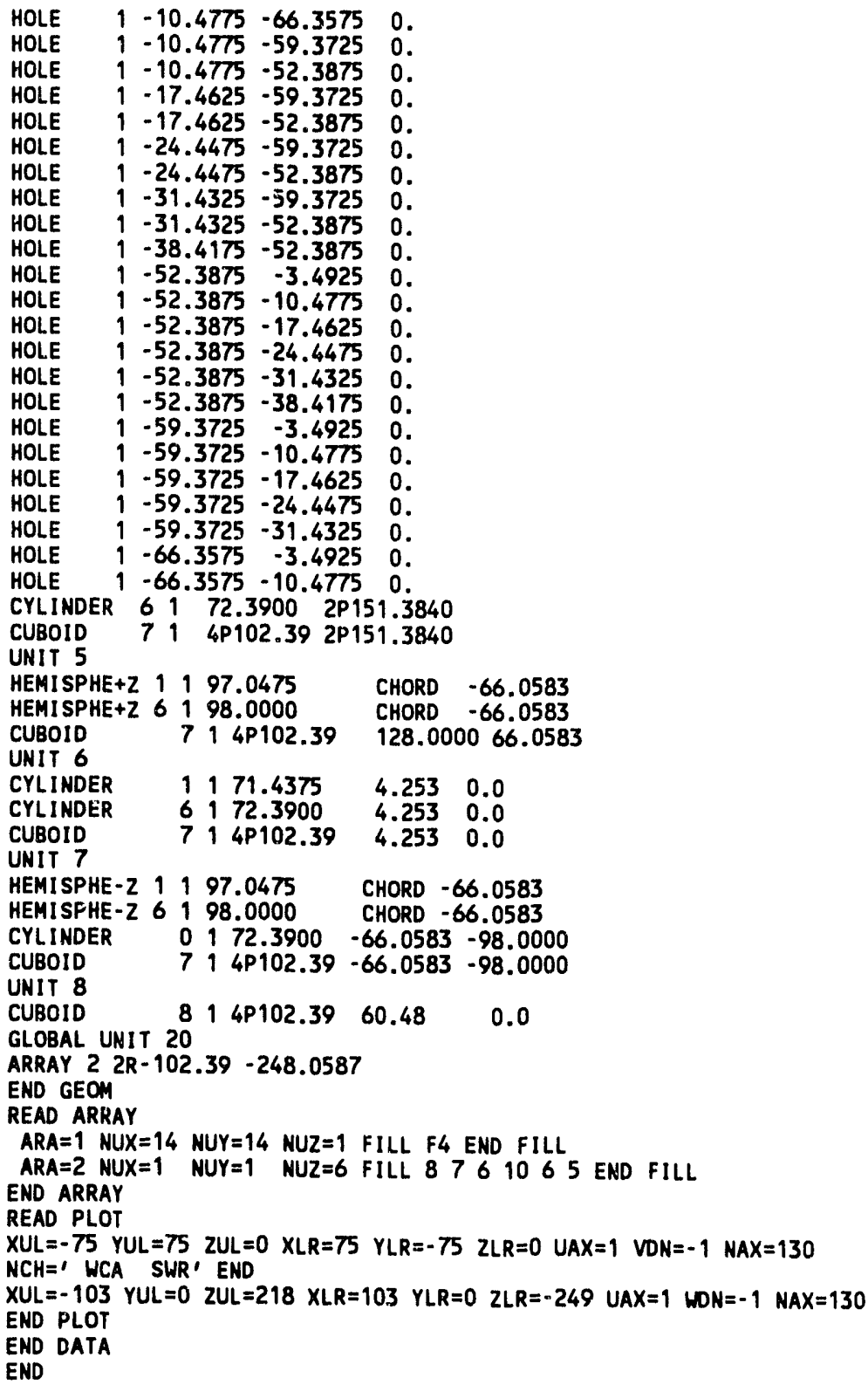


1. T. A. Angelelli

2. D. Baltimore

3. E. J. Barber

4. W. R. Brock

5. L. D. Charles

6. W. K. Crowley

7-9. D. M. D'Aquilla

10. J. C. Dean

11-12. H. R. Dyer

13. D. A. Dyslin

14. D. L. English

15. P. A. Haas

16. H. F. Hartman

17-19. T. W. Hines

20. J. A. Hoffmeister

21. J. C. Ingram III

22-31. W. C. Jordan

32. R. A. Just

33. M. R. Lambert

34. P. D. Lassiter

\section{INTERNAL DISTRIBUTION}

35. J. P. Little, Jr.

36. D. S. Milewski

37. R. L. Newvahner

38. L. F. Norris

39. M. G. Otey

40. A. J. Saraceno

41-42. C. H. Shappert

43. J. N. Sumner

44. C. A. Sweet

45. R. G. Taylor

46. D. A. Walker

47. B. G. Warriner

48. R. M. Westfall

49. G. E. Whitesides

50. D. W. Wilson

51-53. Laboratory Records Dept.

54. Laboratory Records, ORNL-RC

55. ORNL Y-12 Research Library Document Reference Section

56. Central Research Library

57. ORNL Patent Section

\section{EXTERNAL DISTRIBUTION}

58. Office of the Assistant Manager for Energy Research and Development, U.S. Department of Energy Field Office, Oak Ridge (DOE-OR), P.O. Box 2001, Oak Ridge, TN 37831

59-60. Office of Scientific and Technical Information, U.S. Department of Energy, P.O. Box 62, Oak Ridge, TN 37831 

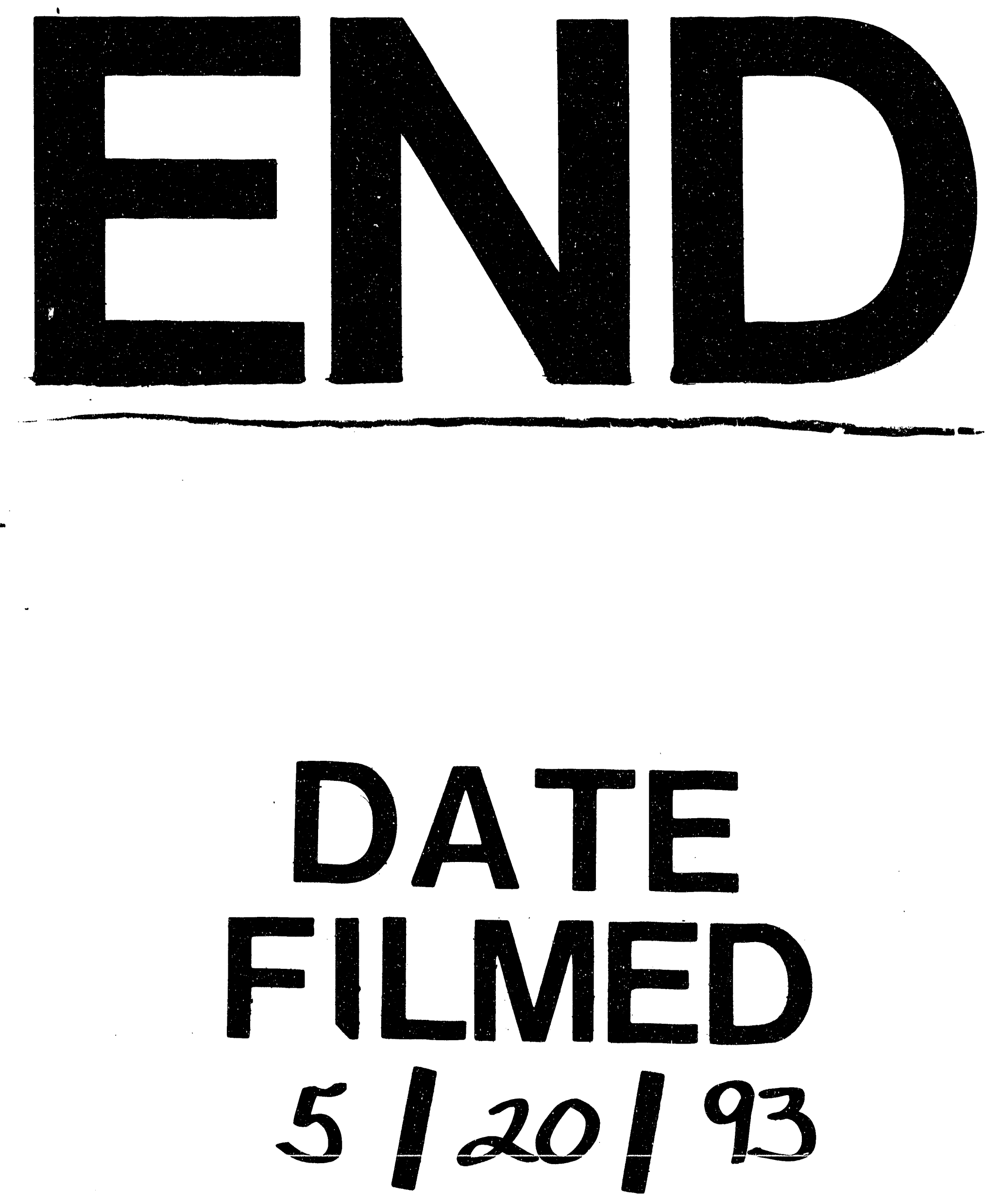

$=$ 
